Texture Design for Skin Friction and Touch Perception of Stainless Steel Surfaces

Sheng Zhang 


\section{Texture Design for Skin Friction and Touch Perception of Stainless Steel Surfaces}

Sheng Zhang 
This work was supported by the Research Programme of the Research Fund for Coal and Steel, contract no. RFSR-CT-2011-00022.

Graduation committee

\section{Chairman}

Prof.dr. G.P.M.R. Dewulf

University of Twente

\section{Promotor:}

Prof.dr.ir. E. van der Heide

University of Twente

Prof. dr. X. Zeng

SARI-CAS, Shanghai, China

\section{Members:}

Prof.dr. Y. Nakanishi

Kumamoto University, Kumamoto,

Japan

Dr. P.K. Sharma

University of Groningen / UMCG

Prof.dr.ir. A.H. van den Boogaard

University of Twente

Prof.dr.ir. H. van der Kooij

University of Twente

\section{Referee:}

Dr. D.T.A. Matthews

Tata Steel / University of Twente 


\title{
TEXTURE DESIGN FOR SKIN FRICTION AND TOUCH PERCEPTION OF
} STAINLESS STEEL SURFACES

\section{DISSERTATION}

\author{
to obtain \\ the degree of doctor at the University of Twente, \\ on the authority of the rector magnificus \\ Prof. dr. H. Brinksma \\ on account of the decision of the graduation committee, \\ to be publicly defended \\ on Wednesday June $22^{\text {nd }} 2016$ at 14:45 hrs \\ by
}

Sheng Zhang

born on March $9^{\text {th }} 1984$

at Shanghai, China 
This doctoral dissertation is approved by

Promotor: $\quad$ Prof. dr. Emile van der Heide Prof. dr. Xiangqiong Zeng 


\section{Summary}

Tactile perception a concept with mechanical, physiological and psychological perspective, is of particular concern to the industrial companies and research area. The hedonic attributes of tactile perception are influential to our daily life like wearing clothes, using personal care products, holding tool handles or in domestic appliances. In a more general case, the tactile perception of surfaces of domestic appliances greatly affects the quality of our daily life. Stainless steel is one of the most common materials used in automobile, architecture, kitchenware and medical applications. In order to fabricate the pre-defined deterministic surface texture on the stainless steel material, the micro-fabrication techniques are investigated and discussed. Micro-casting, Chemical Wet Etching, Plasma Etching, Laser Surface Texturing LST and 3D Printing are the major fabrication methods to produce deterministic micro-structure in micro scale detail. In this thesis, LST is chosen to be the main fabrication method for producing the surface texture due to its accuracy and ability to fabricate on stainless steel sheet material.

A skin contact model was modified based on Hertzian and Westergaard model to take into account the influence of surface texture and orientation effect. This two-term friction model enables the prediction of the contact area, sliding friction between the skin and counter-surface. Furthermore, the tactile perception involved textures were designed and investigated in both perception experiments and skin friction measurements. The thesis focusses on the relationships among tactile perception, sub-micron surface roughness features and friction at light touch conditions, with the general aim to discover design principles that enhance tactile perception. For the perception experiments, a panel test was conducted and the subjective ratings from 0 to 10 were graded by each participant to describe the level of perceived roughness, perceived stickiness and perceived comfort. For the skin friction measurements, a multi-axis force/torque 
transducer was used to measure the dynamic friction between skin and counter-surface in vivo. The correlation of the perception experiment and friction measurement provides design tools for texture design of future product surfaces. With the presented tactile friction model, a strategy was extracted for optimizing surfaces with respect to tactility. The pivotal element is minimizing the adhesion term of friction by minimizing the contact area by designing a surface texture with minimal contact area in sliding motion. In addition, the orientation effect is another key factor for the texture design. The results of the study can be beneficial to understand the tactility related research and product developments in the future. 


\section{Samenvatting}

\section{Textuurontwerp voor huidwrijving en tastperceptie van roestvast staal oppervlakken}

Tactiele perceptie, een breed begrip met een mechanisch, fysiologisch en psychologisch perspectief, is van specifiek belang voor de maakindustrie en onderzoekswereld. De hedonistische aspecten van tactiele perceptie zijn van invloed op ons dagelijks leven, zoals het bij het dragen van kleding, het gebruik van persoonlijke verzorgingsproducten, het gebruik van handvaten van gereedschap of in huishoudelijke toepassingen. De tactiele perceptie van oppervlakken zoals die gebruikt worden in huishoudelijke toepassingen, beïnvloed in algemene zin de kwaliteit van ons dagelijkse leven. Roestvast staal is een veel gebruikt materiaal in automotive toepassingen, in gebouwen, voor witgoed en medische toepassingen. Ter fabricage van vooraf gedefinieerde deterministische oppervlaktetexturen in roestvast staal, worden de huidige micro-fabricagemethoden onderzocht en bediscussieerd. De belangrijkste microfabricagemethoden voor het produceren van deterministische microstructuren met micro schaal detail zijn: micro-casting, chemical wet etching, plasma etching, laser surface texturing LST en 3D printing. In dit proefschrift is LST gekozen als productiemethode voor het creëren van oppervlaktetextuur, vanwege de nauwkeurigheid en geschiktheid om roestvast staal te bewerken.

Een huidcontactmodel is aangepast om de invloed van oppervlaktetextuur en van oriëntatie effecten mee te kunnen nemen, uitgaande van bestaande contactmodellen van Hertz en Westergaard. Dit 'two-term' wrijvingsmodel makt het mogelijk om het contactoppervlak en de glijweerstand tussen huid en het tegenloopvlak te voorspellen. Hiermee zijn texturen ontworpen, specifiek voor het beïnvloeden van tactiele perceptie en beproefd zowel in perceptie-experimenten als in huidwrijvingsexperimenten. Dit proefschrift richt zich op de relaties tussen tactiele perceptie, sub-micron oppervlakteruwheidskenmerken en wrijving onder 
zogenaamde 'light touch' condities. Het algemene doel hierbij is het ontdekken van ontwerpprincipes welke de tactiele perceptie kunnen verbeteren. Een perceptie panel test is uitgevoerd en de subjectieve waarderingen, op een schaal van 0 tot 10 , ten aanzien van de waargenomen ruwheid, stroefheid en comfort zijn vastgesteld door elke deelnemer. In de wrijvingsexperimenten is een multi-assige kracht/moment opnemer gebruikt om in vivo, de dynamische wrijving in het contact van de huid en tegenloopvlak te meten. De correlatie tussen de perceptie-experimenten en de wrijvingsexperimenten creëert de ontwerpgereedschappen voor het ontwerpen van de oppervlaktetextuur van toekomstige productoppervlakken. Vanuit het gepresenteerde tactiele wrijvingsmodel is een methode geëxtraheerd om oppervlakken te optimaliseren naar tactiliteit. Het draait hierbij om het minimaliseren van de adhesieve term van de glijweerstand door het minimaliseren van het contactvlak. Dit wordt bereikt door een textuur te ontwerpen met een minimaal contactvlak in glijdende contacten. Het oriënteringseffect is een andere belangrijke factor in het ontwerpen van textuur. De resultaten van het onderzoek kunnen waardevol zijn in het begrijpen van tactiliteitsonderzoek en in productontwikkeling van de toekomst. 


\section{Nomenclature}

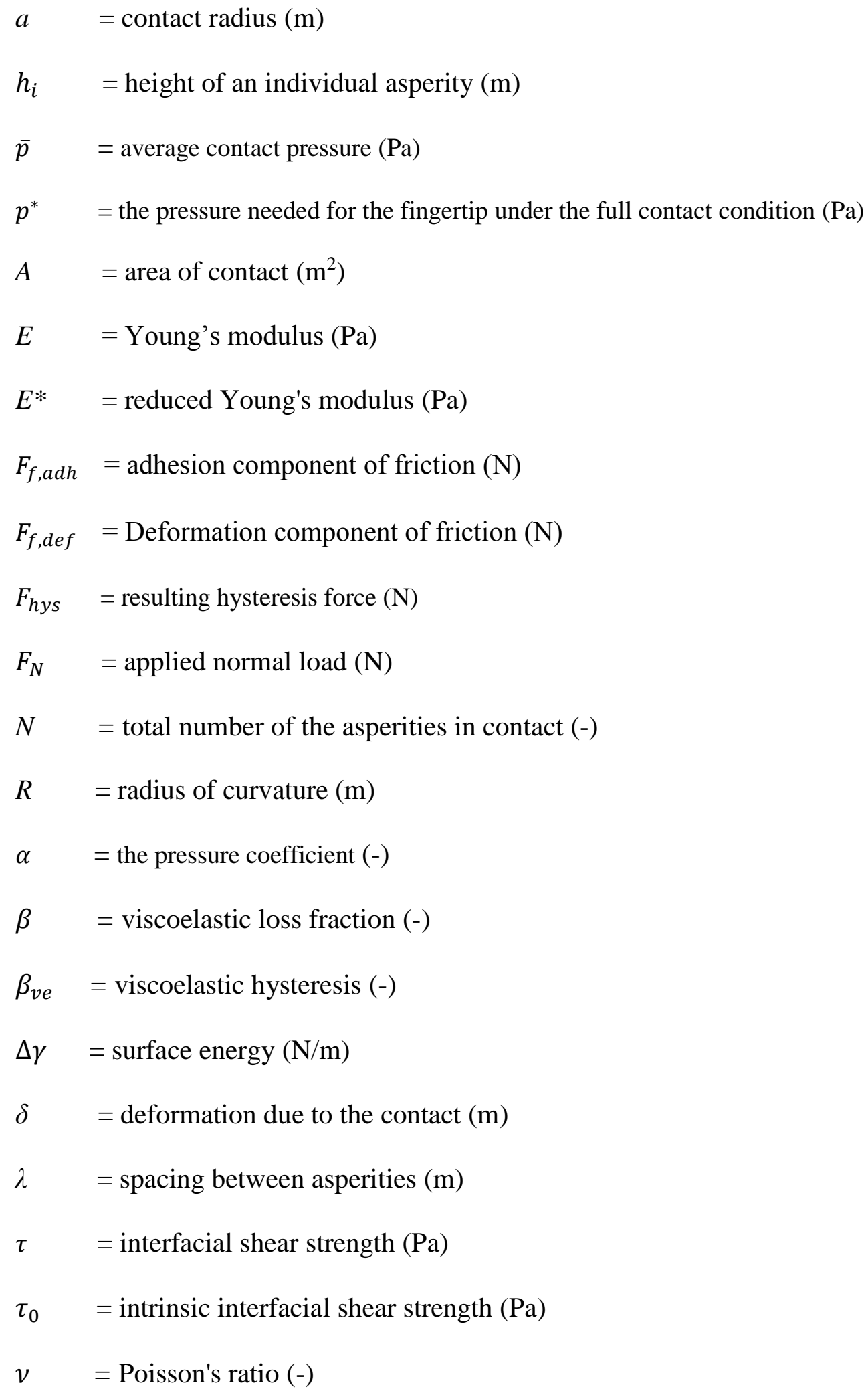




\section{Table of Contents}

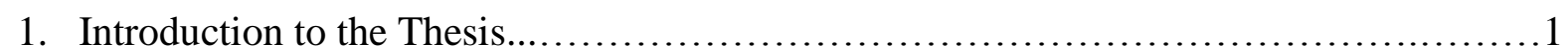

1.1 Tactile Perception.......................................................

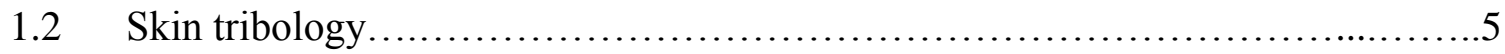

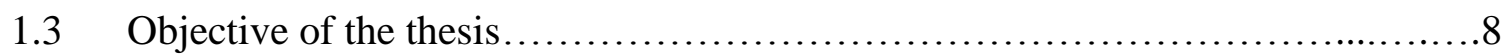

2. Micro-fabrication Techniques for Surface Texturing ................................11

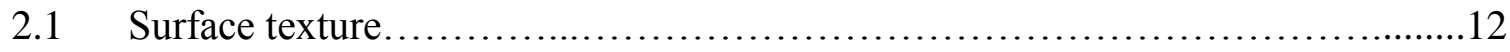

2.2 Micro-fabrication techniques........................................... 14

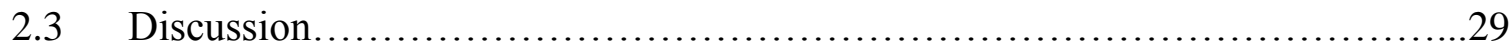

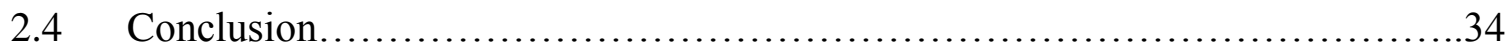

3. The Role of the Sliding Direction against a Grooved Channel Texture on Tool Steel: An Experimental Study on Tactile Friction........................................... 39

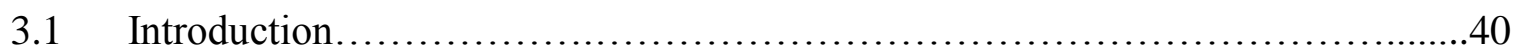

3.2 Skin Tribology.................................................... 41

3.3 Experimental methods............................................43

3.4 Results...........................................................47

4. Texture Design for Reducing Tactile Friction Independent of Sliding Orientation.......65

4.1 Interaction of material surface and skin..................................66

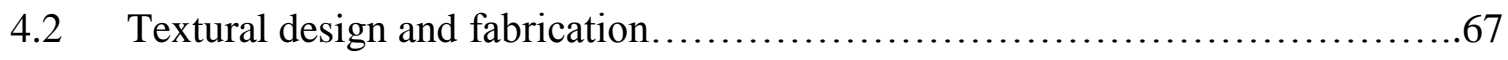

4.3 Results and discussions............................................. 74

5. Texture Design for Light Touch Perception .................................. 87

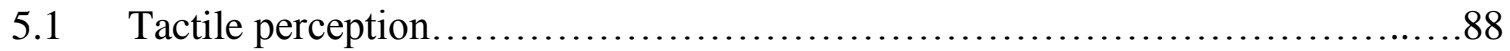

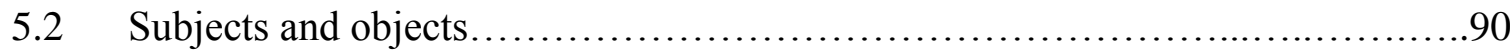

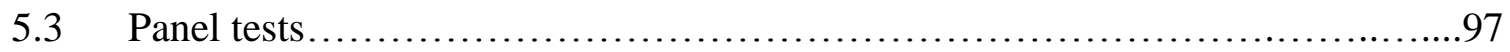

$5.4 \quad$ Results and discussions................................................... 99 
6. Finger Pad Friction and Tactile Perception Laser Treated, Stamped and Cold Rolled Micro-structured Stainless Steel Sheet Surfaces....................................113

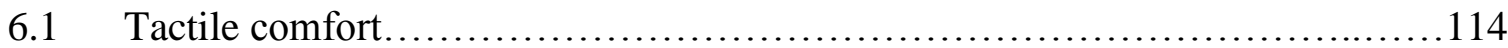

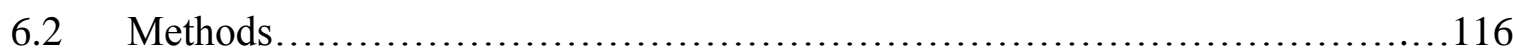

6.3 Results and discussion............................................ 123

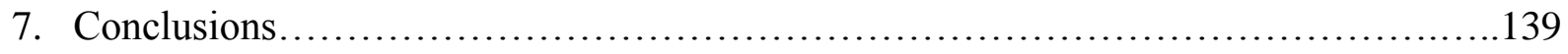

7.1 General conclusions.................................................. 139

$7.2 \quad$ Recommendations.................................................... 141

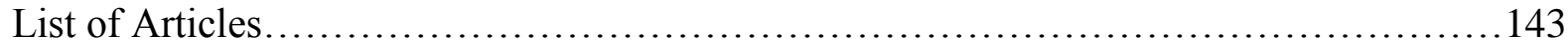

Conference Contributions....................................................... 144

Acknowledgement............................................................. 145 



\section{Chapter 1}

\section{Introduction}

\subsection{Tactile perception}

The tactile experiences with materials and surfaces essentially rely on the interactions between the human skin and objects. People are able to distinguish multidimensional textural stimuli including sensations of roughness versus smoothness, hardness versus softness, stickiness versus slipperiness, and warmth versus coolness based on tactile perception. From the literature, Lederman (Lederman 1981) investigated the perception of surface roughness by touch and found that perceived roughness can be strongly affected by both groove width and finger ridge. The research conducted by Hollins and Risner (Hollins and Risner, 2000) found that lateral movement between the skin and the textured surface has dramatically different effects on the tactile perception of fine and coarse surfaces (refer to Fig 1.1). Moreover, other literature reviewed major material properties accessible through haptic interaction including roughness, friction, compliance and thermal properties, see e.g. (Klatzky et al., 2013). However, the texture design in the criteria of both perception enhancement and skin friction reduction is missing. 


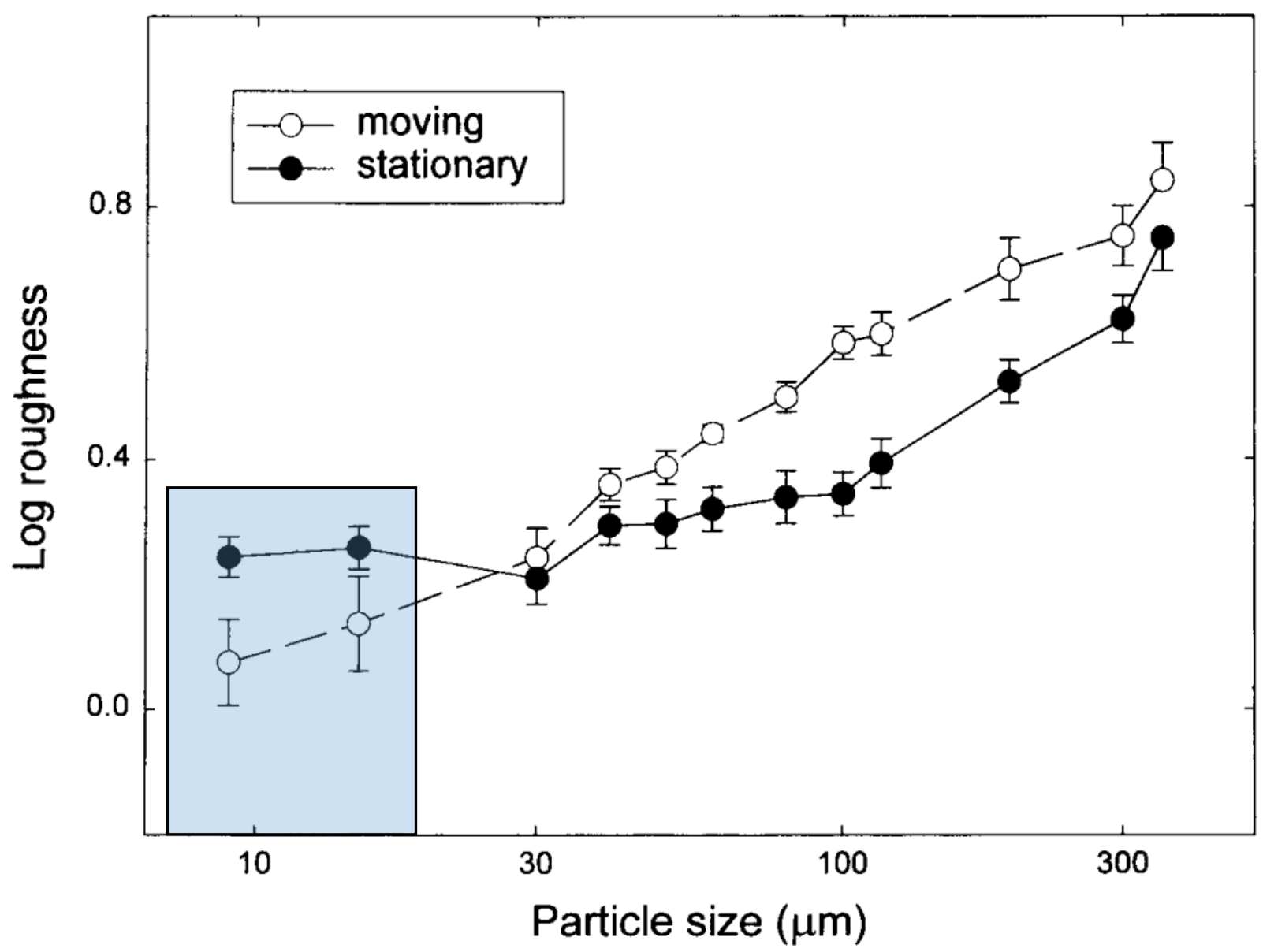

Fig 1.1 The perceived roughness equivalent vs. particle size of abrasive paper. (Hollins and Risner, 2000), indicating that a dynamic exploratory procedure is necessary for sensing differences between fine textures. This thesis focuses on engineering surfaces at the far left of the figure (outlined area in blue).

One form of tactile perception that is of particular relevance, is the light or gentle regime of touch, which is essential for the discrimination of surface structures without skin abrading. Light touch perception is associated with sliding of the glabrous skin that is found on the hands and feet of most mammals, relative to and in contact with surfaces at a certain normal load from $0.1 \mathrm{~N}$ to $1 \mathrm{~N}$. The human hand is often used to explore the material surfaces and is innervated by more than 600 nerve fibers per $\mathrm{mm}^{2}$, conveying cutaneous stimuli that are represented and processed in the spinal cord and brain to touch perceptions (Kelly et al, 2005) (Zimmerman et al, 2014) (refer to Fig 1.2). 

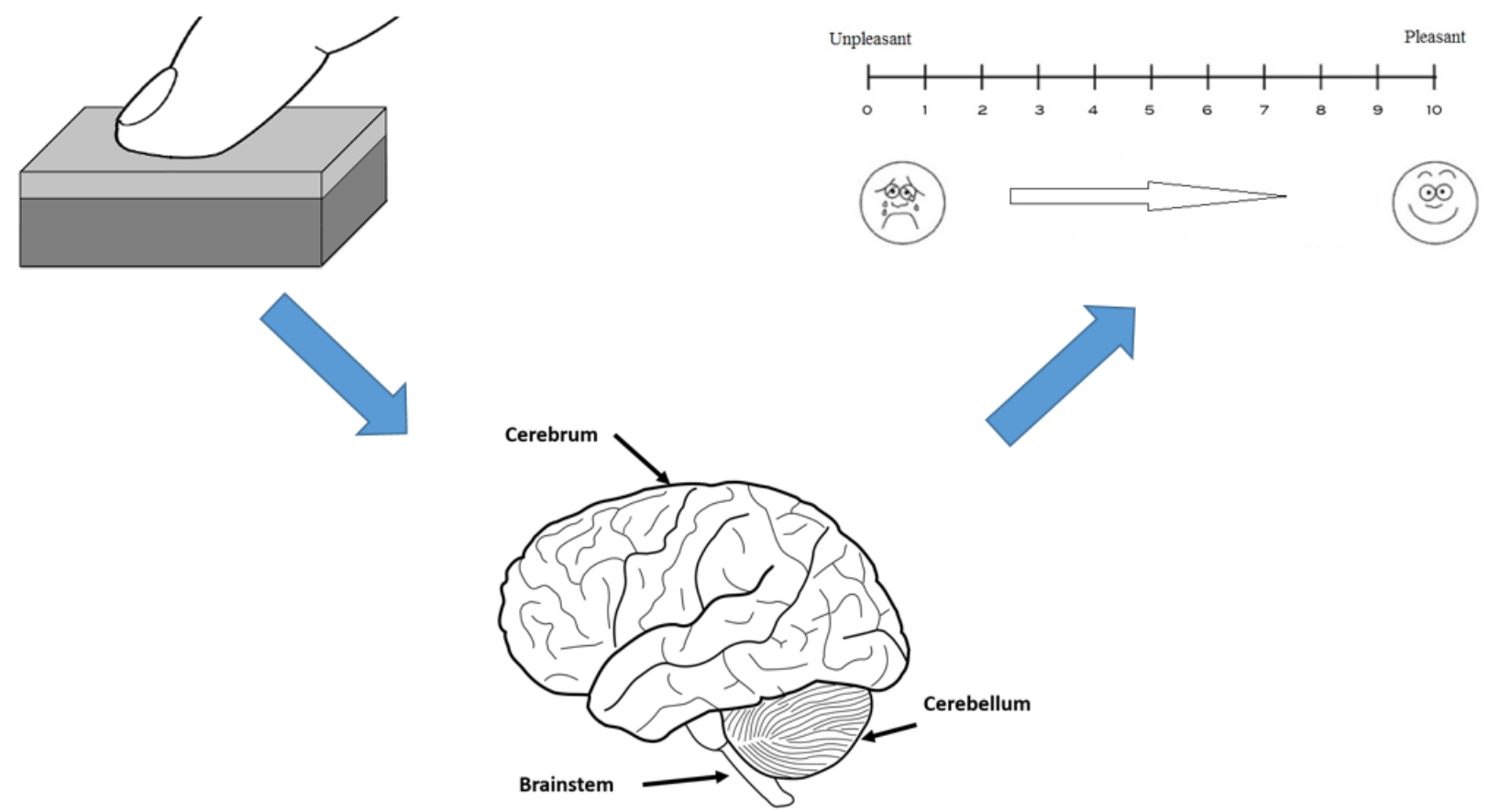

Fig 1.2 Schematic figure of tactile perception process, with the exploratory procedure, the human brain and a relative scale for perception that it causes.

The skin is innervated by a wide variety of sensory neuron subtypes, including lowthreshold mechanoreceptors (LTMRs) which encode mechanical stimuli by detecting the variation and magnitude of stresses when the fingerpad slides over the surface of an object (Zimmerman et al, 2014) (refer to Fig 1.3). 


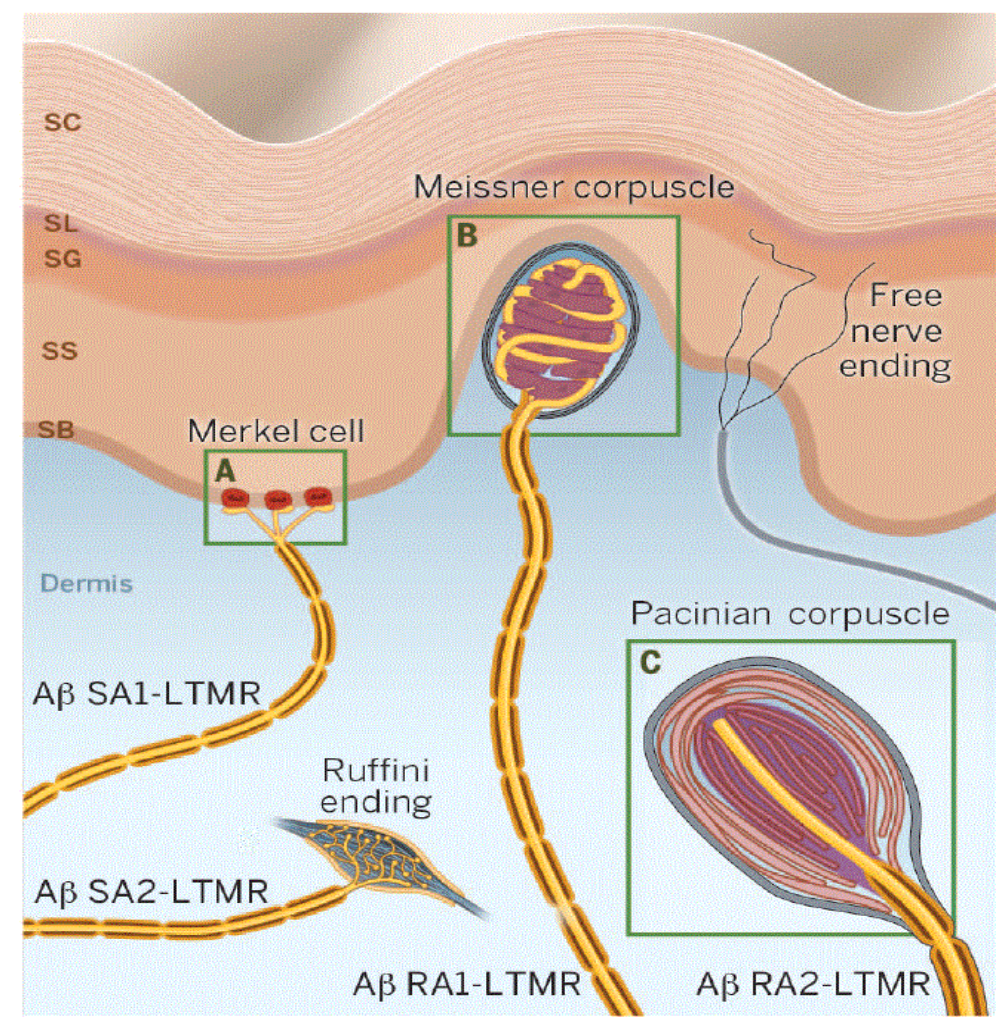

Fig 1.3 LTMR innervation of glabrous skin. SC, stratum corneum; SL, stratum lucidum; SG, stratum granulosum, SS, stratum spinosum; SB, stratum basale (Zimmerman et al., 2014)

The study of friction and the role of surface textures in relation to touch perception is the subject of researches in both science and industry for a wide variety of applications. Since stainless steel is an ideal material for manly application including household hardware, surgical instruments, automotive and construction material for buildings, therefore, the investigation of comfort in tactile contact between the skin and stainless steel surface is important. The enhancement of tactile comfort in daily interaction with stainless steel products can directly increase the customers' satisfaction by the stimulation of the somatosensory system in a positive way. A higher added value could be created by understanding the stimulus parameters and pleasantness factors validated by an experimental approach for stainless steel sheet material. However, the study of texture, perception and friction of stainless steel material is very limited. In this thesis, stainless steel samples were used as the material for all the testing samples conducted in the experiments. All specimens are with the same thermal properties and 
within the same hardness range and as such, only roughness and stickiness are concerned. The corresponding objective measures of skin friction, micro-structure design, surface roughness and micro-fabrication technique are subject of research in this work for the first time in an engineering setting for stainless steel. The effect of skin damage, skin disease, skin ridges, lubrication and wear are not taken into account in this thesis. In the current state, the importance of these factors is either considered of limited relevance or it is neglected for the reason of simplicity.

Specific surface textures were designed for the enhancement of the tribological performance and tactile perception of the stainless steel surfaces. The subjective evaluations of interest are the perceptual attributes including perceived roughness, perceived stickiness and the level of comfort. For the comfort level, the pleasantness of touch perception is indicated in the relation to the perception of roughness and stickiness. Furthermore, the influential factors of tactile perception will be determined and investigated with the assistance of skin friction.

\subsection{Skin tribology}

Skin tribology is a relatively new branch of tribology - the science and technology of interacting surfaces in relative motion - and the human skin is always one of the interacting surfaces. The human skin is a multi-layered living material mainly composed of epidermis, dermis and hypodermis. The stratum corneum, the outmost layer of epidermis, is the shield protecting the entire human body from the surrounding environment. Since it is directly in contact with the counter-body, therefore, it serves an important role in hydration control and in tactile friction. Sensory receptors lay in the layer of dermis which has a role in the tribological response. For the layer of hypodermis, which is the deepest layer of human skin, has the least influence in skin mechanical properties compared to the other layers. Overall, the skin behaves in 
viscoelastic, non-homogeneous and anistropic manner under load. In addition, many factors including the body site, age, hydration level and perhaps nutritional conditions can affect the tribological behaviour of skin, see e.g. the work of Veijgen (Veijgen, 2013). The dynamic friction generated between the skin and counter-surface is a tangential force resisting the moving motion. The skin friction is related to the deformation of the bodies in contact and generated in breaking the adhesive bonds between the skin and counter-surface in the micro-contacts. It depends on the factors including the operational conditions, material properties, surface structures and environmental conditions (refer to Fig 1.4), reflecting the dependence of friction on the tribological system.

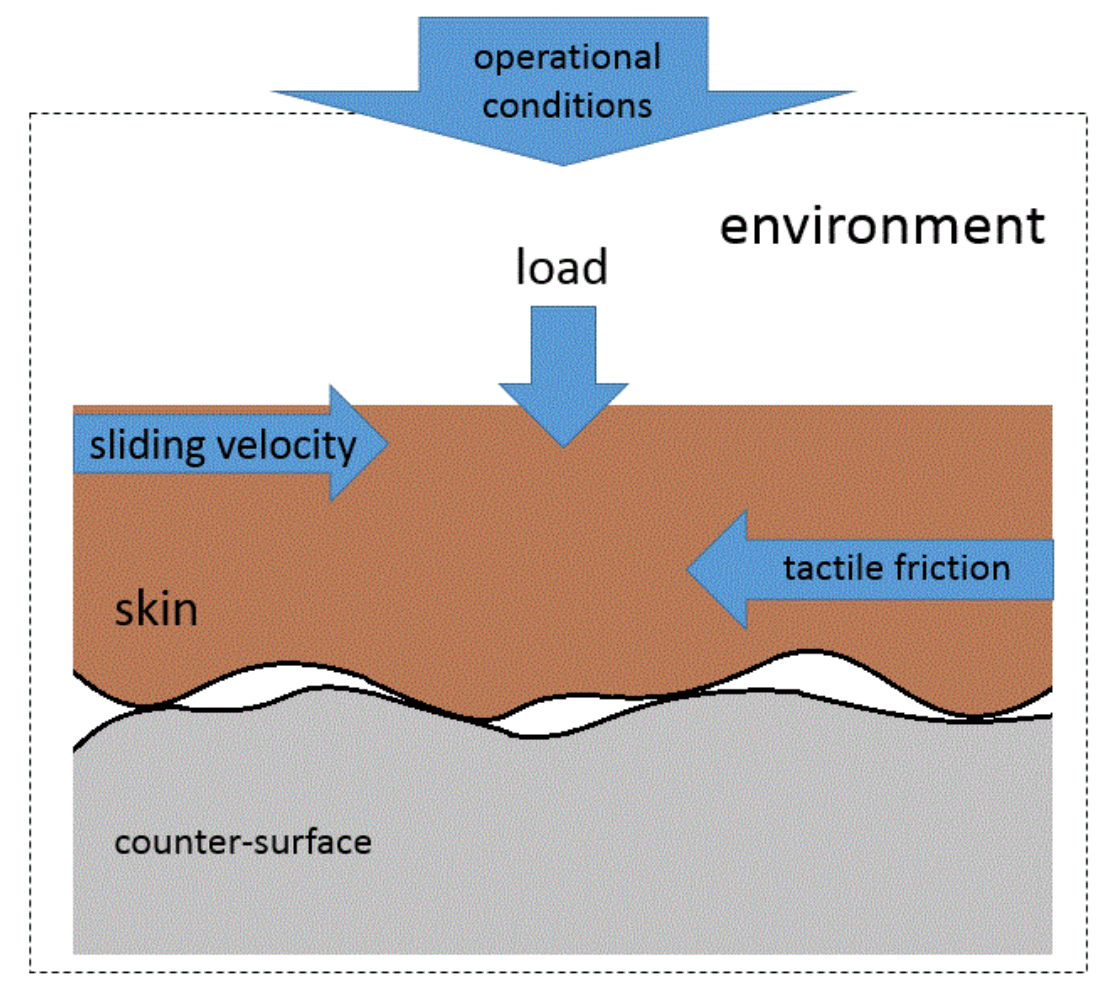

Fig 1.4 Tribological system of skin friction. 
In vivo skin friction measurements were carried out by many researchers, and friction generated between the skin and the counter-surface could be categorized based on the results into two main components: deformation component of friction and the adhesion component of friction (Derler et al., 2009). The adhesion component of friction plays the dominant role for both dry and humid conditions in sliding contacts between skin and other surfaces (Adams et al., 2007) (Duvefelt et al., 2016). In this thesis, the experiments are conducted based on skin in dry conditions, because most sliding touches for consumers' products occur in dry conditions. From the mechanical point of view, the real contact area is an important factor in the skin friction, especially the adhesion component of friction. According to the research, skin friction decreases with the reduction of the real contact area (van Kuilenburg, 2013) just as for other systems where the adhesive component of friction is dominant (Prodanov et al., 2013).

$F_{f, a d h}=\tau A_{\text {real }}$

Where $F_{f, \text { adh }}$ represents the adhesion component of friction; $A_{\text {real }}$ is the real contact area; $\tau$ is the interfacial shear strength. For the interfacial shear strength $\tau$, it has been found to have a linear function of the average contact pressure $(\bar{p})$ as:

$\tau=\tau_{0}+\alpha \bar{p}$

Where $\tau_{0}$ is the intrinsic interfacial shear strength; $\alpha$ is the pressure coefficient. After combining Eq (1) and (2), the coefficient of friction can be expressed as following:

$\mu=\frac{F_{f, a d h}}{F_{N}}=\frac{\tau}{\bar{p}}=\frac{\tau_{0} A_{r e a l}}{F_{N}}+\alpha$

The adhesion component of friction is directly related to the real contact area, and the reduction of real contact area is expected to greatly decrease friction. 


\subsection{Objective of the thesis}

The thesis focusses on the relationships among tactile perception, sub-micron surface roughness features and friction, with the general aim to discover design principles that enhance tactile perception. The experimental approach was adopted based on two perspectives: 1) a panel test with a questionnaire that subjectively rates touch perception of roughness and of slipperiness, and 2) in vivo friction measurements and area roughness measurements as objective ratings of the touch system. The correlation of the two is expected to provide design tools for texture design of future product surfaces. With an adopted and extended tactile friction model, a strategy was extracted for optimizing surfaces with respect to tactility. The pivotal element is minimizing the adhesion term of friction by minimizing the real contact area by designing a surface texture with minimal real contact area in sliding motion. Also, the orientation effect needs to be considered in the texture design. From both the experimental and analytical approaches, the optimal surface texture was designed in the concern of friction reduction and orientation effect.

The contents of the thesis reflect the link between the perceptual attributes and skin friction on the micro-structured stainless steel sheets. In Chapter 2, the state-of-art micro-fabrication techniques are introduced and reviewed. For the texture design, researchers need to understand the feasibility of the micro-fabrication techniques before designing any geometric structures with desired functionality. Without the feasibility of the fabrication techniques, the desired texture cannot be produced and the relationships cannot be validated. Chapter 3 focuses on the contact mechanics and friction model. Both experimental and analytical approaches were used to investigate the tactile friction between skin and micro-structured counter-surface and the role of the sliding direction. Further investigation was conducted in Chapter 4, and new surface textures were designed for reducing the skin friction independent of sliding orientation. Chapter 5 investigates the relationship between the texture and touch perception under light touch 
regime. In addition, the link between the perceptual attributes and skin friction was discussed based on the experimental results. Finally, the study of pleasant touch (comfort level) is investigated in Chapter 6. The relationships between perceptual attributes, skin friction and comfort level were studied. A summary of the conclusions is given in Chapter 7, accompanied by research findings, and recommendations for future research. 


\section{References}

Adams, M.J., Briscoe, B.J., Johnson, S.A., Friction and lubrication of human skin. Tribology Letters, 2007, 26(3): 239-253.

Derler, S., Huber, R., Feuz, H.P., Hadad, M., Influence of surface microstructure on the sliding friction of plantar skin against hard substrates. Wear, 2009, 267(5-8): 1281-1288.

Duvefelt, K., Olofsson, U., Johannesson, C.M., Skedung, L., Model for contact between finger and sinusoidal plane evaluate adhesion and deformation component of friction. Tribology International, 2016, 96: 389-394.

Hollins, M., Risner, S. R., Evidence for the Duplex Theory of Tactile Texture Perception. Perception \& Psychophysics, 2000, 62(4): 695-705.

Kelly, E.J., Terenghi, G., Hazari, A., Wiberg, M., Nerve fibre and sensory end organ density in the epidermis and papillary dermis of the human hand. Br J Plast Surg, 2005, 58:774-779.

Klatzky, R. L., Pawluk, D., Haptic perception of material properties and implications for applications. proceedings of the IEEE, 2013, 101: 2081-2092.

Kuilenburg, J. van, A mechanistic approach to tactile friction, $\mathrm{PhD}$ Thesis, University of Twente, Enschede, the Netherlands, 2013.

Lederman, S.J., The perception of surface roughness by active and passive touch. Bull Psychonomic Soc 1981, 18: 253-255.

Prodanov, N., Gachot, C., Rosenkanz, A., Muchlich, F., Muser, M.H., Contact mechanics of lasertextured surfaces. Tribology Letters, 2013, 50: 41-48.

Veijgen, N.K., Skin Friction: A novel approach to measuring in vivo human skin, PhD Thesis, University of Twente, Enschede, the Netherlands, 2013.

Zimmerman, A., Bai, L., Ginty, D.D., The gentle touch receptors of mammalian skin. Science, 2014, 346 (6212): 950-953. 


\section{Chapter 2}

\section{Micro-fabrication Techniques for Surface Texturing*}

This chapter gives a concise introduction to the state-of-art techniques used for surface texturing including micro-casting, wet etching, plasma etching, Laser Surface Texturing (LST), 3D printing. In order to fabricate deterministic textures with the desired geometric structures and scales, the innovative texturing technologies are developed and extended. Such texturing technology is an emerging frontier with revolutionary impact in industrial and scientific fields. With the help of the latest fabrication technologies, surface textures are scaling down and more complex deterministic patterns may be fabricated with desired functions, e.g. lotus effect (hydrophobic), gecko feet (adhesive) and haptic tactile. The objective of this review is to explore the surface texturing technology and its contributions to the applications.

*S. Zhang, X. Zeng, D.T.A. Matthews, A. Igartua, E. Rodriguez-Vidal, J. Contreras Fortes, V. Saenz de Viteri, F. Pagano, B. Wadman, E. van der Heide, Selection of micro-fabrication techniques on stainless steel sheet for skin friction, Friction, Accepted for Publication, 2016 


\subsection{Introduction}

Surface texturing is a well-known engineering technology for enhancing the tribological properties of mechanical components i.e. for wear resistance, friction reduction and for creating lubricant reservoirs or pockets, see e.g. (Wilklund, 2006) (Pettersson and Jacobson, 2003; Sugihara and Enomoto, 2013; Tang et al., 2013; Ling, 1990; Zahouani et al., 1998; Bruzzone and Costa, 2013). The functionality of the engineered surfaces defines specific characteristics of the surface texturing process, such as for example: enhancing the lifetime of bearing components (Ibatan et al., 2015), or increasing formability of steel sheet (Wiklund et al., 2008). With the development of new and of existing fabrication technologies, surfaces with detailed micro-topography can be fabricated as micro-pits or grooves to effectively improve the tribological properties (Groenendijk and Meijer, 2006). As the surface texturing techniques developed and expanded over the years, the functionality of surface topography can be further comprehended and more applications appeared (Yan et al., 2016; Khatri and Sharma, 2016; Yu, et al., 2016). As the result, the textures are scaling-down further and more complex structures can be produced for broader applications, including skin friction and tactility. (Barnes et al., 2004; van Kuilenburg et al., 2013).

In the field of tactile perception, a substantial amount of work was conducted to understand how people explore and perceive the textured counter-surface by exploring with the finger pads (Klatzky et al., 2013). Klatzky and Lederman (Klatzky and Lederman, 1999) studied the geometric properties of sandpaper-surfaces based on the roughness perception while measuring behavioral and neurophysiological responses. In the work of Skedung (Skedung et al., 2011), finger friction measurements are evaluated to determine the relationship between the coefficient of friction (COF) and surface roughness of a series of printing papers. Furthermore, Skedung (Skedung, et al., 2013) investigated the relationship between the perceptual dimensions and the implicated physical dimensions on the micro-structured 
polydimethylsiloxane (PDMS) samples, and found that people are capable of dynamically detecting surface structures with wavelength of $760 \mathrm{~nm}$ and amplitude of $13 \mathrm{~nm}$.
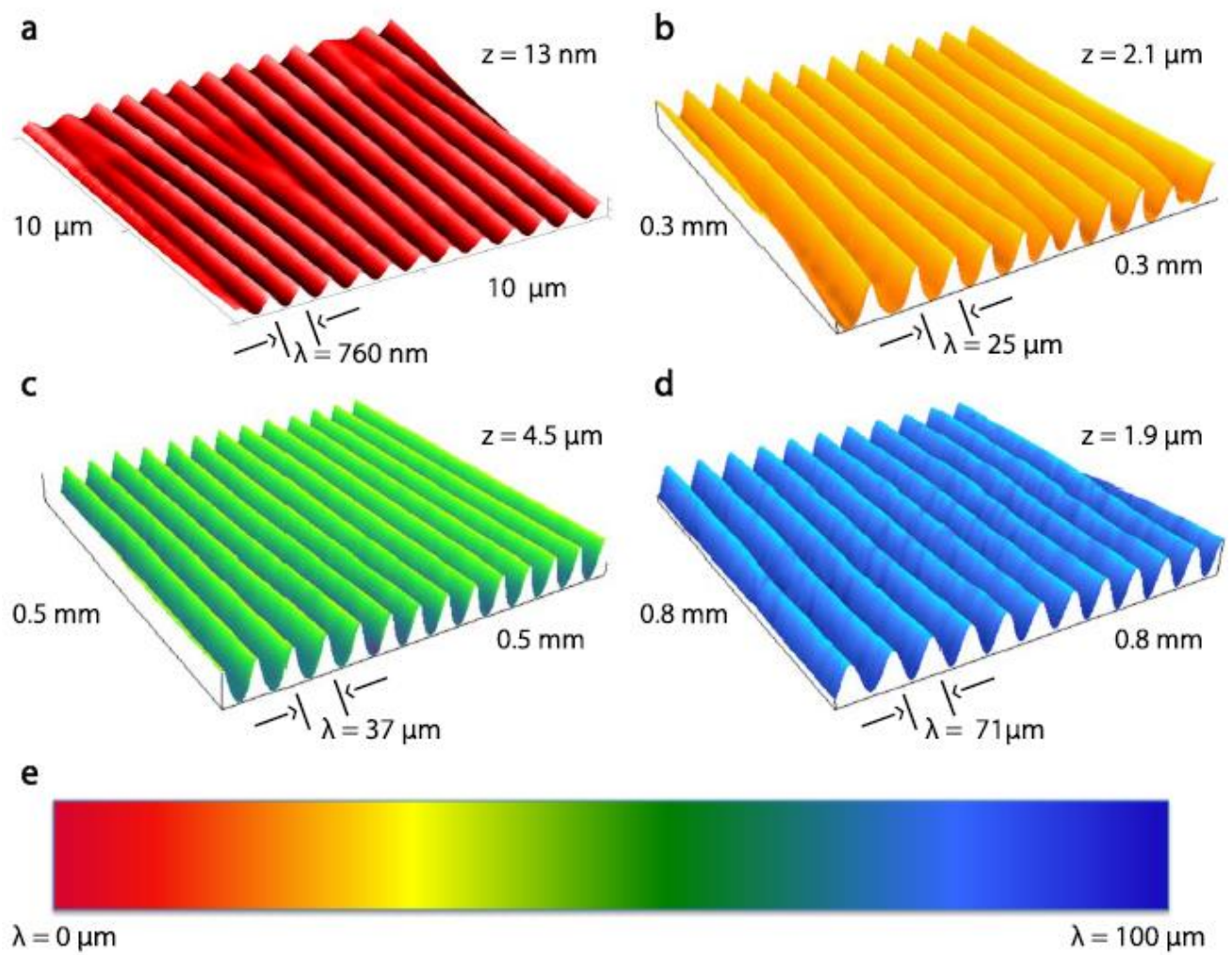

Fig 2.1 Wrinkled-patterned polymeric surfaces with textures for touch perception ranging from nanometers to micrometers. (Skedung, et al., 2013) 
From the tribological perspective, the parameters of surface texture including spacing, amplitude and waviness are influential factors in skin tribology. The required levels for a polymeric surface can be seen from Fig 2.1. The work of Tomlinson (Tomlinson et al., 2011) found that adhesion component of friction is the predominant mechanism for samples with shallow ridges of a height lower than $42.5 \mu \mathrm{m}$. However, with greater height, the skin penetration to the texture ridges which increases the amount of hysteresis friction. Same phenomena are found for the width and size of the ridges.

In this thesis, the tactile perception and skin friction study was conducted on stainless steel sheet material. Before designing any geometric structures with desired functionality on the stainless steel sheet, the knowledge of basic concepts and feasibility of the micro-fabrication techniques that allow for predefined, deterministic textures, are important. As the spine of texture design, various surface texturing techniques have to be discussed and studied. In the following sections, the core texturing techniques for deterministic textures at the required scale are introduced from retrospective to the state-of-art, and finally the best suitable fabrication technique will be selected to produce the designed deterministic micro-structures on stainless steel sheet samples.

\subsection{Micro-fabrication Techniques}

\subsubsection{Micro-casting}

Casting is one of the key fabrication techniques for manufacturing and generally known as lost-mold technique by using a textured mold with materials melt into it (Khodai and Parvin, 2008) (Li et al., 2011). First, the mold texture needs to be produced by other micro-fabrication techniques including laser surface texturing, 3D printing and other various micro-fabrication techniques in order to create the deterministic pattern. In general, the plastic or wax pattern is produced and embedded in a ceramic slip. The dried mold will be filled with melt materials and the pattern will be lost due to melting and burning and transfer the texture to the filling 
materials. After solidification, the mold is mechanically removed without damaging the cast surface. Depending on the casting and mold materials, additional chemical cleaning processes may be applied as an extra step.

This technique has been successfully applied for micro-fabricating miniaturized devices for mechanical engineering and bio-mimic duplication (Ferro et al., 2013) (McGinley et al., 2013). For example of fabricating complicated metal micro-components, the group of Li et al. successfully produced a three-dimensional Zn-Al4 alloy microgear including one gear panel and two gear shafts by using metal mold micro-scale precision casting method (Li et al., 2008). Another study uses micro-casting technique to replicate the surface microstructures that contribute to the lotus leaf effect - superhydrophobicity (Adithyavairavan et al., 2011). The lotus surface is directly replicated via a two-stage (negative-positive) direct micro-casting method using three different materials: Vinyl Polysiloxane (VPS), Polydimethylsiloxane (PDMS) and Polymethylmethacrylate (PMMA). During the fabrication process, a negative template with the microstructures of lotus leaf was made first by pouring VPS directly onto a section of the lotus lead. After peeled off the lotus leaf, a positive template was created by pouring PDMS onto the cured negative template (refer to Fig 2.2). The same process was used to fabricate PDMS-PMMA replicates. Under the pattern examination, VPS-PMMA and PDMS-PMMA replicates display shorter peak heights and larger base widths with contact angles of $132.1^{\circ}$ and $129.2^{\circ}$ respectively.

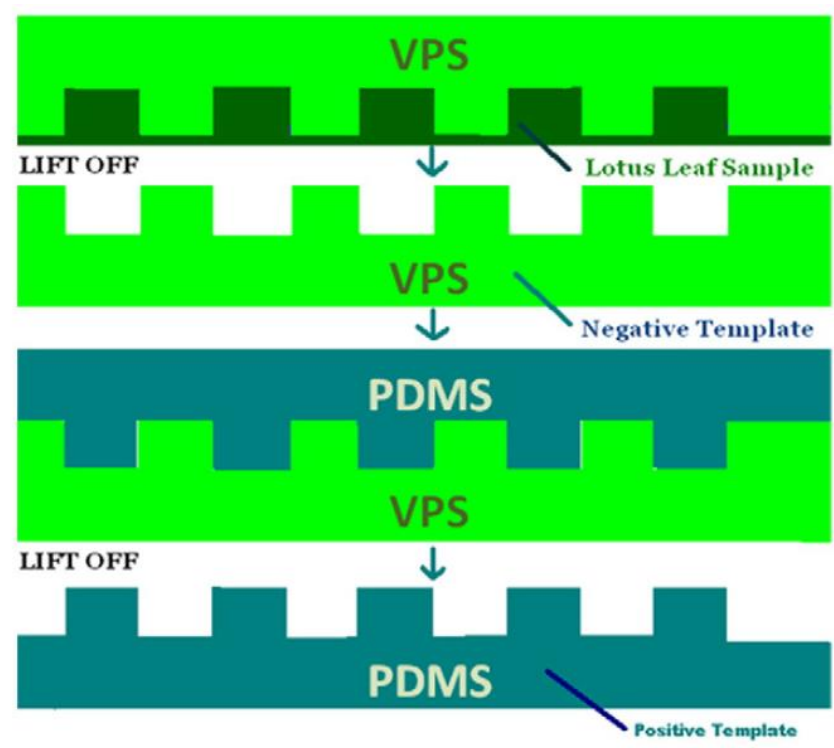

Fig 2.2 Schematic illustration of direct replication and process sequence. (Adithyavairavan et al., 2011) 


\subsubsection{Chemical Wet Etching}

Wet etching, also known as chemical wet etching or liquid etching, uses liquid chemicals or etchants to perform a material removal process on the sample surface (Chao et al., 2015; Chen et al., 2015; Kumar et al., 2015). The predefined masks with desired textures are attached to the sample surface before the chemical wet etching process. Usually, these masks are prefabricated by using lithography technique (Jaeger, 2002). During the etching process, the surface regions not covered by the masks are etched away to produce deterministic textures. Meanwhile, multiple chemical reactions are performed which involves three steps: diffusion of the etchant to the material surface which is not covered by the mask; the chemical reaction between the etchant and the materials have been etched away; Secondary diffusion of the reacted sample surface.

Chemical wet etching methods can be categorized into two types: anistropic and isotropic (Bauhuber et al., 2013; Mondiali et al., 2015). Both processes have different etching rates which depend on the material properties of the sample. The most common application of anistropic wet etching method is applied for the fabrication of crystalline materials (Reshak et al., 2013; Lee et al., 2015). The etching rate varies base on the plane of the crystalline material and the concentrations of the etchants. For instance, crystalline material like silicon may have high anisotropic effect by using etchants e.g., Potassium Hydroxide (KOH), Ethylenediamine Pyrocatechol (EDP), Tetramethylammonium Hydroxide (TMAH), etc. The typical applications for anisotropic wet etching are e.g. J-FET arrays, solar cell anti-reflecting surfaces and waveguides.

In 1983, a series of electrochemical measurements of n- and p-type Si wafers with crystal plane of $\left\{\begin{array}{lll}1 & 0 & 0\end{array}\right\}$ and $\left\{\begin{array}{lll}1 & 1 & 1\end{array}\right\}$ were analyzed to study the importance of the orientation dependent etching (Faust, et al., 1983). Potassium Hydroxide (KOH) was used as etchant for the anisotropic wet etching process. Researcher (Seidel, 1990) attempted to study the reaction 
mechanism and key features of all alkaline anisotropic etchants upon silicon materials. In the study, experimental data were analyzed base on the anisotropy, selectivity and voltage dependence of anisotropic etchants. In the conclusion, the concentration of molar water and $\mathrm{pH}$ value are the two key parameters for the etching behaviour of alkaline solutions. In 1995, a research group in IBM's Microelectronics Division, USA (Linde, et al., 1995), was using an etchant consisting of ethanolamine, gallic acid, surfactant, catalyst and water for anistropic wet etching on the three major crystal planes of silicon. The objective was to study the catalytic control of anisotropic wet etching rate. During the experiments, chemical etching method was strongly influenced by a variety of oxidative catalysts. The results were categorized intro three groups by how fast catalysts can accelerate the chemical etching rate of a specific crystal plane compared to the uncatalyzed rate: two to five times; less than twice and below the uncatalyzed level.

Different from anisotropic wet etching process, the etching rate is same in all direction for isotropic wet etching (Sheeja et al., 2003). It is suitable for removal of pre-damaged surfaces, rounding of pre-etched sharp corners, fabricating the structures on single-crystal lattices and producing large geometries. Similar to anisotropic wet etching process, the plane of the crystalline material and the concentrations of etchant are the important factors for etching rate in isotropic wet etching process. The common etchant is the mixture of hydrofluoric acid (HF), nitric acid and acetic acid for crystalline materials. The etching rate is affected by the concentration of each chemical etchant. In some researches, isotropic wet etching was combined with laser surface texturing technique (Lim, et al., 2005). The concave micro lens arrays were fabricated by a third harmonic Nd: YAG laser on a gold film which coated on a glass substrate. Followed by the isotropic wet etching process, the exposed area on glass substrate was etched by using hydrofluoric acid solutions (refer to Fig 2.3). In the study, the effect of various types of HF solutions on etching efficiency were analyzed. 


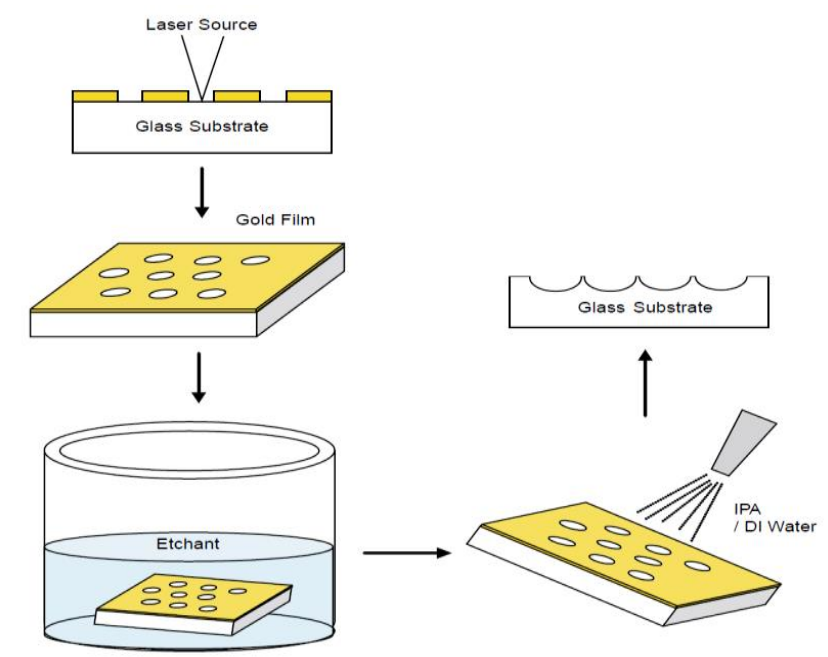

Fig 2.3 Schematic of the etching process flow. (Lim, et al., 2005)

Recently, a research group applied isotropic wet etching technique to fabricate desired texture for light guidance application (Bauhuber et al., 2013). HNA based etchant solution is used to produce the surface structure of $300 \mu \mathrm{m}$ deep channel with smooth wall. The etchant composition was selected by surface quality of etching process and etching rate. A spin etcher tool was used to further reduce the surface roughness. This method was able to produce deep isotropic channels in optical quality (refer to Fig 2.4).

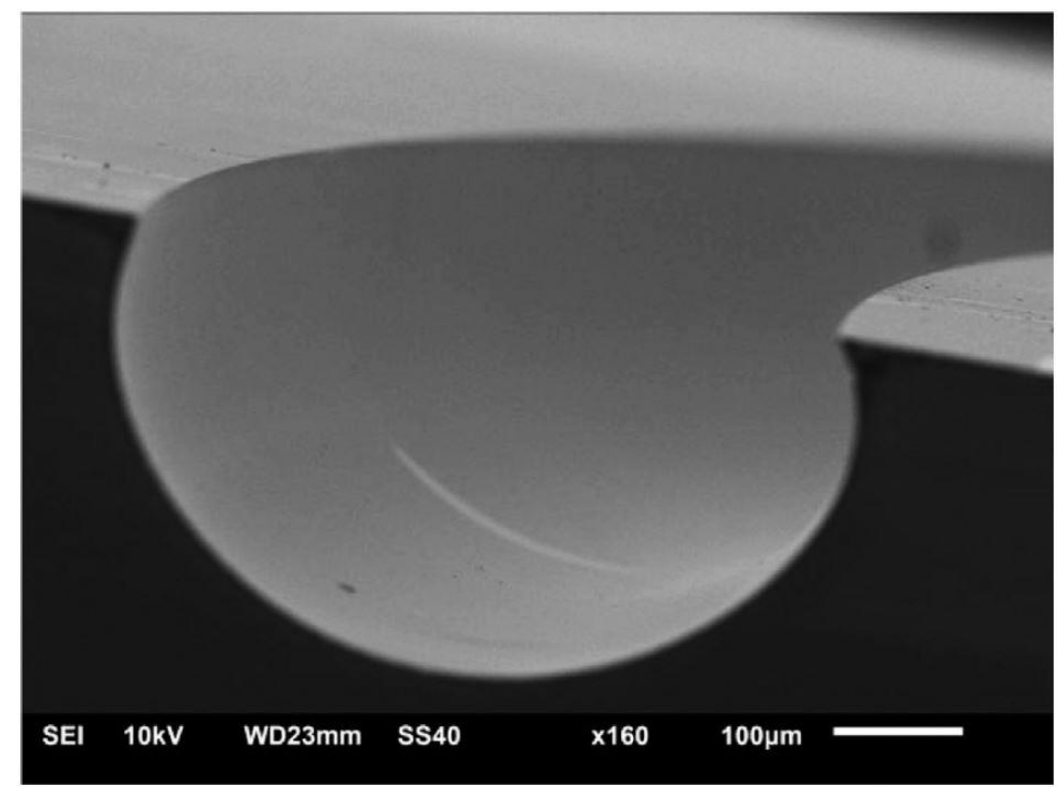

Fig 2.4 Image of a $300 \mu \mathrm{m}$ deep channel which has a channel wall in optical quality. (Bauhuber et al., 2013) 


\subsubsection{Plasma Etching}

Plasma etching is a mature technique specific for the fabrication of microsystems and surface texturing (Freires de Queiroz, et al., 2014). From the mid-1960s, the mechanisms of plasma etching were first introduced as a revolutionary technique for the fabrication of integrated circuit (Donnelly and Kornblit, 2013). In the 1970s, it was widely accepted and expected to be an important fabrication technique in the industry of semiconductor and other applications requiring fine-line lithography (Coburn and Winters, 1979). In general, plasma etching undergoes a chemical reaction between the solid atoms from the substrate material and gas atoms from the gas etchant. The gas etchants are in the form of molecules, but not chemically reactive enough to fabricate the material surface. The role of plasma is to dissociate the molecules of the gas etchant into reactive atoms in order to be sufficient in the task of fabrication. Over the years, various plasma etching techniques are introduced, and radio frequency (RF) sputter etching technique is still the most common and core plasma etching technique for surface texturing.

The radio frequency (RF) sputter etching method was first introduced from IBM (Davidse, 1969), and was found to be very useful for fabricating Thin film resistors on Cr-SiO films. The $1 \frac{1}{4}$ inch silicon wafers were used as the substrates pre-coated film with a $1.5 \mu$ thickness. Kodak thin film resist (KTFR) was used as the resist through the sputter etching (refer to Fig 2.5). From the results, RF sputter etching demonstrated its universality and ability to prevent under-cutting. This technique is able to etch any kinds of substrates with standard photoresist. Later, fluorine and chlorine-containing gas etchants were introduced to RF sputter etching (Hosokawa et al., 1974). The compositions of gas etchants are $\mathrm{CF}_{4}, \mathrm{CCl}_{2} \mathrm{~F}_{2}, \mathrm{CCl}_{3} \mathrm{~F}, \mathrm{CHCl}_{2} \mathrm{~F}$, $\mathrm{CHClF}_{2},\left(\mathrm{CCl}_{2} \mathrm{~F}\right)_{2}, \mathrm{CCl}_{2} \mathrm{FCClF}_{2}$ and $\left(\mathrm{CBrF}_{2}\right)_{2}$. The etching rate is enhanced by using fluorine and chlorine-containing gas etchants on $\mathrm{Si}$, quartz, glass, $\mathrm{Al}$, Mo, stainless steel and 
photoresist. From the results, RF sputter etching method with fluorine and chlorine-containing gas etchants is characterized as a high rate, precise and dry etching technique.

Recently, the work from Aizawa and Fukuda developed a high-density RF-DC plasma etching system (OXP-1; YS-Electrics, CO. Ltd.) to fabricate the diamond-like carbon (DLC) coating via PVD/CVD on the SKD11 substrate (refer to Fig 2.6) (Aizawa and Fukuda, 2013). The oxygen gas instead of hazardous etchants such as $\mathrm{CF}_{4}$ was attained with high etching rate. During the etching process, the specimens were fixed on the cathode table before evacuation down to the base pressure of $0.1 \mathrm{~Pa}$. The chamber was filled with a carrier gas to attain the specific pressure. With the use of magnetic lens, the ignited RF-DC oxygen plasmas were focused onto the surface of specimens during etching. The RF-voltage, DC bias and pressure were selected to be $250 \mathrm{~V},-450 \mathrm{~V}$ and 25 to $40 \mathrm{~Pa}$ respectively.
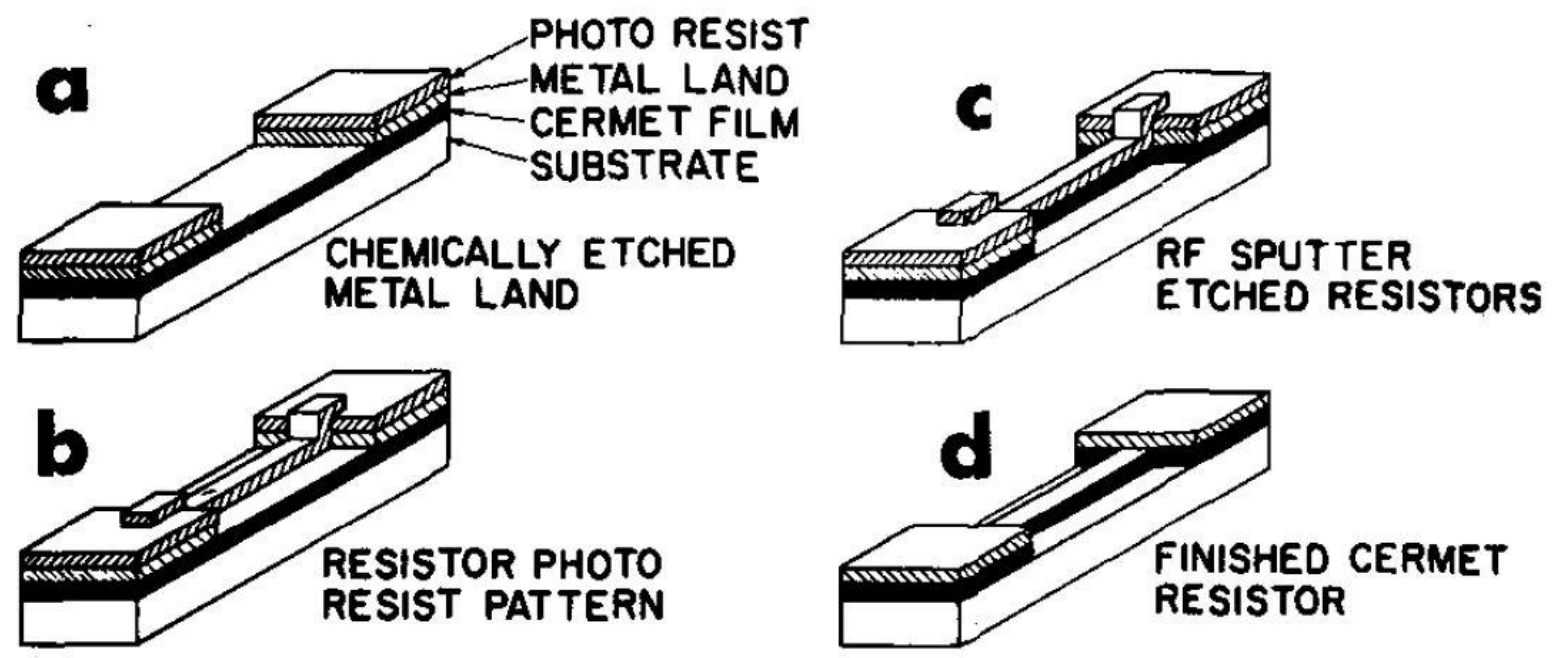

Fig 2.5 Sputter-etching of thin-film resistors. (Davidse, 1969) 


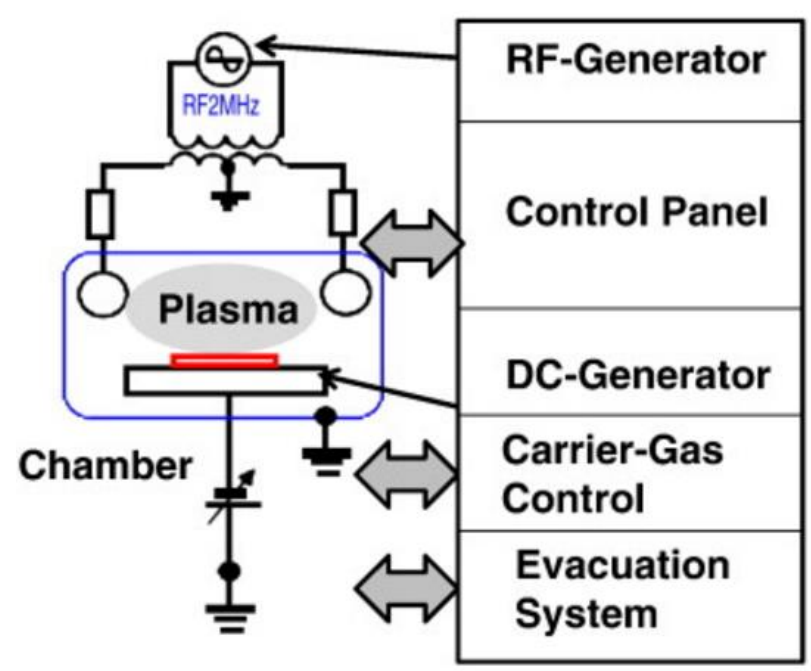

Fig 2.6 Schematic diagram of high-density plasma etching system. (Aizawa and Fukuda, 2013)

\subsubsection{Three-Dimensional Printing}

Three-dimensional printing (3DP) is a revolutionary bottom-up fabrication technique. Compared to traditional top-down fabrication techniques, it has many advantages like moldless production, cheap manufacturing, less waste and the ability to produce complex structures. The method was introduced by Charles Hull and first known as stereolithography in 1980s (3D Systems Inc., 1987). Early 3D printing method spread the material powder layer by layer and using binder material printed by ink-jet to selectively bind the powder in order to produce the parts (Sachs et al., 1993). After all the layers were finished, the unused powder was removed to complete the process (refer to Fig 2.7). The parts were designed by CAD with complete freedom in complex geometry, surface texture and material composition. The potential material selection includes any materials which are available in a particle sized powder form e.g., polymers, metals and ceramics (Lam and Mo, 2003; Moon and Grau, 2002; Seitz and Rieder, 2005; Utela et al., 2008).

Recently, a new developed super-resolution 3D printing system was introduced by using electrohydrodynamic (EHD) method (Han et al., 2014). It was able to directly fabricate 
micro-structures on the substrate surface with phase-change inks. The material of phasechange ink was wax which can be quickly solidified under room temperature after printed onto the substrate surface. The printing system consists of a XYZ precision stage, a thermal control unit, a pneumatic dispensing system and a high voltage supply (refer to Fig 2.8). The formation and size of droplet can be predicted by Finite Element Analysis (FEA) model. The EHD 3D printing technique is capable of fabricating high aspect-of-ratio and high resolution (sub-10 $\mu \mathrm{m}$ ) surface structures (refer to Fig 2.9).

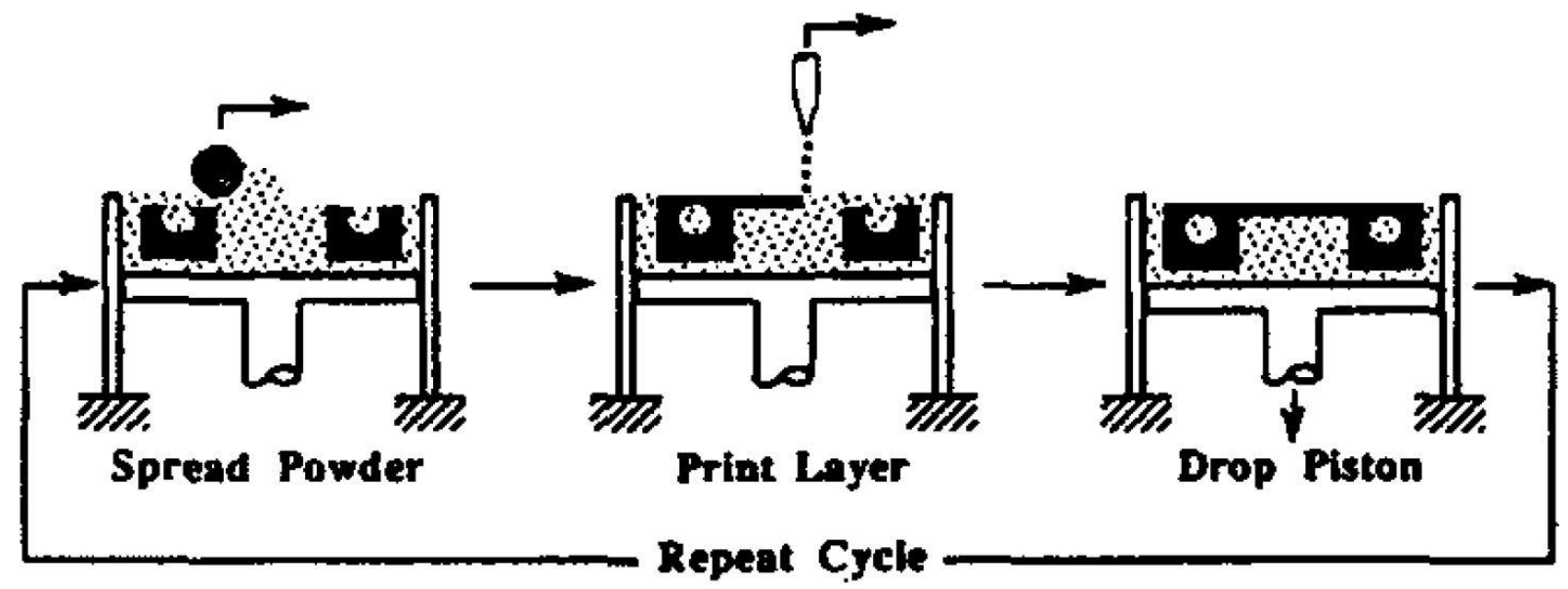

Fig 2.7 The sequence of the operations in 3D Printing. (Sachs et al., 1993)

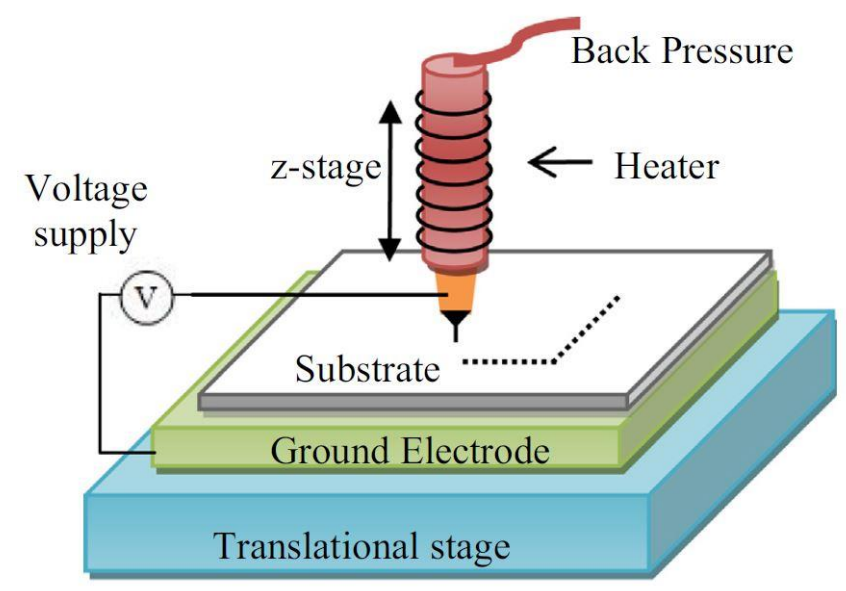

(a)

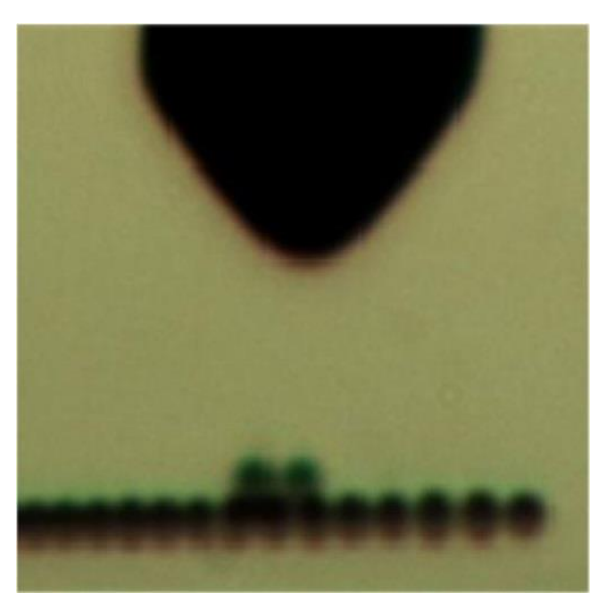

(b)

Fig 2.8 (a) Schematic of the EHD 3D printing set-up system; (b) Pulsating mode of EHD 3D printing of wax. (Han et al., 2014). 


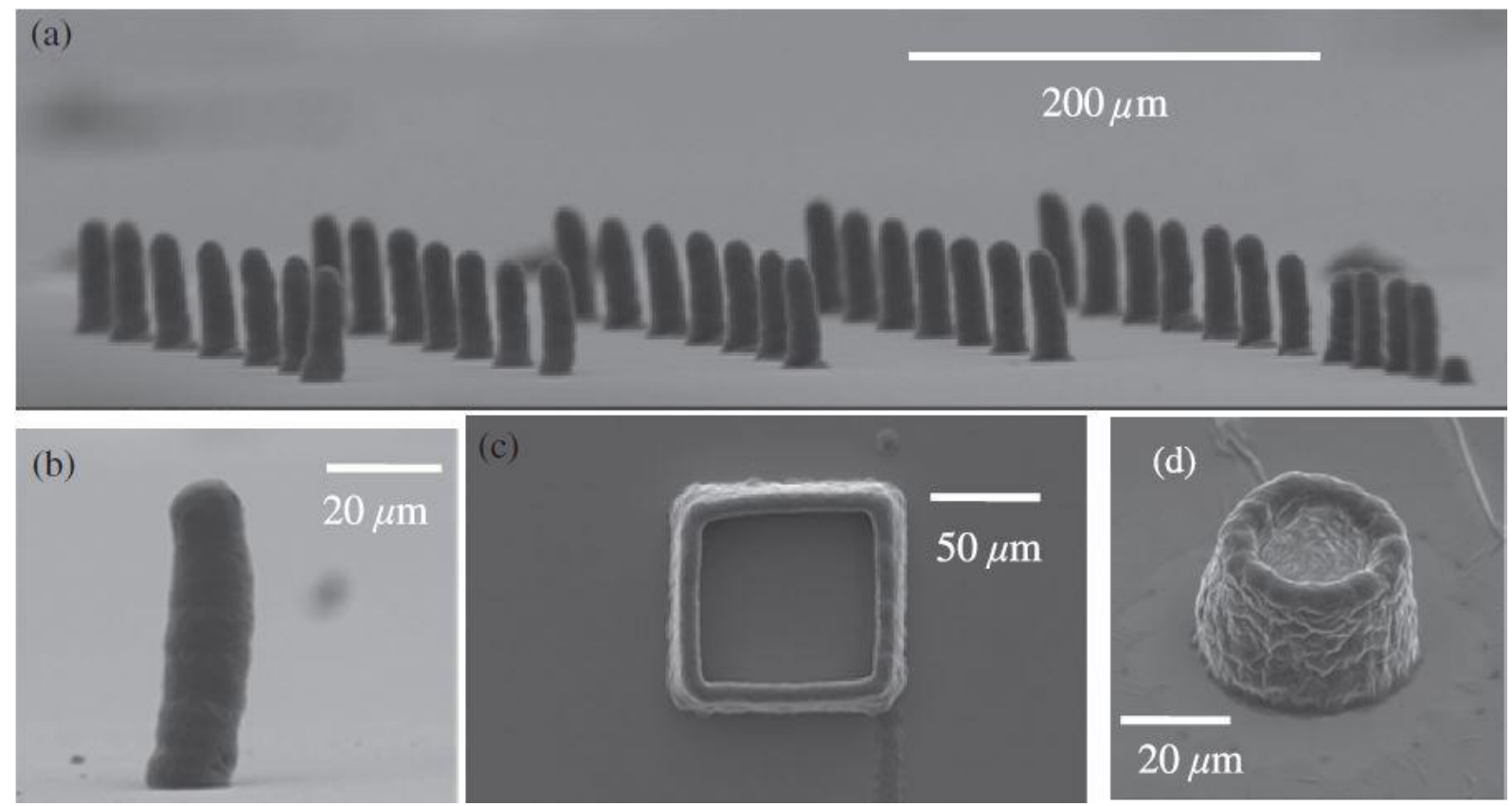

Fig 2.9 Micro-structures printed from EHD 3D printing process. (a) Micro-pillar array; (b) close view of a single pillar; (c) Square with thin wall; (d) Circular tube with thin wall. (Han et al., 2014)

\subsubsection{Laser Surface Texturing}

Laser surface texturing (LST) in particular is regarded as an important technique to enhance tribological performance (Dunn et al., 2015). Over the decades, many researchers (Kurella et al., 2005; Kumari et al., 2015) studied LST. In 1997, a research group was applying Neodymium-Yttrium Aluminum Garnet (Nd-YAG) pulsed solid-state laser to modify the surface of aluminum alloys (Wong, et al., 1997). The Nd-YAG laser emitted at a wavelength of $1.06 \mu \mathrm{m}$ and two main surface features were produced: the non-periodic concentric ring structure and the micro-crack pattern. From the experimental results, both ring structure and micro-crack could be tailored (pre-defined) to a certain extent in order to improve the adhesive bonding of aluminum alloys. One year later, A research group led by Geiger (Geiger, et al., 1998) fabricated microstructures on ceramic surfaces by excimer laser radiation to improve the tribological properties under hydrodynamic and elastohydrodynamic 
sliding conditions (refer to Figure 2.10). Ceramics obtain extremely high hardness, temperature resistance and corrosion resistance. These material properties made ceramics an excellent choice for the application of wear and sliding. Excimer laser processing offers innovative ways to produce textures on ceramics. Pulsed radiation emitted by excimer lasers are in the UV range of the electromagnetic spectrum. In particular, excimer lasers are effective for fabricating microstructures with high resolution. This is benefitted by the short wavelength $(\lambda=193-351 \mathrm{~nm})$ and small penetration depth of excimer laser radiation. This method is able to modify the surface topography of ceramics by changing surface roughness (Ra), even fabricate microstructures with pre-defined geometric properties to have positive influences on the sliding properties, increase lubricant film thickness or serve as lubricant reservoirs.

In 2002, the same group (Geiger, et al., 2002 ) was using a mask illuminated by laser beam to project its geometrical information onto the surface (refer to Figure 2.11) and focusing on the influence of micro textures by excimer laser method on the tribological behaviour of tools in cold forging process. A punch was applied in this method to produce rivets and improve cold forging tool life up to $169 \%$. 

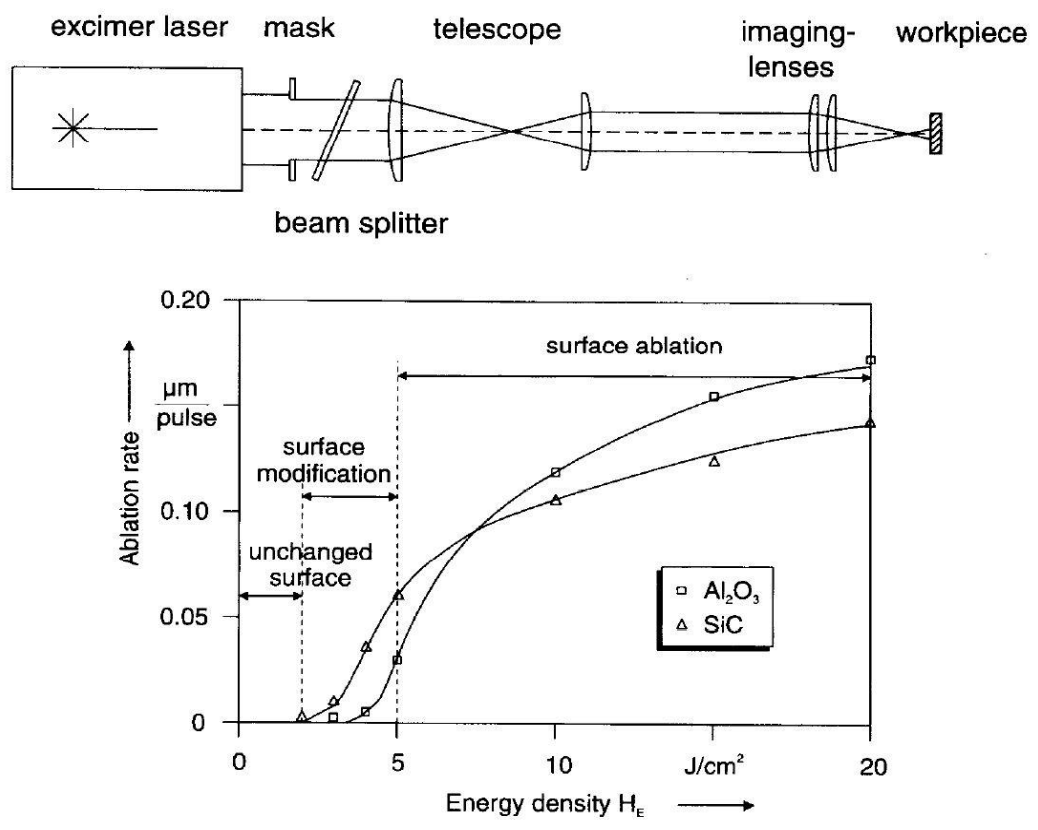

Fig 2.10 Micro-structuring of ceramics by XeCl eximer laser radiation. (Geiger, et al., 1998)

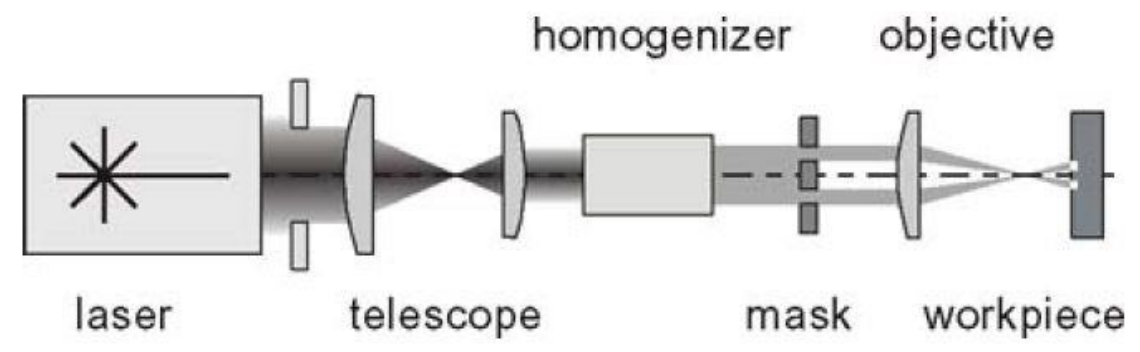

Fig 2.11 Principle of the beam guiding system of an excimer laser for use with masks. (Geiger, et al., 2002) 


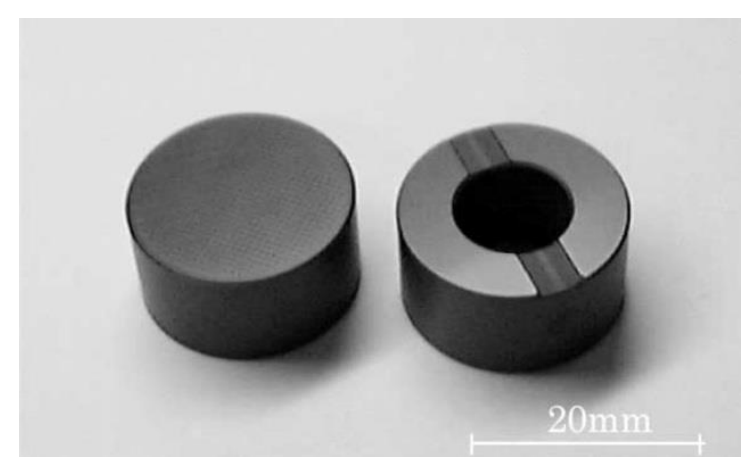

(a)

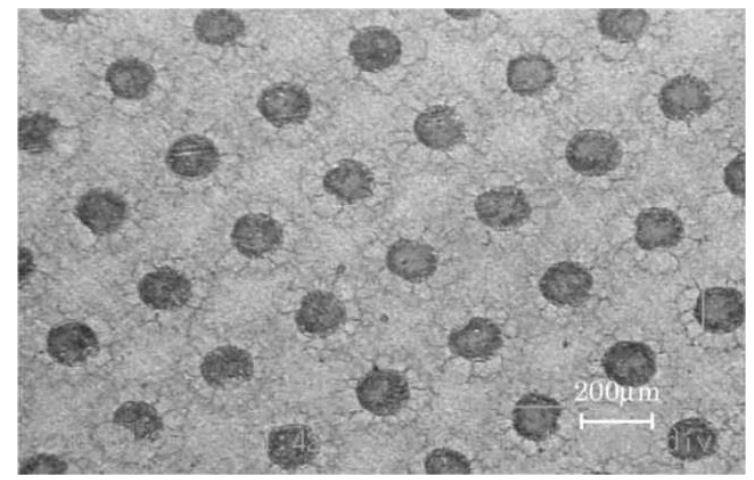

(c)

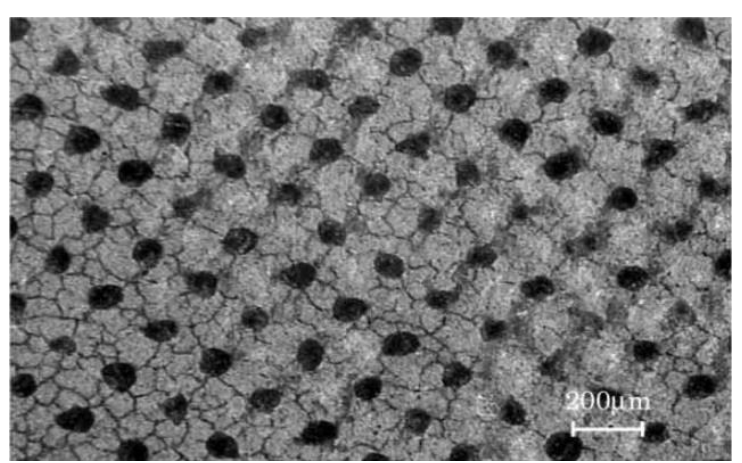

(b)

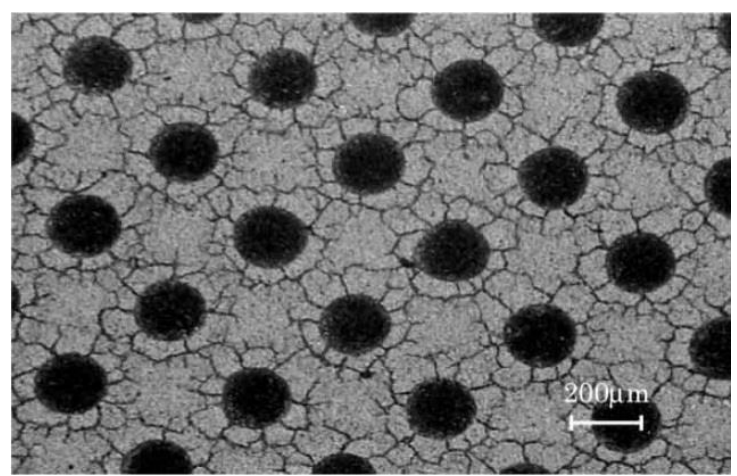

(d)

Fig 2.12 (a) Appearance of disk (left) and cylinder (right); Optical micrographs of pores on the disk surface produced by laser texturing, (b) The pores with diameter of $100 \mu \mathrm{m}$; (c) the pores with diameter of $150 \mu \mathrm{m}$; (d) the pores with diameter of $200 \mu \mathrm{m}$. (Wang, et al., 2001)

$\mathrm{A} \mathrm{CO}_{2}$ laser was used to fabricate micro-pores on $\mathrm{SiC}$ surfaces by a research group in Tohoku University (Wang, et al., 2001). Various textured specimens fabricated with different intervals between the micro-pores were tested and compared to non-textured specimen (refer to Figure 2.12). The effect of the micro-pore area ratio on friction coefficient and the critical load for transition from hydrodynamic to mixed lubrication regime were studied. More extensive research works on LST were done at Argonne National Laboratory, USA (Kovalchenko, et al., 2004; Kovalchenko, et al., 2005) to further understand the effect of micro-structures fabricated by LST on the transition from boundary to hydrodynamic lubrication regime. Friction and electrical-contact resistance were measured by a pin-on-disk setup in unidirectional sliding conformal contact (refer to Fig 2.13). The experimental results illustrated that the range of the hydrodynamic lubrication regime is expanded by LST in terms 
of load and sliding speed. In addition, micro-dimples produced by LST were able to perform a significant reduction of the friction coefficient compared to non-textured surfaces.

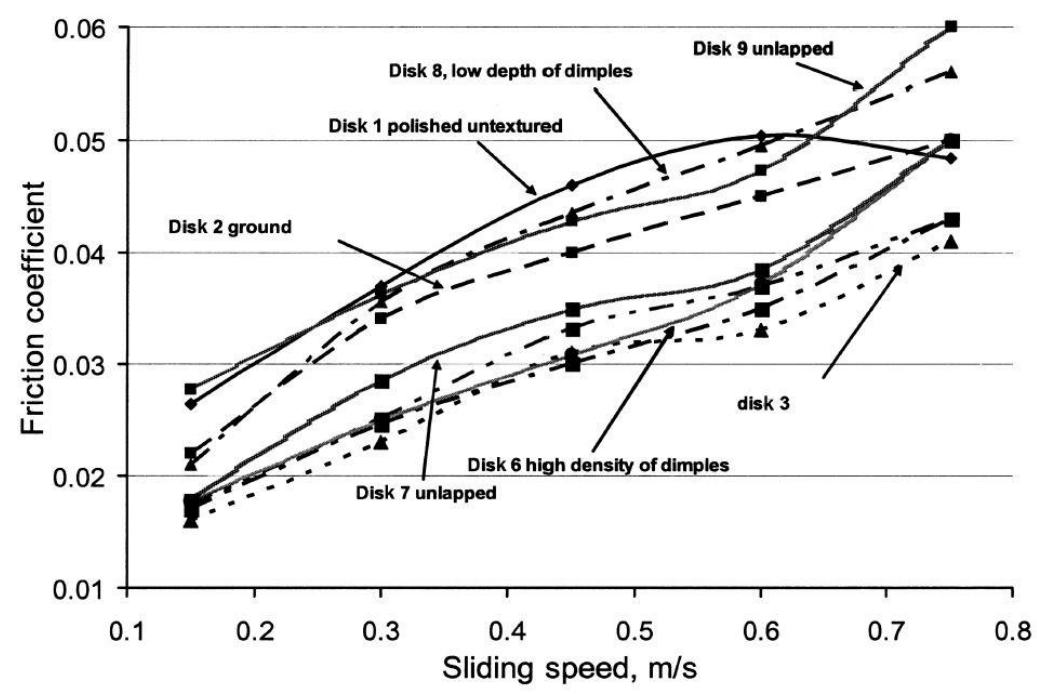

(a)

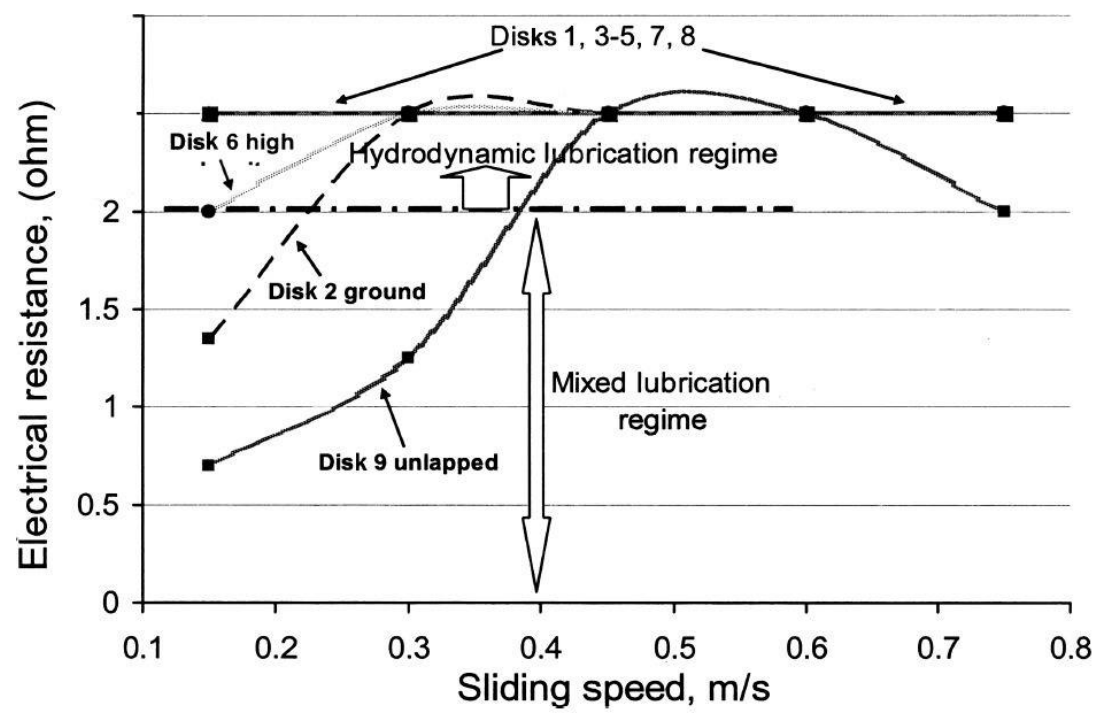

(b)

Fig 2.13 (a) Friction coefficients; (b) electrical resistance between flat-pin and tested disks as a function of sliding speed at $5 \mathrm{~N}$ load and higher viscosity oil lubricant. (Kovalchenko, et al., 2004) 
Furthermore, the application of LST has been expanded to bio-tribology in the recent years. In the Netherlands, samples with well-defined surface topography were used to unlock the "feel" of surfaces by an experimental study on the relation between surface texture and tactile friction (van Kuilenburg et al., 2012). The micro-geometries of the metal samples were fabricated by picosecond laser pulses, also used as injection molds for thermoplastic polyurethane (TPU) samples in experimental work (refer to Fig 2.14). Friction measurements of skin against textured samples were carried out by using a load cell (ATI Gamma three-axis force/torque transducer, ATI Industrial Automation, Apex, NC, USA). Under different normal loads, the coefficient of friction strongly decreased for both textured metal and TPU samples. In the further research, the role of the skin microrelief in the contact between finger and laser textured surfaces was studied (van Kuilenburg et al., 2013). An experimental approach on the friction behavior of the finger pad as a function of asperity geometry was investigated. The surface textures used in vivo testing were fabricated by LST to have evenly distributed asperities with spherical tips. A new multi-scale model was developed to analytically explain skin friction behavior as a function of texture geometry, normal load and skin properties. From the observations of in vivo measurements, the coefficient of friction (COF) was found to increase with the increment of asperity tip radius. With increasing asperity density, COF increased as well. By using relatively simple analytical expressions, the skin friction behavior may be estimated as a function of asperity geometry and operational conditions. Also, LST was proven to be a useful technique to fabricate well-defined micro-textures to study skintribology related researches. 


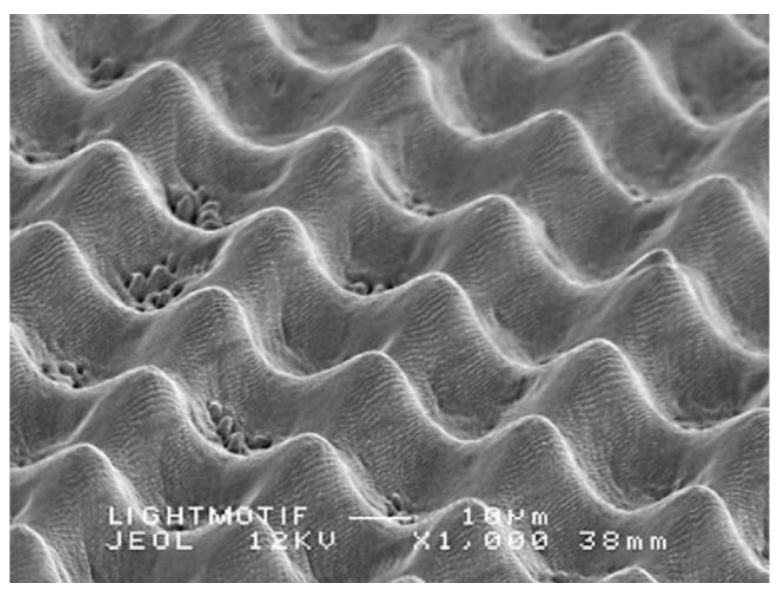

(a)

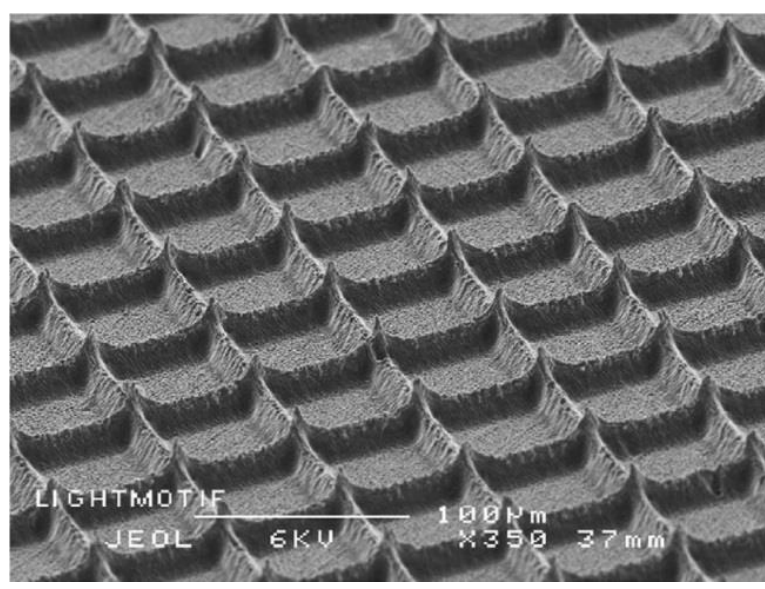

(b)

Fig 2.14 SEM image (a) metal sample with tip radius $\mathrm{R}=5 \mu \mathrm{m}$ and spacing $\lambda=30 \mu \mathrm{m}$; (b) TPU sample with tip radius $\mathrm{R}=1 \mu \mathrm{m}$ and spacing $\lambda=60 \mu \mathrm{m}$. (van Kuilenburg, J., 2012)

\subsection{Discussion}

In the thesis, all textures were fabricated on stainless steel sheet samples. Therefore, it is important to discuss the feasibility of fabrication techniques for stainless steel. From the review of state-of-art fabrication techniques, the pulsed laser surface texturing (LST) is considered as the most suitable method for producing the desired surface structure on the stainless steel sheets (refer to Table 2.1), i.e. directly by laser ablation. Picosecond and nanosecond lasers can be employed to create specific topographic features (van der Heide et al., 2014). Examples are included in this thesis based on work within the STEELTAC project at the University of Twente by the author and at IK4-TEKNIKER based on designs of the author and based on designs by Tata Steel, such as grids (picosecond laser), Hilbert curve (picosecond laser), crater (nanosecond laser), groove (nanosecond laser) patterns with different surface parameters. Secondly, specific operational conditions can be used for texture design aspects.

However, LST is a rather time consuming and high cost fabrication technique. For this reason, stamping (or pressing) and cold rolling, which are low cost with fast production rate, can be applied for the micro-fabrication with textured stamping dies and textured cold rolling rolls by 
LST. Full upscaling of the process is required to gauge the applicability of the laser texturing process to industrial stamping die. Primarily, a TUWI compression rig was used for stamping process at Tata Steel (refer to Fig 2.16) (van der Heide et al., 2014). In the first stage, the roughness transfer capability needs to be evaluated. After an initial texture pattern was considered, the imprinting tests were carried out. For texturing the cold rolling rolls, a 6 -axis robot was used by IK4-TEKNIKER along with a rotary axis during the laser texturing process. Primarily, Tata Steel Pilot Mill (named the MultiMill) (refer to Fig 2.17) in 4-high mode was used for the cold rolling. The textured work rolls are driven and supported by backup rolls. The strip was hand-fed in $150 \mathrm{~mm}$ wide strips with length of $500 \mathrm{~mm}$ to $1000 \mathrm{~mm}$. As a result, the stainless steel sheet were fabricated with the designed textures by LST, stamping and cold rolling techniques. The surface texture of samples were examined by SEM and confocal microscope (refer to Fig 2.15). 
Table 2.1: The advantages and disadvantages of Chemical Wet Etching, Plasma Etching, LST and 3D Printing.

\begin{tabular}{|c|c|c|}
\hline Methods & Advantages & Disadvantages \\
\hline Micro-casting & $\begin{array}{l}\text { - } \text { Cheap } \\
\text { - Low cost } \\
\text { - Complex 3D component }\end{array}$ & $\begin{array}{l}\text { Need other micro-fabrication } \\
\text { techniques to produce the mold }\end{array}$ \\
\hline Chemical Wet Etching & $\begin{array}{l}\text { - Low cost, simple process } \\
\text { - Highly selectivity } \\
\text { - Controllable etching rate }\end{array}$ & $\begin{array}{l}\text { - Chemical Contamination } \\
\text { the crystalline) } \\
\text { - Poor repeatability based on the } \\
\text { influences of temperature and } \\
\text { concentration of etchant } \\
\text { - Undercutting. }\end{array}$ \\
\hline Plasma Etching & $\begin{array}{l}- \text { High feature resolution } \\
\text { - } \quad \text { Easy to control } \\
\text { - High reproducibility } \\
\text { - No liquid chemical waste }\end{array}$ & $\begin{array}{l}\text { - } \text { High cost } \\
\text { - } \text { Poor selectivity } \\
\text { - Potential radiation damage }\end{array}$ \\
\hline LST & 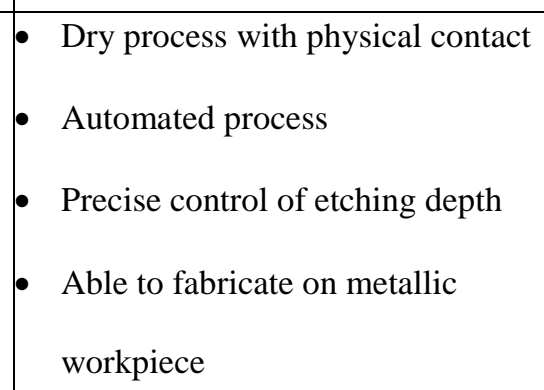 & $\begin{array}{l}\text { - } \text { time consuming } \\
\text { - high cost }\end{array}$ \\
\hline 3D Printing & $\begin{array}{l}\text { - } \text { Complex structures } \\
\text { - Low cost } \\
\text { - Rapid prototyping } \\
\text { - Automated process }\end{array}$ & $\begin{array}{l}\text { - Limited raw materials } \\
\text { - Low feature resolution }\end{array}$ \\
\hline
\end{tabular}



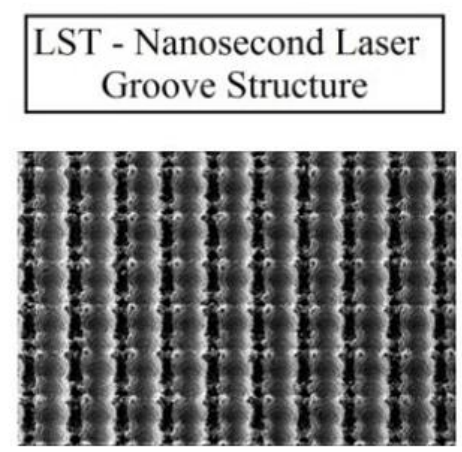

(a)

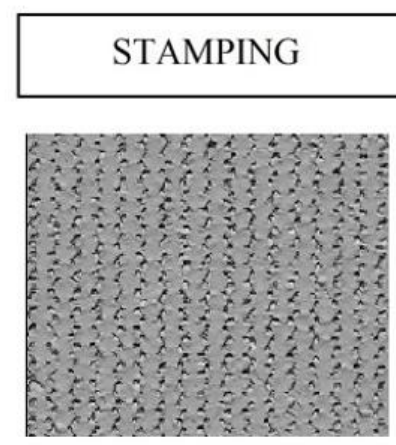

(d)
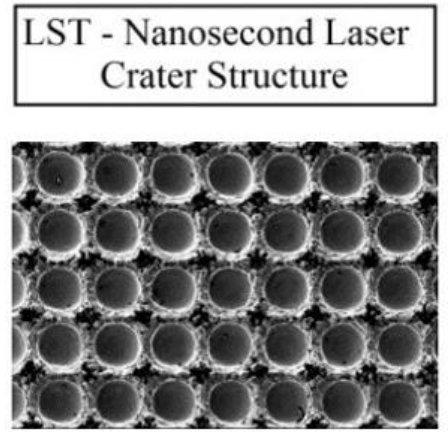

(b)

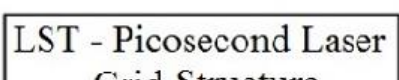
Grid Structure

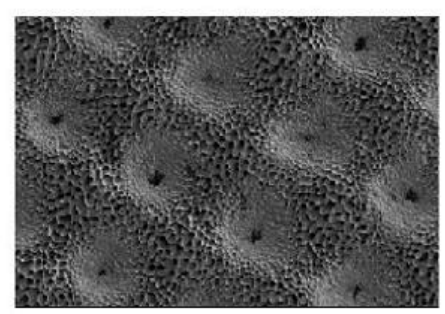

(c)
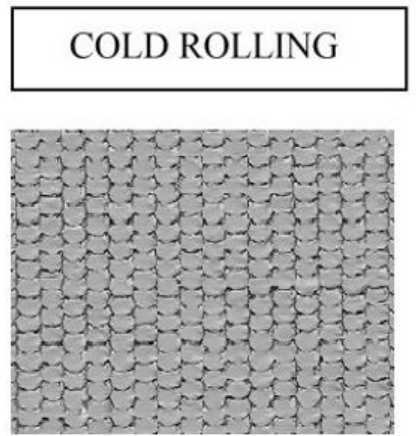

(e)

Fig 2.15 SEM images of samples (a) crater, (b) groove and (c) grid patterns; confocal microscope image of sample (d) stamped and (e) cold rolled samples (van der Heide et al., 2014). 

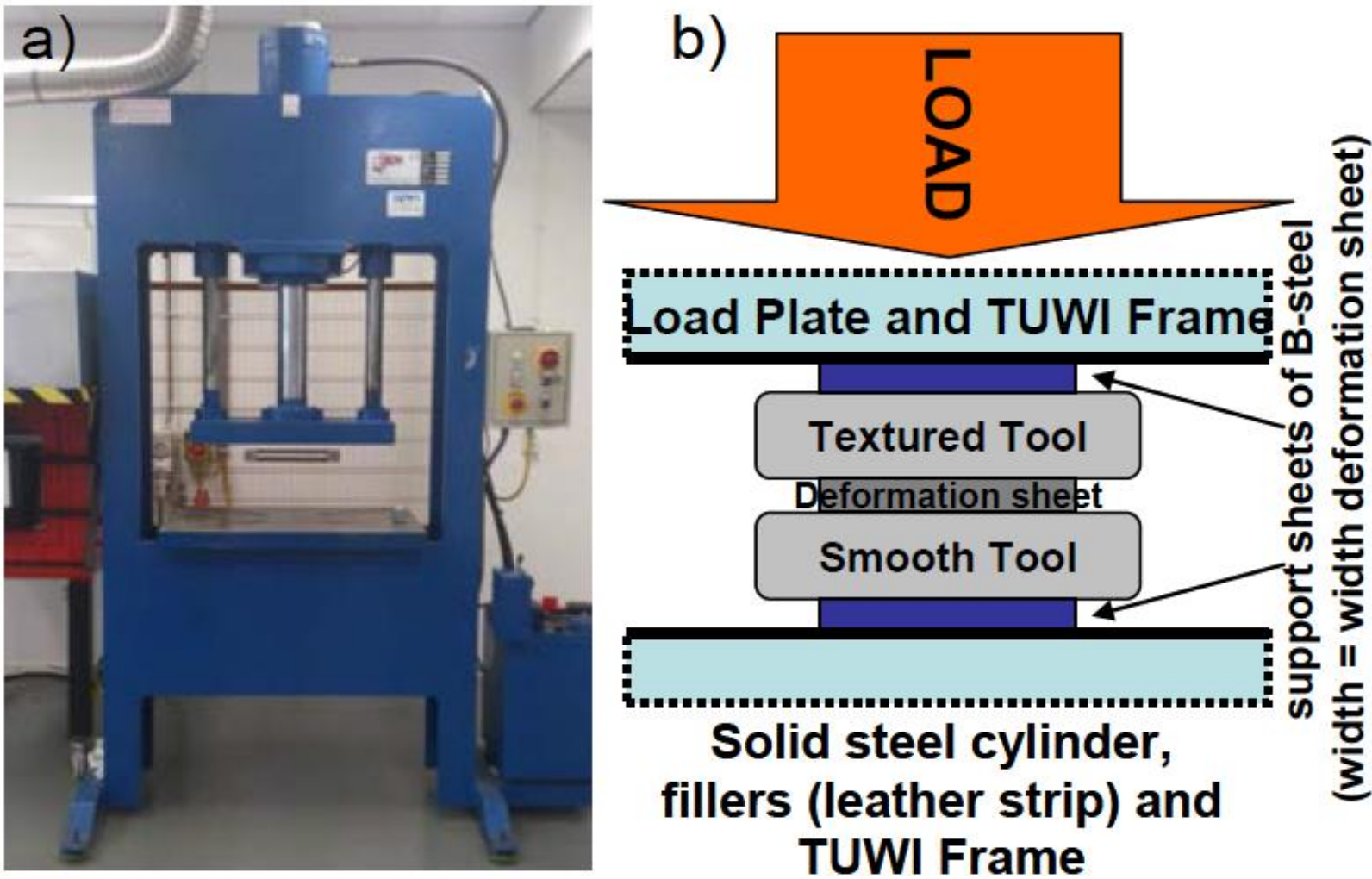

Fig 2.16 (a) Overview of the TUWI compression rig used for stamping, (b) schematic of the key aspects of the set-up at Tata Steel within the STEELTAC project (van der Heide et al., 2014).

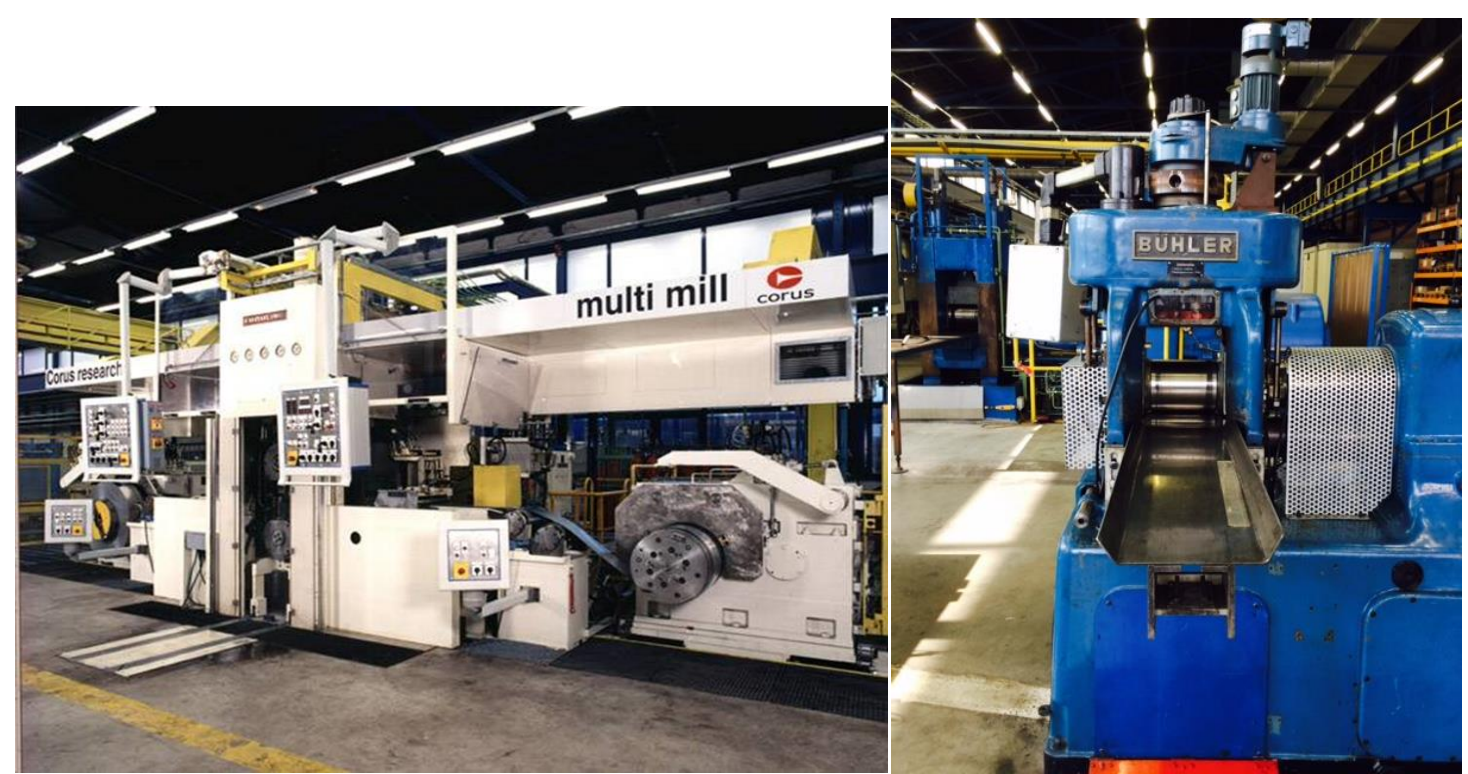

Fig 2.17 Overview of the pilot rolling mills at Tata Steel, used for rolling trials in Steeltac: (left) 4high Multimill, (right) 2-high "Bühler" mill, used for the STEELTAC project (van der Heide et al., 2014). 


\subsection{Conclusion}

Micro-casting, Chemical Wet Etching, Plasma Etching, Laser Surface Texturing and 3D Printing are the major fabrication methods to produce predefined deterministic surface structures in micro scale detail. In addition, Micro-casting and 3D Printing are able to produce complicated 3D components. In comparison, 3D printing is a relatively new method, and its innovative method of bottom-up processing offers the potential to completely revolutionize the process of surface texturing. In this review, the mechanism and application of all five categories of surface texturing techniques are introduced, and each method has its advantages and disadvantages (refer to Table 2.1). Also, it is important to understand that one method may be more appropriate than the other in a given application or producing a specific surface structure.

The needs for the surface structures in industrial and scientific fields are not stalled, and the surface texturing techniques are always evolving. From chemical wet etching to 3D printing, or from a traditional method to a revolutionary bottom-up rapid processing method, surface texturing techniques are improving and innovating continuously.

In this thesis, LST is chosen to be the main fabrication method for producing the surface texture due to its accuracy and ability to fabricate on stainless steel sheet material. For large production, the industrial stamping and cold rolling processes can be used, based on imprinting the negative of the design, to lower the cost and fabrication time. Again, LST has proven its feasibility in creating the negative at the involved forming tools, although only at laboratory scale yet. 


\section{References}

3D Systems Inc., Company Set Up for Stereolithography, CAD in Industry, 1987, 19(4): 223.

Adithyavairavan, M., Subbiah, S., A Morphological Study on Direct Polymer Cast Micro-textured Hydrophobic Surfaces. Surface \& Coatings Technology, 2011, 205: 4764-4770.

Amontons, G., Histoire de l'Académie Royale des Sciences avec les Mémoires de Mathématique et de Physique, 1966: 206.

Barnes, C.J., Childs, T.H.C., Henson, B., Southee, C.H., Surface Finish and Touch - A Case Study in A New Human Factors Tribology. Wear, 2004, 257: 740-750.

Bauhuber, M., Mikrievskij, A., Lechner, A., Isotropic Wet Chemical Etching of Deep Channels with Optical Surface Quality in Silicon with HNA Based Etching Solution. Materials Science in Semiconductor Processing, 2013, 16: 1428-1433.

Bowden, F.P., Tabor, D., The Friction and Lubrication of Solids, 1950: 87-89.

Bruzzone, A.A.G., Costa, H.L., Functional Characterization of Structured Surfaces for Tribological Applications. Procedia CIRP, 2013, 12: 456-461.

Coburn, J.W., Winters, H.F., Plasma Etching - A Discussion of Mechanisms. Journal of Vacuum Science \& Technology, 1979, 16: 391

Chao, B., Cheng, H., Nien, L., Chen, M., Nagao, T., Li, J., Hsueh, C., Anti-reflection Textured Structures by Wet Etching and Island Lithography for Surface-enhanced Raman Spectroscopy. Applied Surface Science, 2015, 357(A): 615-621.

Chen, W., Lin, J., Hu, G., Han, X., Liu, M., Yang, Y., Wu, Z., Liu, Y., Zhang, B., GaN Nanowire Fabricated by Selective Wet-etching of GaN Micro Truncated-pyramid. Journal of Crystal Growth, 2015, 426: 168-172.

Donnelly, V.M., Kornblit, A., Plasma Etching: Yesterday, Today, and Tomorrow. Journal of Vacuum Science \& Technology A, 2013, 31(5): 1-48.

Dunn, A., Wlodarczyk, K.L., Carstensen, J.V., Hansen, E.B., Gabzdyl, J., Harrison, P.M., Shephard, J.D., Hand, D.P., Laser Surface Texturing for High Friction Contacts. Applied Surface Science, 357(B): 2313-2319.

Faust, J.W., Palik, E.D., Study of the Orientation Dependent Etching and Initial Anodizationg of Si in Aqueous KOH. Journal of Electrochemical Society, 1983, 130: 1413-1420.

Ferro, P., Fabrizi, A., Cervo, R., Carollo, C., Effect of Inoculant Containing Rare Earth Metals and Bismuth on Microstructure and Mechanical Properties of Heavy-section Near-eutectic Ductile Iron Castings. Journal of Materials Processing Technology, 2013, 213(9): 1601-1608.

Freires de Queiroz, J.D., Maria de Sousa Leal, A., Terada, M., Agnez-Lima, L.F., Costa, I., Cristhina de Souza Pinto, N., Batistuzzo de Medeiros, S.R., Surface Modification by Argon Plasma Treatment Improves Antioxidant Defense Ability of CHO-k1 cells on Titanium Surfaces. Toxicology in Vitro, 2014, 28: 381-387. 
Geiger, M., Roth, S., and Becker, W., Influence of Laser-Produced Microstructures on the Tribological Behavior of Ceramics. Surface and Coatings Technology. 1998, 100-101: 17-22.

Geiger, M., Popp, U., Engel, U., Eximer Laser Micro Texturing of Cold Forging Tool SurfaceInfluence on Tool Life. CIRP Annals, 2002, 51: 231-234.

Groenendijk, M.N.W., Meijer, J., Surface Microstructures Obtained by Femtosecond Laser Pulses. CIRP Annals, 2006, 55(1): 183-186.

Hosokawa, N., Matsuzaki, R., Asamaki, T., RF Sputter-Etching by Fluoro-Chloro-Hydrocarbon Gases. Japanese Journal of Applied Physics. Supplement. 1974, 2: 435-438.

Ibatan, T., Uddin, M.S., Chowdhury M.A.K., Recent Development of Surface Texturing in Enhancing Tribological Performance of Bearing Sliders. Surface and Coatings Technology, 272: 102120.

Jaeger, R.C., Introduction to Microelectronic Fabrication, 2 ed. Auburn, Upper Saddle River-Prentice Hall, 2002

Khatri, B. C., Sharma, C. S., Influence of Textured Surface on the Performance of Non-recessed Hybrid Journal Bearing Operating with Non-Newtonian Lubricant. Tribology International, 2016, 95: 221-235.

Khodai, M., Parvin, N., Pressure Measurement and Some Observation in Lost Foam Casting, Jouranl of Materials Processing Technology, 2008, 206(1-3): 1-6.

Kumar M. D., Kim, H., Kim, J., Periodically Patterned Si Pyramids for Realizing High Efficient Solar Cells by Wet Etching Process. Solar Energy, 2015, 117: 180-186.

Kurella, A., Dahotre, B. N., Review Paper: Surface Modification for Bioimplatns: The Role of Laser Surface Engineering. Journal of Biomaterials Applications, 2005, 20: 5-50.

Lam, C.X.F., Mo, X.M. Scaffold Development Using 3D Printing with a Starch-based Polymer. Materials Science \& Engineering, C: Biomimetic and Supramolecular Systems, 2002, C20(12): 49-56.

Lee, Y., Kim, H., Hussain, S.Q., Han, S., Balaji, N., Lee, Y., Lee, J., Yi, J., Study of Metal Assisted Anisotropic Chemical Etching of Silicon for High Aspect Ratio in Crystalline Silicon Solar Cells. Materials Science in Semiconductor Processing, 2015, 40: 391-396.

Li, B., Ren, M., Yang, C., Fu, H., Microstructure of Zn-Al4 alloy Microcastings Bymicro Precision Casting based on Metal Mold. Transactions of Nonferrous Metals Society of China, 2008, 18: 327-332.

Li, J., Chen, R., Ke, W., Microstructure and Mechanical Properties of Mg-Gd-Y-Zr Alloy Cast by metal Mould and Lost Foam Casting. Transactions of Nonferrous Metals Society of China, 2011, 21(4), 761-766.

Lim, C.S., Hong, M.H., Senthil Kumar, A., Rahman, M., Liu, X.D., Fabrication of Concave Micro Lens Array Using Laser Patterning and Isotropic Etching. International Journal of Machine Tools \& Manufacture, 2005, 46: 552-558.

Linde, H.G., Austin, L.W., Catalytic Control of Anistropic Silicon Etching. Sensors and Actuators A, 1995, 49: 181-185. 
Ling, F.F., Fractals, Engineering Surfaces and Tribology. Wear, 1990, 136: 141-156.

Klatzky, R.L., Lederman, S.J., Tactile Roughness Perception with a Rigid Link Interposed between Skin and Surface. Perception \& Psychophysics, 1999, 61: 591-607.

Klatzky, R.L., Pawluk, D., Peer, A., Haptic Perception of Material Properties and Implications for Applications. 2013, 101(9): 2081-2092.

Kumari, R., Scharnweber, T., Pfleging, W., Besser, H., Majumdar J.D., Laser Surface Textured Titanium Alloy (Ti-6Al-4V) - Part II - Studies on Bio-compatibility. Applied Surface Science, 2015, 357(A): 750-758.

McGinley, E.L., Moran G.P., Fleming G. J.P., Biocompatibility Effects of Indirect Exposure of Basemetal Dental Casting Alloys to a Human-derived Three-dimensional Oral Mucosal Model. Journal of Dentistry, 2013, 41(11): 1091-1100.

Mondiali, V., Lodari, M., Chrastina, D., Barget, M., Bonera, E., Bollani, M., Micro and Nanofabrication of $\mathrm{SiGe} / \mathrm{Ge}$ Bridges and Membrances by Wet-anisotropic Etching. Mciroelectronic Engineering, 2015, 141: 256-260.

Moon, J., Caballero, J.E., Ink-jet Printing of Binders for Ceramic Components. Journal of the American Ceramic Society, 2002, 85(4): 755-762.

Pettersson, U., Jacobson, S., Influence of Surface Texture on Boundary Lubricated Sliding Contacts. Tribology International, 2003, 36: 857-864.

Reshak, A.H., Shahimin, M.M., Shaar, S., John, N., Surface Modification via Wet Chemical Etching of Single-crystalline silicon for Photovoltaic Application. Progress in Biophysics and Molecular Biology, 2013, 113(2): 327-332.

Schneider, Yu. G., Formation of Surfaces with Uniform Micropatterns on Precision Machine and Instrument parts. Precision Engineering, 1984: 219-225.

Seidel, H., The Mechanism of Anisotropic, Electrochemical Silicon Etching in Alkaline Solutions. IEEE Solid-State Sencor and Actuator Conference, 1990: 86-91.

Seitz, H., Rieder, W., Three-dimensional Printing of Porous Ceramic Scaffolds for Bone Tissue Engineering. Journal of Biomedical Materials Research, Part B, Applied Biomaterials, 2005, 74(2): 782-788.

Sheeja, D., Tay, B.K., Yu, Y.J., Chua, D.H.C., Milne, W.I., Miao, J., Fu, Y.Q., Fabrication of Amorphous Carbon Cantilever Structures by Isotropic and Anisotropic Wet Etching Methods. Diamond and Related Materials, 2003, 12(9): 1495-1499.

Skedung, L., Danerlov, K., Olofsson, U., Johannesson, C. M., Aikala, M., Kettle, J., Arvidsson, M., Berglund, B., Rutland, M. W., Tactile perception: finger friction, surface roughness and perceived coarseness, Tribology International, 2011, 44: 505-512.

Skedung, L., Arvidsson, M., Chung, J.Y., Stafford, C.M., Berglund, B., Rutland, M.W., Feeling small: exploring the tactile perception limits. Scientific Reports, 2013, 3: 1-6.

Sugihara, T., Enomoto, T., Crater and Flank Wear Resistance of Cutting Tools Having Micro Textured Surfaces. Precision Engineering, 2013, 37(4): 888-896. 
Tang, W., Zhou, Y.K., Zhu, H., Yang, H.F., The Effect of Surface Texturing on Reducing the Friction and Wear of Steel under Lubricated Sliding Contact. Applied Surface Science, 2013, 273: 199-204.

Tomlinson, S.E., Carre, M.J., Lewis, R., Franklin, S.E., Human finger contact with small, triangular ridged surfaces. Wear, 2011, 271: 2346-2353.

Utela, B., Storti, D., Anderson, R., Ganter, M., A Review of Process Development Steps for New Material Systems in Three Dimensional Printing (3DP). Journal of Manufacturing Processes 10, 2008: 96-104.

Van der Heide, E., Saenz de Viteri, V., Rodringuez-Vidal, E., Pagano, F., Wadman, B., Wiklund, D., Matthews, D.T.A., Contreras Fortes, J., Zhang, S., Steel sheet surfaces with enhanced tactile feel, European Commission Research Programme of the Research Fund for Coal and Steel, RFSR-CT-2011-00022, 2011-2014.

Van Kuilenburg, J., Masen, M.A., Groenendijk, M.N.W., Bana, V., van der Heide, E., An Experimental Study on the Relation between Surface Texture and Tactile Friction. Tribology International, 2012, 48: 15-21.

Van Kuilenburg, J., Masen, M.A., van der Heide, E., The Role of the Skin Microrelief in the Contact Behaviour of Human Skin: Contact between the Human Finger and Regular Surface Textures. Tribology International, 2013, 65: 81-90.

Wang, X., Kato, K., Adachi, K., Aizawa, K., The Effect of Laser Texturing of SiC Surface on the Critical Load for the Transition of Water Lubrication Mode from Hydrodynamic to Mixed. Tribology International, 2001, 34(10): 703-711.

Wong, R.C.P., Hoult, A.P., Kim, J.K., Yu, T.X., Improvement of adhesive bonding in aluminium alloys using a laser surface texturing process. Journal of Materials Processing Technology 1997, 63: 579-584.

Wiklund, D., Tribology of stamping the influence of designed steel sheet surface topography on friction, PhD Thesis, Chalmers Tekniska Hogskola, Gothenburg, Sweden, 2006.

Wiklund, D., Rosen, B.G., Gunnarsson, L., Frictional mechanisms in mixed lubricated regime in steel sheet metal forming. Wear, 2008, 264: 474-479.

Yan, X, Li, W., Aberle G. A., Venkataraj, S., Investigation of the Thickness Effect on Material and Surface Texturing Properties of Sputtered ZnO:Al Films for Thin-film Si Solar Cell Applications. Vacuum, 2016, 123:151-159.

Yu, S.S., Zhang. S., Xia, Z.W., Liu, S., Lu, H.J., Zeng, X.T., Textured Hybrid Nanocomposite Coatings for Surface Wear Protection of Sports Equipment. Surface and Coatings Technology, 2016, 287: 76-81.

Zahouani, H., Vargiolu, R., Loubet, J.L., Fractal Models of Surface Topography and Contact Mechanics. Mathematical and Computer Modelling, 1998, 28: 517-534.

Zhang, S., Rodriguez Urribarri, A., Morales Hurtado, M., Zeng, X., van der Heide, E., The role of the sliding direction against a grooved channel texture on tool steel: an experimental study on tactile friction. International Journal of Solids and Structures, 2015, 56-57: 53-61. 


\title{
Chapter 3
}

\section{The Role of the Sliding Direction against a Grooved Channel Texture on Tool Steel: An Experimental Study on Tactile Friction*}

\begin{abstract}
To control tactile friction, that is the friction between fingertip and counter-body, the role of surface texture is required to be unveiled and defined. In this research, an experimental approach is used based on measuring tactile friction for directional texture (grooved channel) with varying depths. For a reference surface, in this current case a polished surface from the same tool steel is compared. The experimental results are analyzed to explain the observed skin friction behaviour as a function of surface texture parameters, sliding direction and applied normal load. Sliding parallel to the groove length shows greater values in COF than sliding perpendicular to the groove direction. Furthermore, parallel sliding reveals a higher dependency of COF on the depth of the grooved channel texture than perpendicular sliding. Application of the two term friction model suggests that the adhesion component of friction has greater impact on parallel than perpendicular sliding direction. According to the observations, grooved channels are well suited to control skin friction in direction dependent sliding, for moderately loaded contact situations. This experimental research contributes to the haptic perception related research, and to the development of other direction-dependent surface structures for touch.
\end{abstract}

*S. Zhang, A. C. Rodriguez Urribarri, M. Morales Hurtado, X. Zeng and E. van der Heide, The Role of the Sliding Direction against a Grooved Channel Texture on Tool Steel: An Experimental Study on Tactile Friction, International Journal of Solids and Structures, 56-57, pp $53-61,2015$ 


\subsection{Introduction}

The study of friction and the role of surface textures in relation to touch perception is the subject of researches in both science and industry for a wide variety of applications (van Kuilenburg et al., in press; Derler et al., 2009; van der Heide et al., 2013). Tactility is directly related to the functional behaviour and perception of products like haptic devices, smartphone cases, tool handles, personal care products and for example kitchenware. In most cases, the exploratory procedure to detect the surface features of various objects consists of a sliding movement of our finger(s) at a moderate load and relatively low sliding velocity (Klatzky and Pawluk, 2013; Barnes et al., 2004). Surface recognition is deciphered by the cutaneous sensory neurons from the specific movement made by our finger during active touch (Fagiani et al., 2012). The touch perception is greatly influenced by the friction generated between the fingertip and countersurfaces (Darden and Schwartz, 2013; Klatzky and Pawluk, 2013; Liu et al., 2008; Skedung et al., 2011).

Perception can be linked to psychophysical factors such as smooth-rough, slippery-grippy, warm-cold and soft-hard (Liu et al., 2008). The frictional behaviour of skin - surface sliding is important in all of these factors (Kuramitsu et al., 2013). Tactile friction requires an in-depth understanding of the contact mechanics and the behaviour of human skin. Surface textures can be categorized as deterministic nature or as stochastic nature (Steinhoff et al., 1996). Deterministic textures have a repetition of fixed geometric structure, and stochastic textures are non-deterministic with random surface pattern. Stochastic surfaces typically use roughness parameters based on distribution characteristics and could result in surfaces that are distinctively different in pattern, yet which have the same distribution parameters. In the work of Skedung (Skedung et al., 2011), finger friction measurements are evaluated to determine the relationship between the coefficient of friction $(\mathrm{COF})$ and surface roughness of a series of 
printing papers. The research found that both roughness and finger friction can be related to perceived coarseness. The topography of paper samples is stochastic and as such directionalindependent. As the relation between distribution related parameters and touch functionality is not known, it seems likely that progress can only be made in this field by using surfaces with pre-defined features. These pre-defined features with deterministic nature are better controlled for touch functionality related experiments.

In this research, directional texture like grooved channel is designed as deterministic surface structures for the purpose of studying the role of the sliding direction for tactile friction. The finger friction tests are performed on the steel samples with directional textures. The structures are fabricated as grooved channels by using laser surface texturing technology. The objective is to find the relation between surface topography parameters and COF with the influence of sliding directions (perpendicular and parallel) on directional textures.

\subsection{Skin tribology}

Human skin has a layered and complex structure. Each skin layer has a different composition, thickness and hydration degree which results in different mechanical properties (Morales Hurtado, et al., 2014). Consequently, the full skin structure shows a viscoelastic, nonhomogeneous, nonlinear, anisotropic behaviour when skin is under load.

Basically, skin is composed of 3 layers: epidermis, dermis and hypodermis. The stratum corneum is the outermost layer of epidermis which is directly in contact with the surrounding environment. It has an important role in hydration control and tactile friction (Tagami and Yoshikuni, 1985). The next layer in the skin structure is dermis. Sensory receptors have their origin in this layer which have a role in the tribological response (Silver et al., 1992; Edwards and Marks, 1995). Hypodermis is the deepest layer of the human skin. Its role in skin 
mechanical properties could be neglected for tactile application (Ramsay, 1996). Skin's response to stress depends on the combined behaviour of these layers. In addition, the state and properties are a function of the body site, age, degree of hydration or nutritional conditions (Lapière, 1990; Hendriks and Franklin, 2010, Derler et al., 2009; Diridollou et al., 2001; Cua et al., 1990; Veijgen et al., 2013). As a result, a specific value for tribo mechanical properties of skin, cannot be given.

The relationship between skin structure, hydration and skin friction response is the subject of several experimental studies, see e.g. the work of Derler (Derler and Gerhardt, 2012). From the review, it is concluded that for both dry and humid conditions, the adhesion component is dominant in sliding contacts between skin and other surfaces. In this research, the experiments are conducted based on skin in dry conditions, because most sliding touches for consumers' products occur in dry conditions.

The friction force $\left(F_{f}\right)$ between human skin and a counter-surface can be composed of an adhesive term $\left(F_{f, a d h}\right)$ and a term resulting from deformation $\left(F_{f, d e f}\right)$ as in Eq. 1 (Greenwood and Tabor, 1958).

$F_{f, t o t}=F_{f, a d h}+F_{f, d e f}$

The adhesion force from Equation (1) can be predicted by the following equations (Greenwood and Tabor, 1958; Johnson et al., 1993; Adams et al., 2007).

$F_{f, a d h}=\tau \cdot A_{\text {real }}$

Where $A_{\text {real }}$ is the real contact area; $\tau$ is the shear strength of the interface;

The deformation term depends on the actual contact situation. The real contact area is more important compared to apparent contact area in order to predict the friction due to adhesion component of friction and it is difficult to be measured experimentally (Derler et al., 2014). The 
apparent contact area is defined as the area of the fingertip in contact with the counter-surface (Bowden and Tabor, 1950; van Kuilenburg et al., 2012). The real contact area is constituted by the sum of all contacted spots between two surfaces and it is a function of surface texture, material properties and interfacial loading conditions (Bowden and Tabor, 1950; Zahouani et al., 2011).

\subsection{Experimental method}

\subsubsection{Materials}

The experimental work was conducted by using samples from tool steel WN 1.2510. The grooved channels with varying depths $D$ (see Fig 3.1) were produced as the deterministic pattern by using laser surface texturing technology. The surface topography of each sample was examined by using a confocal laser scanning microscope (VK 9700 KEYENCE, Japan) (refer to Table 3.1). For the sample with stochastic surface roughness, arithmetic mean $(R a)$, the rootmean-square roughness $(R q)$ and maximum peak to valley height $(R z)$ were obtained from the surface area. Deterministic surface patterns were described by the top to valley distance $(D)$, spacing $(\lambda)$ and width $(W)$, and the surface roughness and horizontal distance for the high portions on the top of the grooves are shown as well. 
Table 3.1 The surface parameters of the samples. For the group of samples with stochastic surface roughness, arithmetic mean $(R a)$, the root-mean-square roughness $(R q)$ and maximum peak to valley height $(R z)$ were obtained from the surface area. Deterministic surface patterns were described by the top to valley distance $(D)$, spacing $(\lambda)$, width $(W)$ and for the high portions on the top of the grooves the $R a, R q, R z$ and horizontal distances, were obtained from the surface area.

\begin{tabular}{|c|c|c|c|c|c|c|c|}
\hline \multicolumn{8}{|c|}{ Deterministic structures } \\
\hline $\begin{array}{c}\text { Sample } \\
\text { No. }\end{array}$ & $\begin{array}{c}\text { Depth D } \\
{[\mu \mathrm{m}]}\end{array}$ & $\begin{array}{c}\text { Spacing } \lambda \\
{[\mu \mathrm{m}]}\end{array}$ & 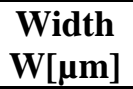 & $\begin{array}{c}\mathbf{R a} \\
{[\mu \mathrm{m}]}\end{array}$ & $\begin{array}{c}\mathbf{R q} \\
{[\mu \mathrm{m}]}\end{array}$ & $\begin{array}{c}\mathbf{R z} \\
{[\mu \mathrm{m}]}\end{array}$ & $\begin{array}{l}\text { Horz. Dist. } \\
{[\mu \mathrm{m}]}\end{array}$ \\
\hline S001 & 30 & 100 & 45 & 0.06 & 0.07 & 0.90 & 48.4 \\
\hline S002 & 15 & 100 & 45 & 0.09 & 0.10 & 2.00 & 46.7 \\
\hline S003 & 5 & 100 & 45 & 0.04 & 0.05 & 1.03 & 46.4 \\
\hline \multicolumn{8}{|c|}{ Stochastic surface } \\
\hline & $\begin{array}{c}\text { Depth D } \\
{[\mu \mathrm{m}]}\end{array}$ & $\begin{array}{c}\text { Spacing } \lambda \\
{[\mu \mathrm{m}]}\end{array}$ & 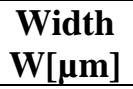 & $\begin{array}{c}\mathbf{R a} \\
{[\mu \mathrm{m}]}\end{array}$ & $\begin{array}{c}\mathbf{R q} \\
{[\mu \mathrm{m}]}\end{array}$ & $\begin{array}{c}\mathbf{R z} \\
{[\mu \mathrm{m}]}\end{array}$ & $\begin{array}{c}\text { Horz. Dist. } \\
{[\mu \mathrm{m}]}\end{array}$ \\
\hline S000 & - & - & - & 0.40 & 0.50 & 4.50 & - \\
\hline
\end{tabular}

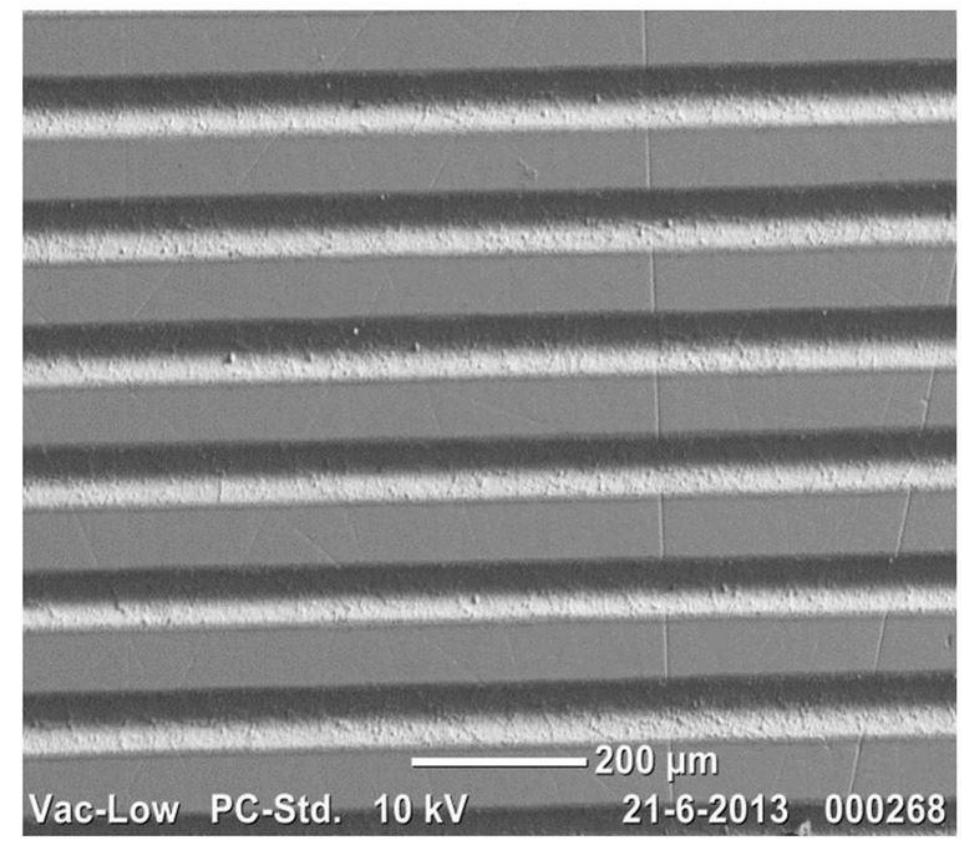

(a)

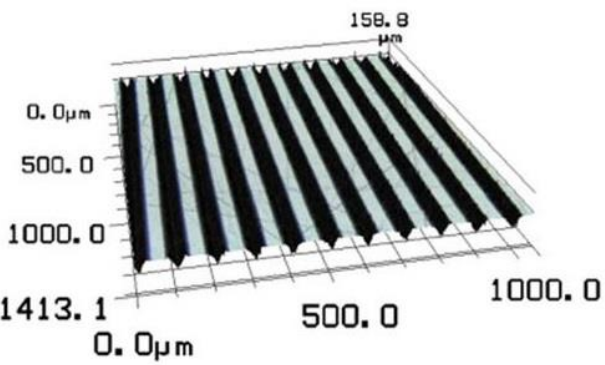

(b)

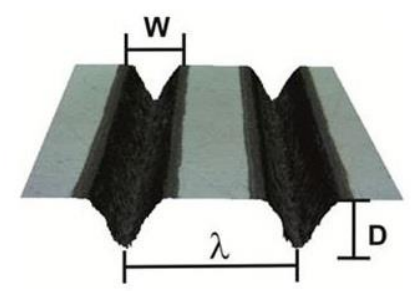

(c)

Fig 3.1 Grooved channel texture on tool steel samples (a) SEM image: upper view; (b) 3D profile using confocal microscope; (c) texture parameters 


\subsubsection{Experimental set-up and preparation}

Friction measurements on skin in vivo were carried out by using a load cell (ATI Gamma threeaxis force/torque transducer, ATI Industrial Automation, Apex, NC, USA). The ATI force transducer uses six degrees of freedom to measure the forces (normal force in z-direction, tangential forces in xy-plane and torques around $\mathrm{x}, \mathrm{y}$ and $\mathrm{z}$ axes). The force measurements have a resolution of $25 \mathrm{mN}$ in normal direction and $12.5 \mathrm{mN}$ in tangential direction, with a sampling rate of $100 \mathrm{~Hz}$. The sliding velocity was calculated from the displacement of initial contact position and final position over time.

Each sample was fixed to the top of the friction transducer using double sided tape. For the group of samples with deterministic surfaces, each counter-body was aligned with a parallel or perpendicular orientation to that of the moving axis of the finger. The middle finger of the nondominant (left) hand of a healthy female adult (25 years old) was used for all the experiments reported here. One experiment consisted of three repetitive single strokes of the finger, sliding towards the body. The stroke length on each sample depended on the size of the surface and shape. For the samples with deterministic surface pattern, the stroke length was $25 \mathrm{~mm}$. For the samples with stochastic surface pattern, the stroke length was $45 \mathrm{~mm}$.

The normal load was controlled by placing a mass on the top of the sliding finger as shown in Fig 3.2(a). Once the normal load was comfortably placed over the skin area tested, each stroke started with imminent movement of the fingertip against the surface tested. During each stroke, the sliding velocity was kept as constant as possible. The end of each stroke was determined when there was no contact anymore, or when the normal load was equal to zero. Coefficients of friction $(\mathrm{COF})$ were calculated within a selected range with respect to the targeted normal load $(0.5 \mathrm{~N}, 1 \mathrm{~N}$ and $2 \mathrm{~N})$. In this way, the data at the beginning and end of each stroke was excluded as shown in Fig 3.2 (b) below. An average velocity of $37 \pm 8 \mathrm{~mm} / \mathrm{s}$ was employed in 
all the experiments reported in this work. This window of operational conditions was taken as representative of those used when exploring a surface with a finger (Liu et al., 2008). All measurements were carried out in an environmentally controlled laboratory at $20 \pm 1^{\circ} \mathrm{C}$ and $40 \pm 5 \%$ relative humidity. Before each experiment, the subject cleaned her finger with a tissue in combination with an amount of isopropanol to remove any sweat from most of the upper surfaces of the ridges of the skin. The hydration level of the skin surface was monitored before the measurements using a Corneometer CM 825 (Courage+Khazaka GmbH, Germany). The average hydration level of the skin was $40 \pm 3$ AU. This level is typical for 'dry'conditions (Heinrich et al., 2003).

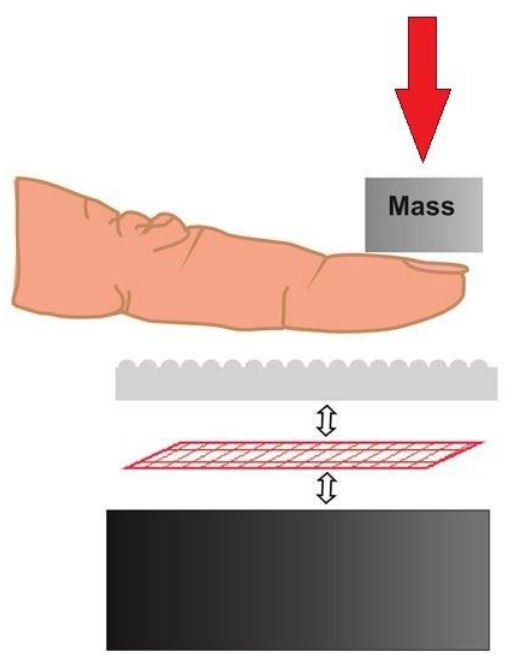

(a)

\section{Normal Load}

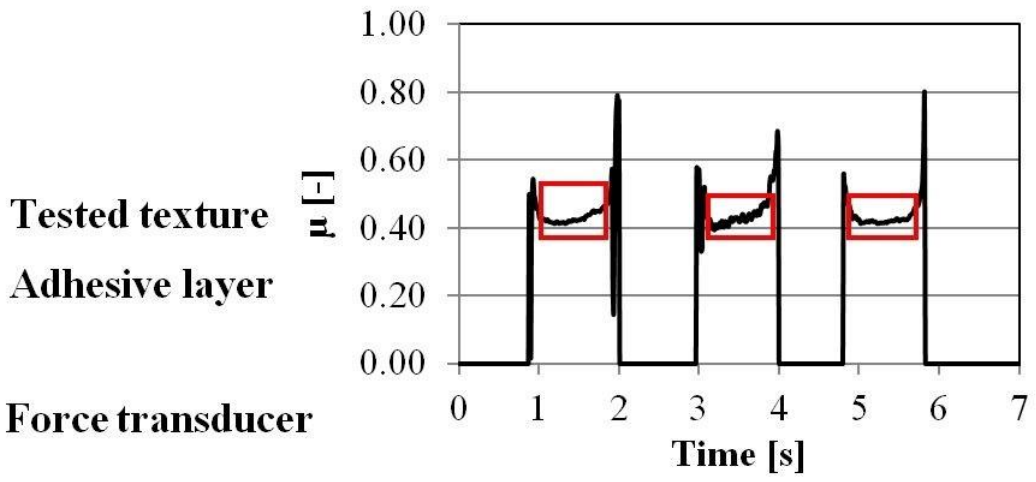

(b)

Fig 3.2 Description of the experimental procedure: a) test set-up; b) measurements of friction. 


\subsection{Results}

For each sample, three friction cycles with one sliding movement in direction 'towards the human body' were analyzed to calculate each COF. The average of COF and its corresponding standard deviation (STD) were calculated from the data obtained from three strokes (Fig 3.2 b). Fig 3.3 shows an overview of COF measured against dry skin with deterministic and stochastic surfaces in both perpendicular and parallel sliding direction with respect to the groove length. The mean value of dynamic COF is calculated under different normal loads. The standard deviations ranged from 0.01 to 0.2 , indicating variations between sliding cycles. COF ranged from 0.9 to 1.3 in the sliding direction parallel to the groove length. Meanwhile COF ranged from 0.3 to 0.7 in the sliding perpendicular direction. The stochastic surface is relative smooth, and was measured for the purpose of comparison ( $\mathrm{S} 000$ ). COF ranged from 0.56 to 0.85 for stochastic surface in the parallel sliding direction and from 0.62 to 0.75 in the perpendicular sliding direction. The sliding direction used with respect to the surface pattern is defined as " $\perp$ " in perpendicular and " $/ /$ " in parallel. 
Table 3.2 Experimental data for deterministic and stochastic surfaces in both perpendicular and parallel sliding direction

\begin{tabular}{|c|c|c|c|c|}
\hline $\begin{array}{l}\text { Sliding } \\
\text { motion }\end{array}$ & Sample & $\begin{array}{l}\text { Normal load }[\mathrm{N}] \\
\text { Mean } \pm \text { STD }\end{array}$ & $\begin{array}{c}\text { COF } \\
\text { Mean } \pm \text { STD }\end{array}$ & $\begin{array}{c}\text { Depth D } \\
{[\mu \mathrm{m}]}\end{array}$ \\
\hline \multirow{12}{*}{$\begin{array}{l}\text { Perpendicular } \\
\text { motion }(\perp)\end{array}$} & S000 & $0.38 \pm 0.10$ & $0.68 \pm 0.05$ & - \\
\hline & S001 & $0.44 \pm 0.05$ & $0.56 \pm 0.04$ & 30 \\
\hline & S002 & $0.50 \pm 0.12$ & $0.54 \pm 0.07$ & 15 \\
\hline & S003 & $0.57 \pm 0.10$ & $0.52 \pm 0.06$ & 5 \\
\hline & SO00 & $0.97 \pm 0.23$ & $0.66 \pm 0.03$ & - \\
\hline & S001 & $0.89 \pm 0.56$ & $0.62 \pm 0.06$ & 30 \\
\hline & S002 & $0.93 \pm 0.08$ & $0.62 \pm 0.07$ & 15 \\
\hline & S003 & $0.83 \pm 0.05$ & $0.59 \pm 0.04$ & 5 \\
\hline & SO00 & $2.23 \pm 0.43$ & $0.75 \pm 0.05$ & - \\
\hline & S001 & $2.42 \pm 0.22$ & $0.37 \pm 0.02$ & 30 \\
\hline & S002 & $2.39 \pm 0.26$ & $0.36 \pm 0.02$ & 15 \\
\hline & S003 & $2.31 \pm 0.23$ & $0.41 \pm 0.03$ & 5 \\
\hline \multirow{12}{*}{$\begin{array}{c}\text { Parallel } \\
\text { motion (//) }\end{array}$} & S000 & $0.38 \pm 0.04$ & $0.65 \pm 0.03$ & - \\
\hline & S001 & $0.34 \pm 0.06$ & $1.03 \pm 0.12$ & 30 \\
\hline & S002 & $0.48 \pm 0.05$ & $1.33 \pm 0.08$ & 15 \\
\hline & S003 & $0.62 \pm 0.11$ & $1.34 \pm 0.23$ & 5 \\
\hline & S000 & $0.97 \pm 0.08$ & $0.56 \pm 0.05$ & - \\
\hline & S001 & $0.93 \pm 0.08$ & $0.93 \pm 0.10$ & 30 \\
\hline & S002 & $0.93 \pm 0.05$ & $1.10 \pm 0.10$ & 15 \\
\hline & S003 & $0.81 \pm 0.05$ & $1.23 \pm 0.11$ & 5 \\
\hline & So00 & $2.23 \pm 0.15$ & $0.85 \pm 0.06$ & - \\
\hline & S001 & $2.19 \pm 0.14$ & $0.93 \pm 0.08$ & 30 \\
\hline & S002 & $2.07 \pm 0.15$ & $1.04 \pm 0.15$ & 15 \\
\hline & S003 & $2.00 \pm 0.08$ & $1.17 \pm 0.16$ & 5 \\
\hline
\end{tabular}




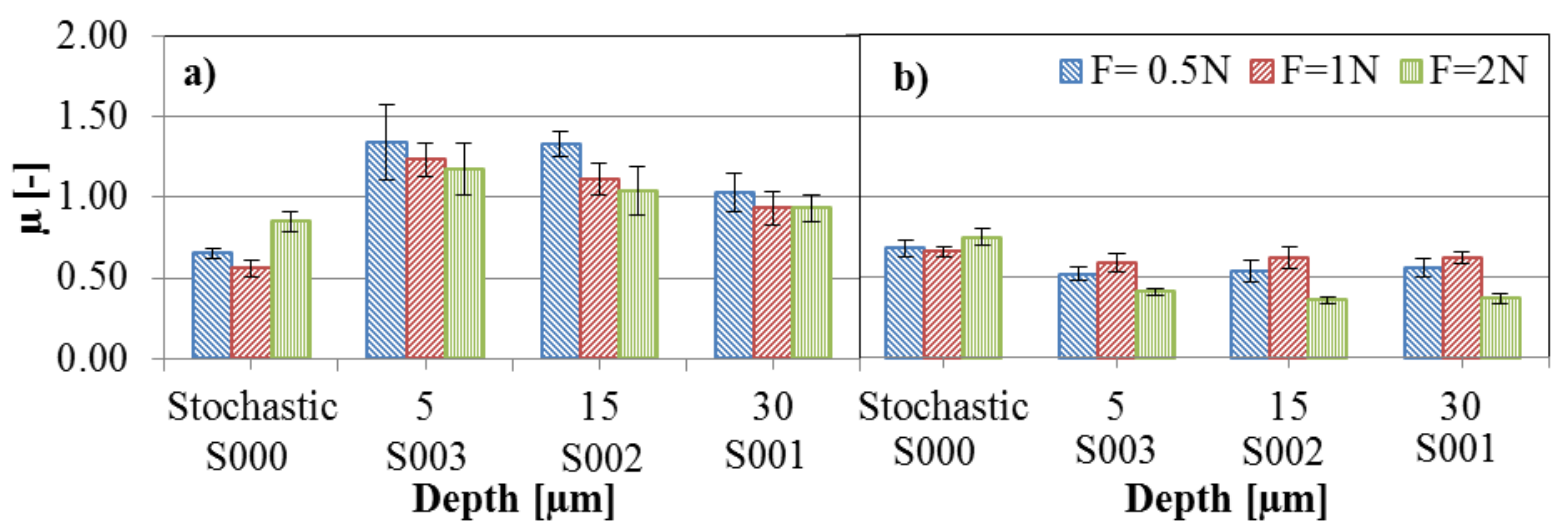

Fig 3.3 Overview of COF: (a) motion parallel to groove length and (b) motion perpendicular to groove length, compared to stochastic surface.

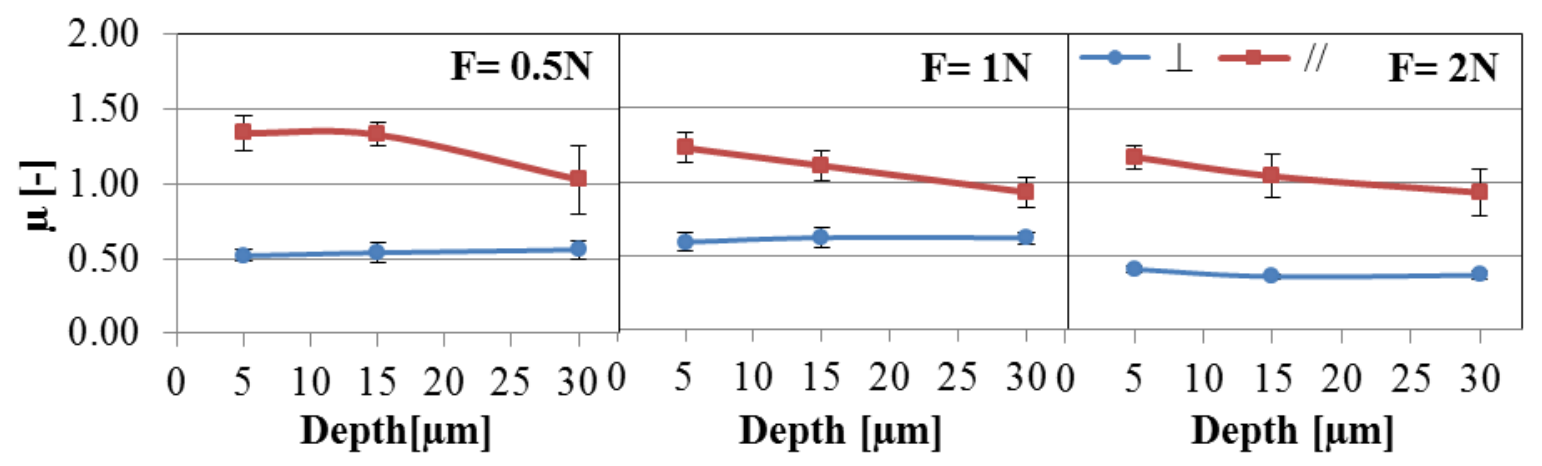

Fig 3.4 COF vs. depth for steel samples at different normal loads 


\subsection{Discussion}

For fingertip sliding on counter-body, Tomlinson (Tomlinson et al., 2009) reported COF of 0.23 for stainless steel. Gee (Gee et al., 2005) investigated the friction of the finger in the left to right direction on different materials, and found COF of 1.75 for steel. COF within this range were also found in the touch experiments presented here: i.e. $0.3-1.3$ for steel including both parallel and perpendicular sliding direction.

\subsubsection{The effect of the grooved surface texture}

It is expected that COF can vary at the higher normal load level by changing lambda spacing $(\lambda)$ or the width of grooves, because the contact area of skin varies accordingly (Smith et al., 2002; Taylor and Lederman, 1975; Wang et al., 2008).

Based on the experimental results of this paper, the deeper the depth of grooves, the lower COF for the parallel sliding (refer to Fig 3.4). According to the experiments of Skedung et al. (Skedung et al., 2011), a similar phenomenon is observed with various paper samples, as there is an inverse relation found between skin friction and surface roughness. A possible explanation for this phenomenon is that due to the reduced contact area between skin and counter-surface, the adhesion component of the friction force decreases (refer to Eq. 2).

A contact model is able to estimate the contact ratio between an elastic half-space and rigid wavy surface with wavelength $(\lambda)$ and amplitude (the depth of groove, $D$ ) (Westergaard 1939; Johnson et al., 1985).

$\frac{(\lambda-w)}{\lambda}=\frac{2}{\pi} \sin ^{-1}\left(\frac{\bar{p}}{p^{*}}\right)^{1 / 2}$

Where $\lambda$ is the lambda spacing between grooves; $w$ is the width of the groove valley; $\bar{p}$ is the actual surface pressure; $p^{*}$ is the pressure needed for finger under full contact condition (refer 
to Eq. 4 \& 5). The Westergaard model also can be applied for the sliding contact of a rigid wavy surface with a viscoelastic half-space (Menga et al., 2014). A modified model is used in this paper to predict the actual surface pressure and the pressured needed for the fingertip under full contact condition.

$\bar{p}=\frac{F_{N}}{\pi a^{2}}$

$p^{*}=\pi E^{*} \frac{D}{2 \lambda}$

$\frac{1}{E^{*}}=\frac{1-v_{\text {finger }}^{2}}{E_{\text {finger }}}+\frac{1-v_{\text {surface }}^{2}}{E_{\text {surface }}}$

$a=\sqrt[3]{\frac{3 R F_{N}}{4 E^{*}}}$

Where $F_{N}$ is the applied load; $a$ is the contact radius of fingertip in contact with counter-surface predicted by Hertz equation; $D$ is the depth of groove (amplitude); $E^{*}$ is the effective Young's modulus; $v_{\text {finger }}$ and $v_{\text {surface }}$ are the Poisson ratio of finger and counter-surface accordingly; $R$ is the radius of fingertip.

The apparent contact area $\left(A_{a p p}\right)$ is influenced by the contact condition which is determined by the pressure ratio $\left(\frac{\bar{p}}{p^{*}}\right)$. When the pressure ratio $\left(\frac{\bar{p}}{p^{*}}\right)$ is smaller than 1 , the contact area of grooved channels is under the partial contact condition. the pressure ratio $\left(\frac{\bar{p}}{p^{*}}\right)$ is larger than or equal to 1 , the contact area of grooved channels is under the full contact condition.

The apparent contact area of grooved channels under the minimum partial contact $\left(A_{a p p, P C}\right)$ and full contact $\left(A_{a p p, F C}\right)$ conditions are predicted as:

$$
A_{a p p, P C}=\pi a^{2}-N w \bar{l}=N(\lambda-w) \bar{l}, \quad \text { for } \overline{\mathrm{p}}<\mathrm{p}^{*}
$$


$A_{a p p, F C}=N(\lambda-w) \bar{l}+N\left[2\left(\sqrt{\left(\frac{w}{2}\right)^{2}+D^{2}}\right)\right] \bar{l}, \quad$ for $\overline{\mathrm{p}} \geq \mathrm{p}^{*}$

Where $a$ is the contact radius of fingertip in contact with counter-surface predicted by Hertz equation (Eq. 7); $N$ is the number of grooves in contact; $\lambda$ is the lambda spacing between grooves; $w$ is the width of the groove valley; $\sqrt{\left(\frac{w}{2}\right)^{2}+D^{2}}$ is an approximation to the slope of groove sides; $\bar{l}$ is the average length of the grooves in contact (refer to Fig 3.5 a). As illustrated in Fig 3.5, under the same load, the contact condition between the fingertip and counter body depends on the depth of grooved textures. With deeper depth, the valley of the texture is not contacted. There is less contact area of skin under partial contact condition compared to full contact condition with shallow depth.

Parameters from literature (refer to Table 3.3) are used in the analytical model to estimate pressure ratio and contact area ratio (refer to Fig 3.6). To better understand the contact condition such as partial or full contact, the fingertip is assumed to be flat. There is an upper limit for the contact ratio which can be predicted by the maximum contact area under full contact (refer to Eq. 9) over the contact area estimated by Hertz theory. 
Table 3.3 Parameters from literature are used in the analytical model to estimate the contact ratio between finger and grooved channel (Maeno et al., 1998; Dandekar et al., 2003; Shao et al., 2010; Greaves et al., 2011).

\begin{tabular}{cc}
\hline & Values \\
\hline $\boldsymbol{E}_{\text {finger }}$ & $0.2 \mathrm{MPa}$ \\
$\boldsymbol{E}_{\text {surface }}$ & $150 \mathrm{GPa}$ \\
$\boldsymbol{v}_{\text {finger }}$ & 0.48 \\
$\boldsymbol{v}_{\text {surface }}$ & 0.3 \\
Depth of groove & $30 \mu \mathrm{m}, 15 \mu \mathrm{m}, 5 \mu \mathrm{m}$ \\
\hline
\end{tabular}

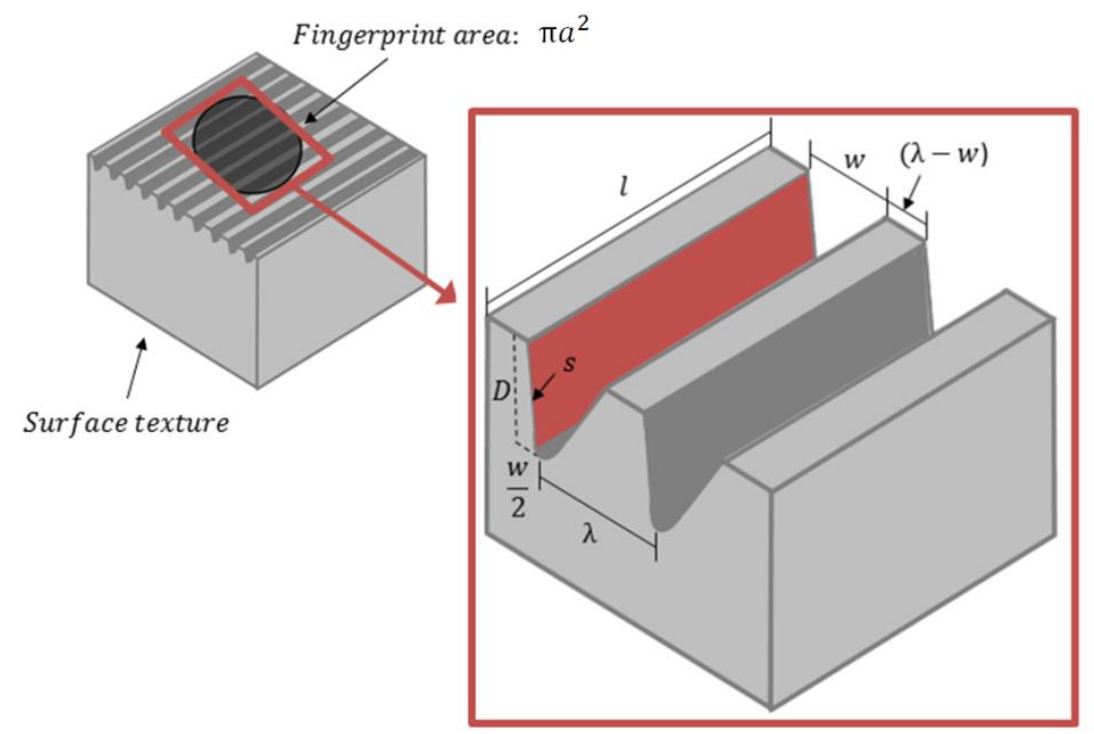

(a)

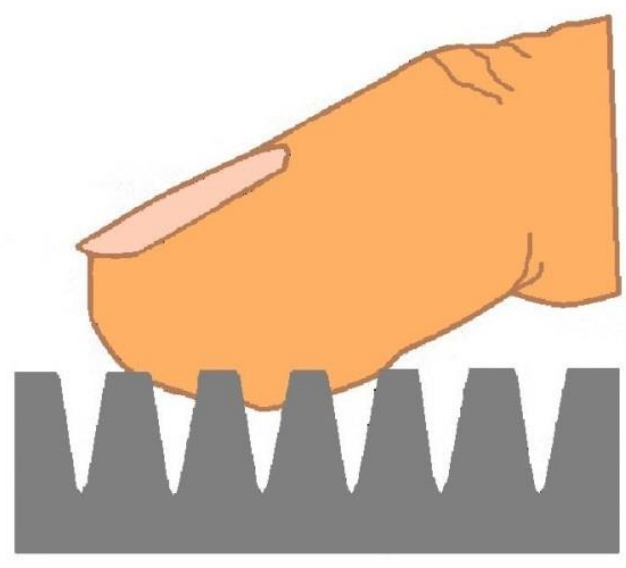

(b)

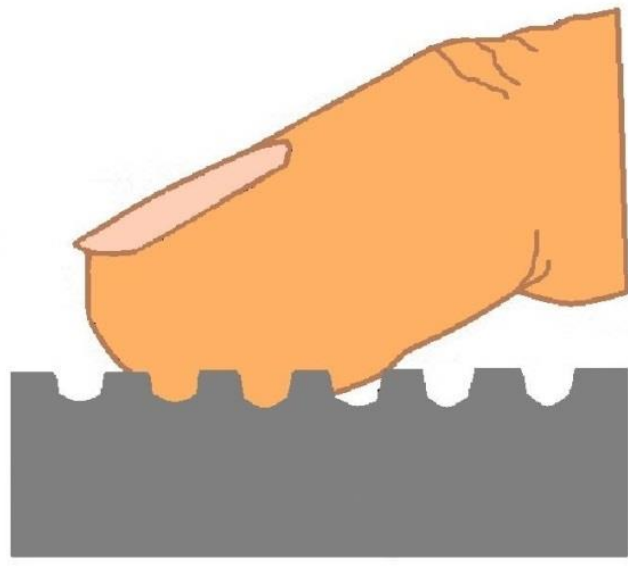

(c)

Fig 3.5 (a) Parameters of grooved channel in contact; (b) partial contact and (c) full contact depends on the top to valley distance of the grooved channel. 


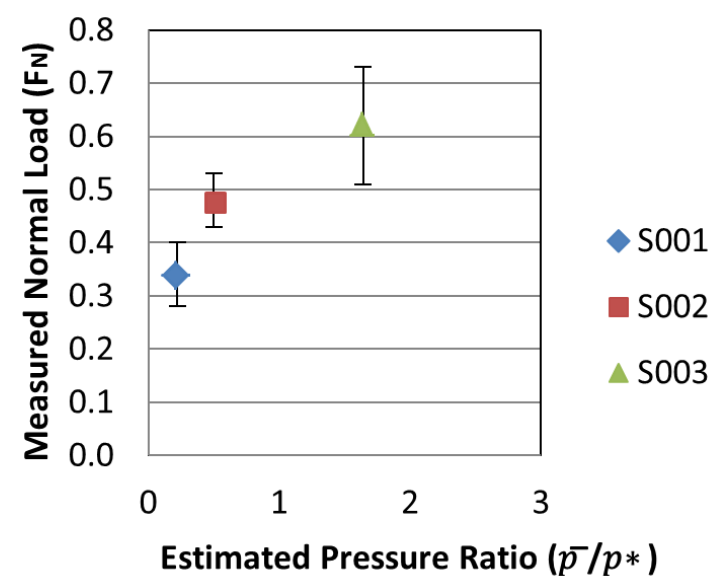

(a)

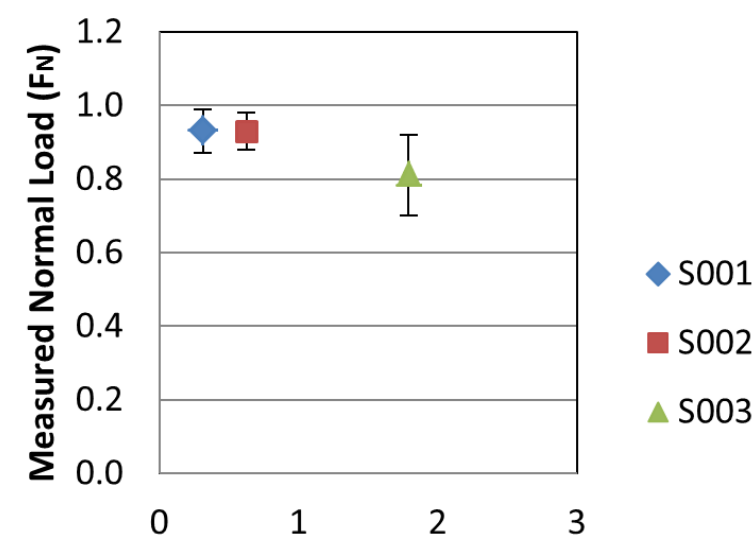

Estimated Pressure Ratio $(\bar{p} / p *)$

(c)

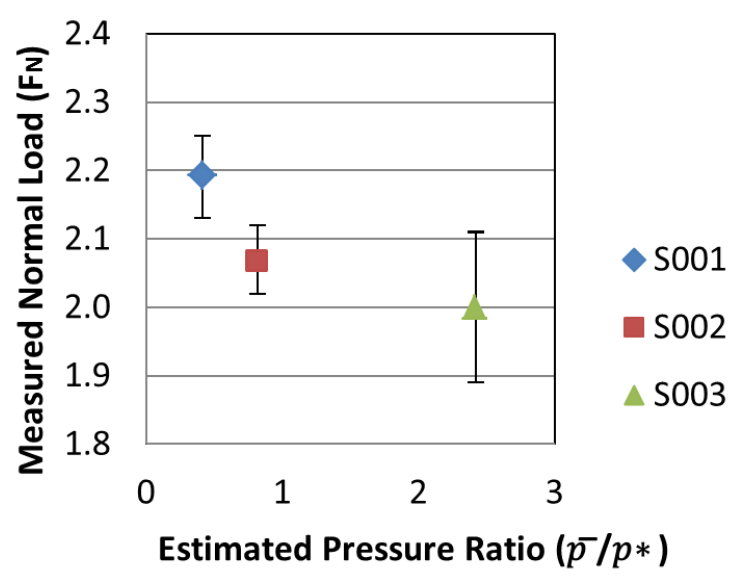

(e)

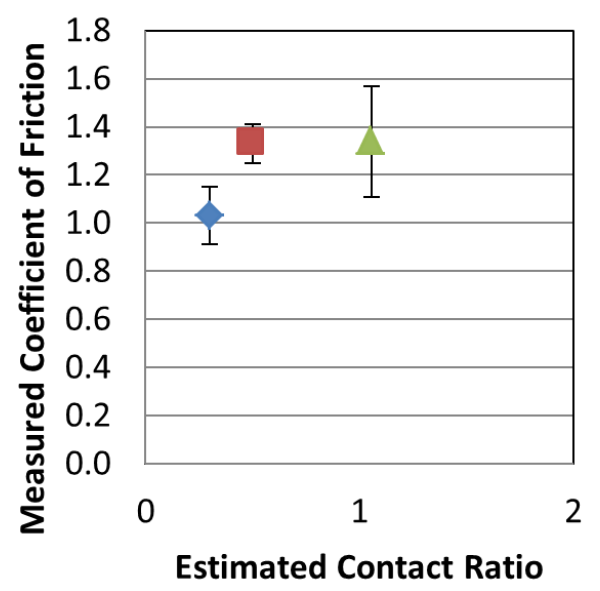

(b)

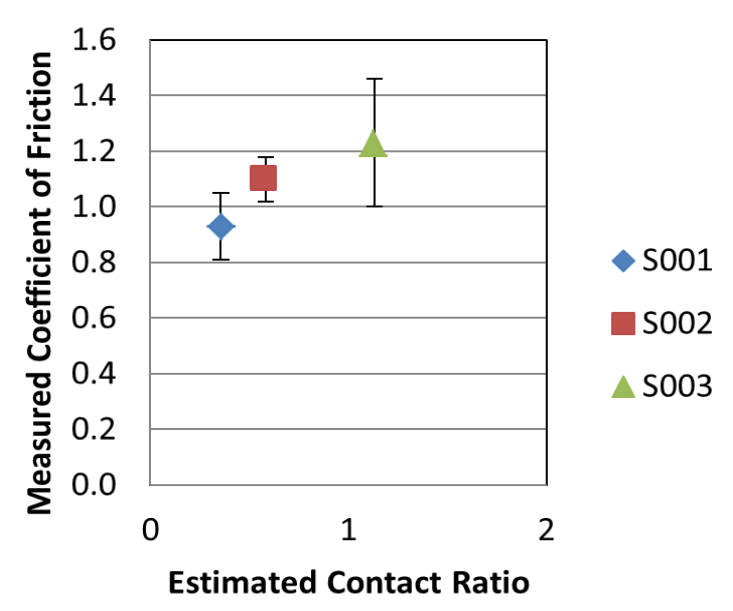

(d)

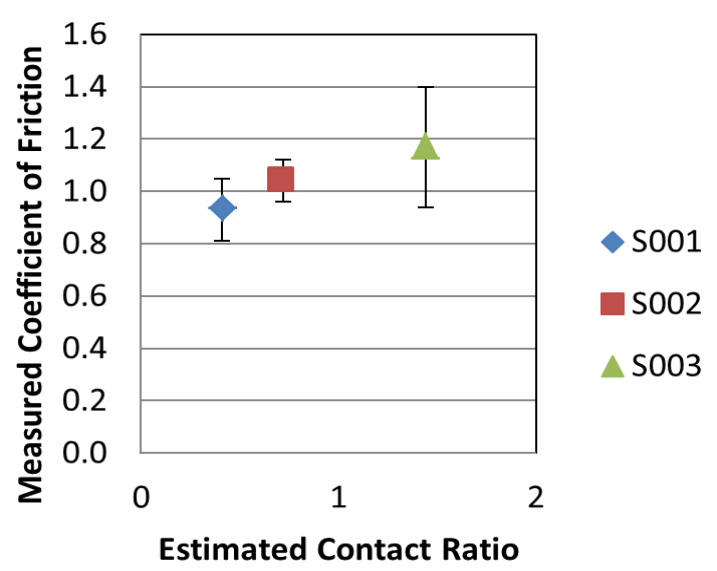

(f)

Fig 3.6 Measured normal load vs. estimated pressure ratio at (a) $F_{N}=0.5 \mathrm{~N}$, (c) $F_{N}=1 \mathrm{~N}$, (e) $F_{N}=2$ $\mathrm{N} ; \quad$ and measured COF vs. estimated contact ratio at (b) $F_{N}=0.5 \mathrm{~N}$, (d) $F_{N}=1 \mathrm{~N}$, (f) $F_{N}=2$ $\mathrm{N}$. 
Fig 3.6 (a) (c) \& (e) show the relation between the pressure ratio $\left(\frac{\bar{p}}{p^{*}}\right)$ and applied normal load $\left(\mathrm{F}_{\mathrm{N}}\right)$ for the different depth of grooves $(D)$. Fig 3.6 (b) (d) \& (f) show that estimated contact ratio is in direct proportion to the measured COF. When finger is under partial contact condition $\left(\frac{\bar{p}}{p^{*}}<1\right.$ ), the contact ratio is smaller than 1 (range from 0.30 to 0.41 for $\mathrm{D}=30 \mu \mathrm{m} ; 0.50$ to 0.72 for $\mathrm{D}=15 \mu \mathrm{m})$. When finger is under full contact condition $\left(\frac{\bar{p}}{p^{*}} \geq 1\right)$, the contact ratio can be greater than 1 (range from 1.06 to 1.44 for $\mathrm{D}=5 \mu \mathrm{m}$ ) which is possible due to the combination area of the surface, groove sides and groove valley (bottom) of the counter-body when the pressure needed for finger under full contact condition $\left(p^{*}\right)$ is reached.

Skin friction arises from the interaction with the contact surface, and is directly related to the contact area. The grooved channels are able to reduce the apparent contact area (under partial contact condition) or increase the apparent contact area (under full contact condition) in order to affect the real contact area. For the partial contact $\left(\frac{\bar{p}}{p^{*}}<1\right)$, the apparent contact area is mainly focused on the surface of the counter body (refer to Fig $3.5 \mathrm{~b}$ ), the reduction of the apparent contact area is up to approximately $60 \%$ by calculating the amount of area removed by grooved channels over the non-grooved surface apparent area (refer to Eq. 9). On the contrary, when the pressure needed for finger under full contact condition $\left(p^{*}\right)$ is reached $\left(\frac{\bar{p}}{p^{*}} \geq 1\right)$, skin touches the combination area of the surface, groove sides and groove valley (bottom) of the counter body under the full contact condition (refer to Fig $3.5 \mathrm{c}$ ). The contact pressure is one key factor which directly affects the contact condition as the partial or full contact. The effect of contact condition is able to influence the friction force due to the change of apparent contact area. The real contact area is a fraction of apparent contact area, therefore, if apparent contact area is increasing, the real contact area increases accordingly (Zahouani et al., 2011). The adhesion component of the friction force increases when the real contact area increases (refer to Eq. 2). 


\subsubsection{The effect of the sliding direction}

From the experimental results described here, the relationship between COF of skin and load depends on the sliding direction as well. Perpendicular sliding has lower values in COF than parallel sliding for grooved channel (as shown in Fig 3.4). This phenomenon has to do with viscoelastic behaviour of skin, which causes deformation delay against the surface texture (Derler et al., 2007). As a result of deformation delay, the contacted skin region is under partial contact condition due to the loop of deforming and bouncing against the grooved texture in perpendicular sliding (refer to Fig 3.7 a).

In addition, the hysteresis friction is added to the total friction as deformative component of friction force (Tomlinson et al., 2011). Greenwood and Tabor (Greenwood and Tabor, 1958) proposed a hysteresis friction model of a rigid conical slider moving along a soft elastomer like rubber. From the method, the hysteresis friction for a finger sliding along a ridged surface can be derived as:

$\mu_{h}=\frac{\beta}{\pi} \cot \theta$

Where $\mu_{h}$ is the coefficient of friction due to hysteresis; $\beta$ is the viscoelastic loss fraction due to hysteresis; $\theta$ is the hysteresis of contact angles (the angle which the conical indenter makes with the vertical centre line). In our case, the high portions of the samples on top of the grooves act as the ridges. This hysteresis friction model can be applied to grooved textures in perpendicular sliding.

The skin deformed against the edges along the length $d l$, and the force $(W)$ due to the pressure of the ridge is predicted as (Tomlinson et al., 2011):

$W=\int p L d l$ 
Where $p$ is the pressure along the contact area of the ridge and skin; $L$ is the length of the ridge in contact. $d t=d l \sin \theta$ is the distance from central axis $(t)$ between the limits of 0 and a, and hysteresis force $\left(F_{\text {hys }}\right)$ is the horizontal component of the applied pressure $(W)$. Based on this approach, which was slightly adapted to the current case, the pressure and the resulting hysteresis force $\left(F_{\text {hys }}\right)$ along the leading edge can be determined as follows:

$F_{\text {hys }}=W \cdot \cos \theta=\int_{0}^{s} \int_{0}^{a} p \cdot L \cdot \cot \theta \cdot d t \cdot d s=\frac{F_{N}}{2} \cot \theta$

Where $d t$ is the distance from the central axis $(t) ; d s$ is the distance of the apparent contact width (refer to Fig 3.8).

The normal force $\left(F_{N}\right)$ applied on the single 3D trapezoidal ridge is described as follows:

$F_{N}=\int_{0}^{s} 2 \int_{0}^{a} p \cdot L \cdot d t \cdot \cot \theta \cdot d s$

Combined with experimental data and prediction of analytical model (based on Eq. 13) Tomlinson concludes that once the applied loads are greater (normal load $>1 \mathrm{~N}$ ) with larger ridges (ridge height $>105 \mu \mathrm{m}$ ), interlocking and hysteresis frictions have a large percentage of the overall friction (Tomlinson et al., 2011). But for small ridges (ridge height $<33.5 \mu \mathrm{m}$ ), interlocking and hysteresis frictions have little influence on the total friction and can almost be neglected when ridge height is as small as $4.75 \mu \mathrm{m}$.

In our case, the depths of grooves are $30 \mu \mathrm{m}, 15 \mu \mathrm{m}$ and $5 \mu \mathrm{m}$ and hysteresis friction has limited influence of the overall friction. Also, the loop of deforming and bouncing against the grooved texture (perpendicular sliding) can only touch the leading edge of the ridge. The trailing edge of the ridge is not contact by the fingertip during the loop. Therefore, the full contact condition is not reached for perpendicular sliding. Under the partial contact condition, the contact area decreases and the adhesion component of friction force decreases accordingly (refer to Section 5.1). The adhesion component of friction has the largest influence on the total measured friction. 
This conclusion is consistent with other experimental studies which suggest that adhesion friction has the dominant role in skin friction (Wolfram, 1983; Asserin et al., 2000; Koudine et al., 2000; Sivamani et al., 2003; Adams et al., 2007; Tang et al., 2008; van Kuilenburg et al., 2012; Veijgen et al., 2013). Therefore, even with the contribution of hysteresis friction, the total friction decreases due to the decrease of adhesion force in perpendicular sliding.

On the contrary, when the pressure needed for full contact condition $\left(p^{*}\right)$ is reached during parallel sliding, the contacted skin region is under full contact condition without undergoing the hysteresis loop of deforming and bouncing (refer to Fig $3.7 \mathrm{~b}$ ). Therefore, parallel sliding generates more real contact area compared to perpendicular sliding for grooved channel, and as a result, higher friction force is observed in parallel sliding direction. In addition, the friction force is smaller for the deterministic structures in perpendicular sliding compared to stochastic surface because of reduced contact area as well (refer to Fig 3.3 b). 


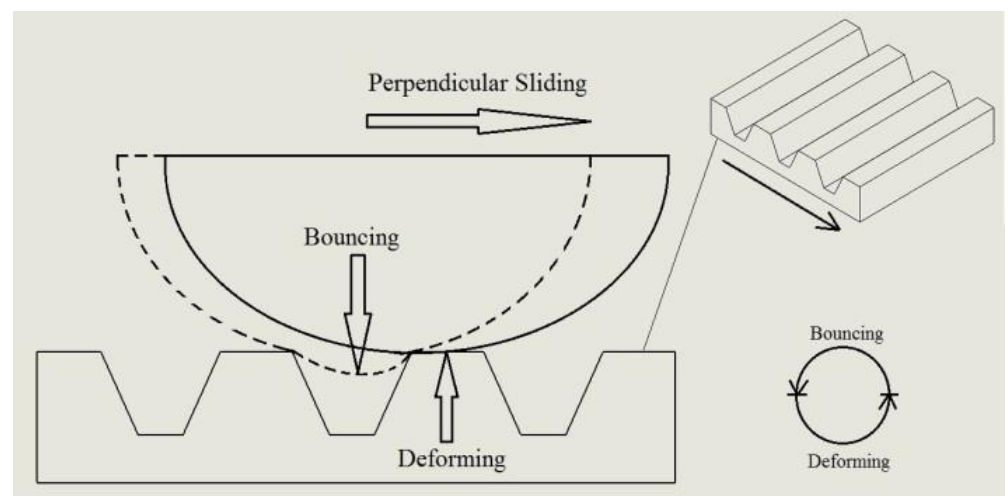

(a)

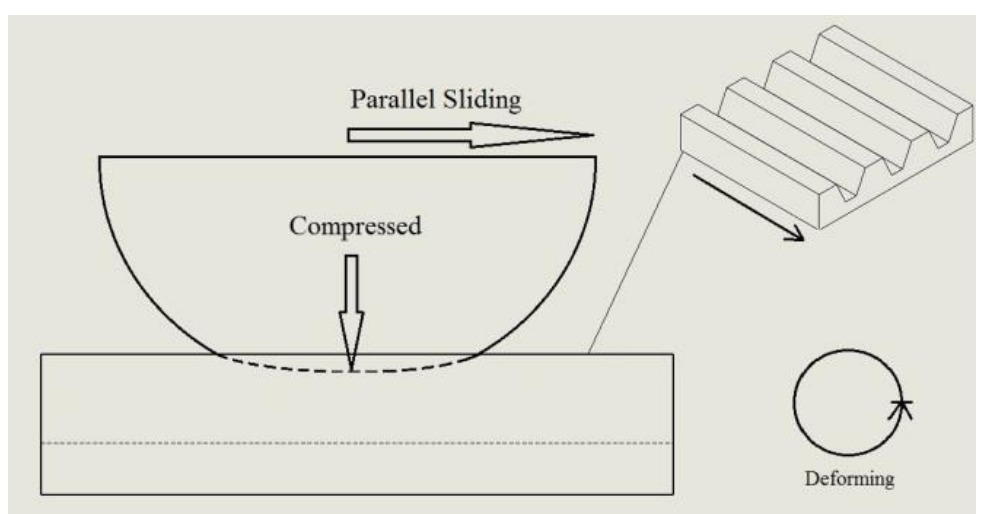

(b)

Fig 3.7 Schematic diagram of (a) perpendicular sliding and (b) parallel sliding.

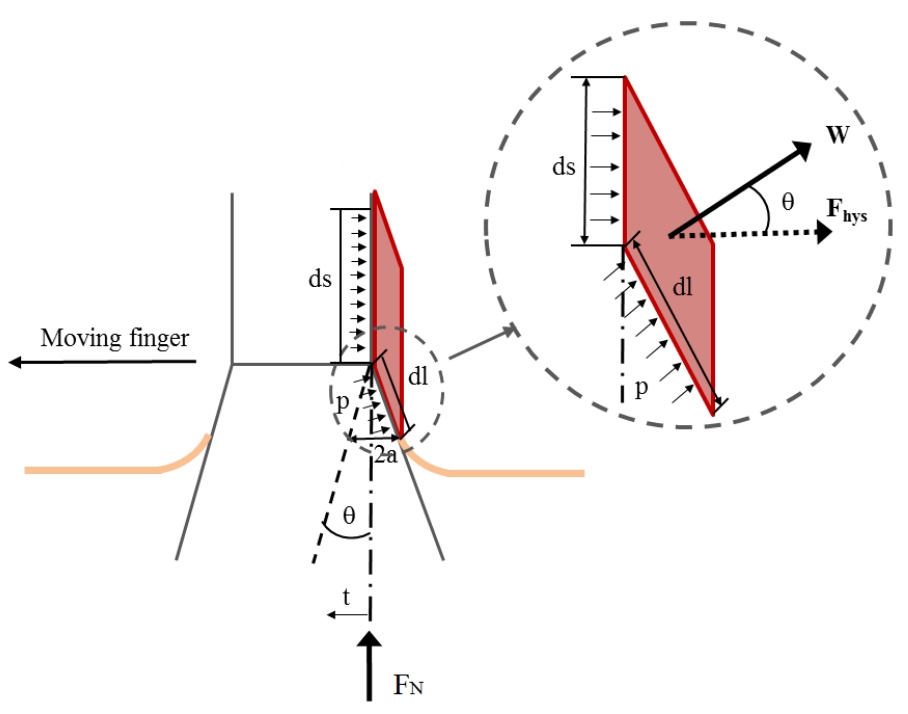

Fig 3.8 Schematic of ridge-skin contact model. 


\subsection{Conclusions}

In this research, friction of fingertip was measured against deterministic surface structures, i.e. grooved channels on the steel samples. Based on the experimental results, the role of groove depth and sliding direction are investigated for the grooved channels. The greater depth of grooved channel is able to reduce the apparent contact area under partial contact condition, however, the apparent contact area is increased under full contact condition. And, the real contact area varies as a fraction of apparent contact area. As a result, the adhesion component of friction can be directly influenced under different contact condition.

The sliding direction is another key factor to consider when measuring friction. During parallel sliding, a higher friction force was observed due to the increased contact area for grooved channels. On the contrary, in perpendicular sliding lower friction was obtained including limited contribution of the deformation component due to hysteresis. The contacted skin region is under partial contact condition due to the loop of deforming and bouncing against the grooved texture in perpendicular sliding. Furthermore, a comparison between deterministic and stochastic samples validated the effect of directionality on tactile friction.

This experimental research contributes to the haptic perception related research, and to the development of other direction-dependent surface structures for touch like: straight line, curve and chevron texture (v-shaped pattern). 


\section{References}

Adams, M. J., Briscoe, B. J., Johnson, S. A., Friction and lubrication of human skin, Tribology Letters, 2007, 26 (3):239-253.

Asserin, J., Zahouani, H., Humbert, Ph., Counturaud, V., Mougin, D., Measurements of the friction coefficient of the human skin in vivo: quantification of the cutaneous smoothness, Colloids and Surfaces B: Biointerfaces, 2000, 19: 1-12.

Barnes, C. J., Childs, T. H. C., Henson, B., Southee, C. H., Surface finish and touch - a case study in a new human factors tribology. Wear, 2004, 257: 740-750.

Bowden F. P., Tabor, D., The friction and lubrication of solids. Cambridge University Press, Oxford, 1950.

Cua, A. B., Wilhelm, K. P., Maibach, H. I., Frictional properties of human skin: relation to age, sex and anatomical region, stratum corneum hydration and trans epidermal water loss. British Journal of Dermatology, 1990, 123: 473-479.

Dandekar, K., Raju, B. I., Srinivasan, M. A., 3-D finite-element models of human and monkey fingertips to investigate the mechanics of tactile sense. Journal of Biomechanical EngineeringTransactions of the ASME, 2003, 125(5): 682-691.

Darden, M. A., Schwartz, C. J., Investigation of friction mechanisms during the sliding of elastomers against hard parallel-ridge textures, Tribology International, 2013, 63: 2-7.

Derler, S., Huber, R., Feuz, H. P., Hadad, M., Influence of surface microstructure on the sliding friction of plantar skin against hard substrates. Wear, 2009, 267: 1281-1288.

Derler, S., Gerhardt, L.-C., Tribology of skin: review and analysis of experimental results for the friction coefficient of human skin, Tribology Letters, 2012, 45:1-27.

Derler, S., Rotaru, G.-M., Ke, W., El Issawi-Frischknecht, L., Kellenberger, P., Scheel-Sailer, A., Rossi, R.M., Microscopic contact area and friction between medical textiles and skin. Journal of the Mechanical Behavior of Biomedical Materials, 2014, 38: 114-125.

Derler, S., Schrade, U., Gerhardt, L.-C., Tribology of human skin and mechanical skin equivalents in contact with textiles. Wear, 2007, 263: 1112-1116.

Diridollou, S., Vabre, V., Berson, M., Vaillant, L., Black, D., Lagarde, J. M., Grégoire, J. M., Gall, Y., Patat, F., Skin ageing: changes of physical properties of human skin in vivo. International Journal of Cosmetic Science, 2001, 23: 353-62.

Edwards, C., Marks, R., Evaluation of biomechanical properties of human skin. Clinics in Dermatology; 1995, 13: 375-380.

Fagiani, R., Massi, F., Chatelet, E., Costes, J. P., Berthier, Y., Contact of a finger on rigid surface and textiles: friction coefficient and induced vibrations, Tribo Letters, 2012, 48: 145-158.

Grease, G.N., Greer, A.L., Lakes, R.S., Rouxel, T., Poisson's ratio and modern materials. Nature Materials, 2011, 10: 823-837. 
Gee, M. G., Tomlins, P., Calver, A., Darling, R. H., Rides, M., A new friction measurement system for the frictional component of touch. Wear, 2005, 259: 1437-1442.

Greenwood, J. A., Tabor, D., The friction of hard sliders on lubricated rubber: the importance of deformation losses. Proceedings of the Physical Society, 1958, 71(6): 989-1001.

Heinrich, U., Koop, U., Lenveu-Duchemin, M. -C., Osterrieder, K., Bielfeldt, S., Chkarnat, C., Degwert, J., Hantschel, D., Jaspers, S., Nissen, H.-P., Rohr, M., Schneider, G., Tronnier, H., Multicentre comparison of skin hydration in terms of physical-, physiological- and product-dependent parameters by the capacitive method (Corneometer CM 825), International Journal of Cosmetic Science, 2003, 25: 45-53

Hendriks, C. P., Franklin, S. E., Influence of surface roughness, material and climate conditions on the friction of human skin. Tribology Letters, 2010, 37: 361-373.

Johnson, K.L., Greenwood, J.A., Higginson, J.G., The contact of elastic regular wavy surface. International Journal of Mechanical Sciences, 1985, 6: 383-396.

Johnson, S. A., Gorman, D. M., Adams, M. J., Briscoe, B. J., The friction and lubrication of human stratum corneum, in: proceedings 19th Leeds-Lyon symposium on tribology, Elsevier, 1993, ISBN: 9780444897893, 663-672.

Klatzky, R. L., Pawluk, D., Haptic perception of material properties and implications for applications. proceedings of the IEEE, 2013, 101: 2081-2092.

Koudine, A., Barquins, M., Anthoine, P. H., Aubert, L., Leveque, J. L., Friction properties of skin: proposal of a new approach. International Journal of Cosmetic Science, 2000, 22: 11-20.

Kuramitsu, K., Nomura, T., Nomura, S., Maeno, T., Nonomura, Y., Friction evaluation system with a human finger model. Chemistry Letters, 2013, 42: 284-285.

Lapière, C.M., The ageing dermis: the main cause for the appearance of 'old' skin. British Journal of Dermatology, 1990, 122: pp. 5-11.

Liu, X., Yue, Z., Cai, Z., Chetwynd, D.G., Smith, S.T., Quantifying touch - feel perception: tribological aspects. Measurement Science and Technology, 2008, 19: 1-9.

Maeno, T., Kobayashi, K., Yamazaki, N., Relationship between the structure of human finger tissue and the location of tactile receptors. JSME International Journal Series C-Mechanical Systems Machine Elements and Manufacturing, 1998, 41(1): 94-100.

Menga, N., Putignano, C., Carbone, G., Demelio, G.P., The sliding contact of a rigid wavy surface with a viscoelastic half-space. Proceedings of the Royal Society A: Mathematical Physical \& Engineering Sciences, 2014, 470: 1-14.

Morales Hurtado, M., Zeng X., and van der Heide, E., The Human Skin and Hydration, Hydrated Materials: Applications in Biomedicine and the Environment. Edited by Yoshitaka Nakanishi, Copyright (C) 2015 Pan Stanford Publishing Pte. Ltd. ISBN 978-981-4316-31-6

Ramsay, T. G., Fat cells. Endocrinology and Metabolism Clinics of North America, 1996, 25: 847-70.

Shao, F., Childs, T.H.C., Barnes, C.J., Henson, B., Finite element simulations of static and sliding contact between a human fingertip and textured surfaces. Tribology International, 2010, 43: 2308-2316. 
Silver, F. H., Kato, Y. P., Ohno, M., Wasserman, A.J., Analysis of mammalian connective tissue: relationship between hierarchical structures and mechanical properties. Journal of Long-term Effects of Medical Implants, 1992, 2: 165-198.

Sivamani, P. K., Goodman, J., Gitis, N., Maibach, H. I., Friction coefficient of skin in real-time, Skin Research and Technology, 2003, 9: 235-239.

Skedung, L., Danerlov, K., Olofsson, U., Johannesson, C. M., Aikala, M., Kettle, J., Arvidsson, M., Berglund, B., Rutland, M. W., Tactile perception: finger friction, surface roughness and perceived coarseness, Tribology International, 2011, 44: 505-512.

Smith, A., Chapman, C., Deslandes, M., Langlais, J., Thibodeau, M-P., Role of friction and tangential force variation in the subjective scaling of tactile roughness. Experimental Brain Research, 2002, 144: 211-223.

Steinhoff, K., Rasp, W., Pawelski, O., Development of deterministic-stochastic surface structures to improve the tribological conditions of sheet forming processes, Journal of Materials Processing Technology, 1996, 60: 355-361.

Tagami, H., Yoshikuni, K., Interrelationship between water-barrier and reservoir functions of pathologic stratum corneum. Archives of Dermatology, 1985, 121: 642-645.

Tang, W., Ge, S., Zhu, H., Cao, X., Li, N., The influence of normal load and sliding speed on frictional properties of skin, Journal of Bionic Engineering, 2008, 5: 33-38.

Taylor, M. and Lederman, S., Tactile roughness of grooved surfaces: a model and the effect of friction. Perception \& Psychophysics, 1975, 17(1): 23-36.

Tomlinson, S. E., Lewis, R., Carré, M. J., The effect of normal force and roughness on friction in human finger contact. Wear, 2009, 267: 1311-1318.

Tomlinson, S.E., Carre, M.J., Lewis, R., Franklin, S.E., Human finger contact with small, triangular ridged surfaces. Wear, 2011, 271: 2346-2353.

van Kuilenburg, J., Masen, M. A., Groenendijk, M.N.W., Bana, V., van der Heide, E., An experimental study on the relation between surface texture and tactile friction. Tribology International, 2012, 48: $15-21$.

van Kuilenburg, J., Masen, M. A., van der Heide, E., Contact modeling of human skin: what value to use for the modulus of elasticity. Journal of Engineering Tribology, 2012, 227 (4): 349-361.

van Kuilenburg, J., Masen. M. A., van der Heide, E., A review of fingerpad contact mechanics and friction and how this affects tactile perception. Proceedings of the IMechE Part J: Journal of Engineering Tribology, DOI: 10.1177/1350650113504908, In Press

van der Heide, E., Zeng, X., Masen, M. A., Skin tribology: science friction? Friction, 2013, 1 (2): 130142 .

Veijgen, N. K., Masen, M. A., van der Heide, E., Variables influencing the frictional behaviour of in vivo human skin. Journal of the Mechanical Behavior of Biomedical Materials, 2013, 28: 448461.

Veijgen, N. K., Masen, M. A., van der Heide, E., Relating friction on the human skin to the hydration and temperature of the skin. Tribology Letters, 2013, 49: 251-261. 
Wang, Q. and Hayward, V., Tactile synthesis and perceptual inverse problems seen from the viewpoint of contact mechanics". ACM Transactions on Applied Perception, 2008, 5 (2): 2-19.

Westergaard, H.M., Bearing pressures and cracks. Journal of Applied Mechanics - Transactions of the ASME, 1939: 49-53.

Wolfram, L., Friction of skin. Journal of the Society of Cosmetic Chemists, 1983, 34: 465-476.

Zahouani, H., Ben Tkaya, M., Mezghani, S., Pailler-Mattei, C., Adhesive contact in the context of multiasperity interaction. Comptes Rendus Mecanique, 2011, 339: 502-517. 


\title{
Chapter 4
}

\section{Texture Design for Reducing Tactile Friction Independent of Sliding Orientation*}

\begin{abstract}
Surface texture is pivotal for contact mechanical and tribological phenomena such as the contact area and friction. In this research, three different types of geometrical micro-structures were designed, and fabricated by pulsed laser surface texturing as semi-symmetric (grooved channel), asymmetric fractal (Hilbert curve) and symmetric patterns (grid). A conventionally finished surface as a reference sample from the same stainless steel sheet material was compared. From the experimental approach, a multiaxis force/torque transducer was used to investigate the functionality of surface texture based on measuring the tactile friction in three different sliding directions: perpendicular, parallel and $45^{\circ}$ to the textures. According to the dynamic friction measurements, the grid texture was indeed orientation independent. The other samples showed orientation dependent frictional behavior, especially the grooved channel texture and reference sample. Furthermore, an analytical approach was applied to estimate the values of the friction coefficient by the pressure distribution method. From both the experimental and analytical approaches, the grid pattern was validated to be the optimal texture design in the concern of friction reduction and orientation independent behavior.
\end{abstract}

"S. Zhang, X. Zeng, A. Rodriguez Urribarri, A. Igartua, E. Rodriguez-Vidal and E. van der Heide, Texture Design for Reducing Tactile Friction Independent of Sliding Orientation on Stainless Steel Sheet, submitted to International Journal of Solids and Structures, 3/2016 


\subsection{Introduction}

Tactile friction, or skin friction, is a resistive force that prevents the skin from sliding freely against the counter-surface. Whether putting the clothes on in the morning, texting the message on the cell phone, or playing a musical instrument to entertain yourself, skin friction is inevitable and plays an important role in tactile perception. In the modern market, touch sensation was not forgotten or underestimated. In fact, great concerns in skin friction, especially fingertip skin friction, were raised in relation to the feel of products to the consumers (Derler and Gerhardt, 2012). The dynamic friction between the fingertip and counter-body determines how we perceive a surface, which can sway the consumers' judgments towards the lucrative products (Chen et al., 2009).

In skin tribology, many experimental studies of the friction contacts between skin and different objects were conducted with in vivo measurements (Soneda et al., 2010; Tomlinson et al., 2011; Pasumarty et al., 2011). As a multi-layered biomaterial, skin consists of stratum corneum (SC), epidermis, dermis, and hypodermis (subcutaneous tissues) (Yuan and Verma, 2006). Each skin layer has different mechanical properties associated with different composition, thickness and hydration degree. From the literature, the frictional behaviour of skin is influenced by the complex interaction of the material and surface properties of the counter-body and the skin itself (Kim et al., 2013). From the mechanical perspective, the micro-scaled geometric structure of texture can affect the friction between the skin and counter-surface. Groove patterns for example, as the most common geometric structure, was studied and found to have the ability of reducing the tactile friction during fingertip exploration (Suh et al., 2010). Recent studies are focused on the influential factors like the material properties, skin condition and contact parameters of the counter-body and the skin (Schreiner et al., 2011; van Kuilenburg et al., 2012). From our previous work (Zhang et al., 2015), in vivo measurements reveal that certain type of geometry can have great impact on tactile friction, dependent of the sliding orientation. For 
example, parallel or perpendicular sliding to the grooved channel texture as two extreme cases, greatly influenced the frictional performance. Now, the question arises: can the textural design also reduce skin friction without sliding orientation effect? This question was approached both experimentally and analytically in this work.

\subsection{Textural Design and Materials}

\subsubsection{Friction Model and Measurement}

The real contact area plays a pivotal role in skin friction. According to the research, skin friction decreases with the reduction of the real contact area (Prodanov et al., 2013; Zhang et al., 2015). In skin tribology, both the adhesion and deformation components of friction (two-term model of friction) contribute to tactile friction (Derler et al., 2009). However, the adhesion component of friction (refer to Eq 1) plays the dominant role (Adams et al., 2007) (Duvefelt et al., 2016).

$F_{f, a d h}=\tau A_{\text {real }}$

Where $F_{f, a d h}$ represents the adhesion component of friction; $A_{\text {real }}$ is the real contact area; $\tau$ is the interfacial shear strength. The real contact area is significantly less than the apparent contact area when skin is interacting with the micro-structured counter-surface. For the interfacial shear strength $\tau$, it has been found to have a linear function of the average contact pressure $(\bar{p})$ as:

$\tau=\tau_{0}+\alpha \bar{p}$

Where $\tau_{0}$ is the intrinsic interfacial shear strength; $\alpha$ is the pressure coefficient. After combining Eq (1) and (2), the coefficient of friction can be expressed as following:

$\mu=\frac{F_{f, a d h}}{F_{N}}=\frac{\tau}{\bar{p}}=\frac{\tau_{0} A_{r e a l}}{F_{N}}+\alpha$

The adhesion component of friction is directly related to the real contact area, and the reduction of real contact area can greatly decrease friction. 
For the friction measurements, each specimen was fixated on the top of a load cell (ATI Gamma three-axis force/torque transducer, ATI Industrial Automation, Apex, NC, USA) (refer to Fig 4.1). The resolution of the force measurement is $25 \mathrm{mN}$ in normal direction ( $\mathrm{z}$ axis) and 12.5 $\mathrm{mN}$ in tangential direction ( $\mathrm{x}$ and $\mathrm{y}$ axis). Each experiment consisted of five sliding repetitions towards the body. Three sliding directions were performed: $0^{\circ}$ (parallel), $45^{\circ}$ and $90^{\circ}$ (perpendicular) to the surface texture. The contact finger (right hand index finger) used in this experiment is from a 32 year-old male. The fingertip was washed by soap and air-dried, and the stainless steel samples were cleaned by ethanol before each measurement. The environmental conditions of the lab were at $20 \pm 1{ }^{\circ} \mathrm{C}$ as room temperature and $40 \pm 5 \%$ as relative humidity. The hydration level of the testing finger was measured by Corneometer CM 825 (Courage+Khazaka GmbH, Germany) at $32 \pm 3$ AU. During the dynamic skin friction measurements, the testing finger was in contact with the specimen, and sliding occurred at a steady velocity with an average of $17 \pm 4 \mathrm{~mm} / \mathrm{s}$. The sampling rate was $100 \mathrm{~Hz}$. Followed by the same procedure, the applied normal load, friction force and coefficient of friction (COF) were recorded by the ATI transducer. 


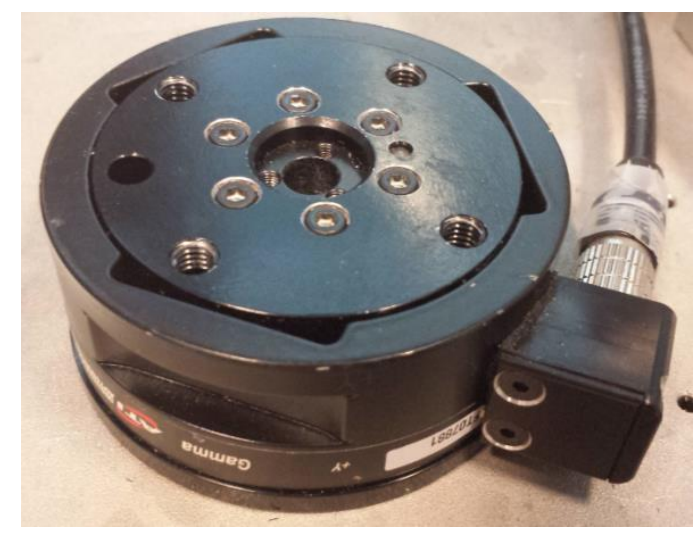

(a)

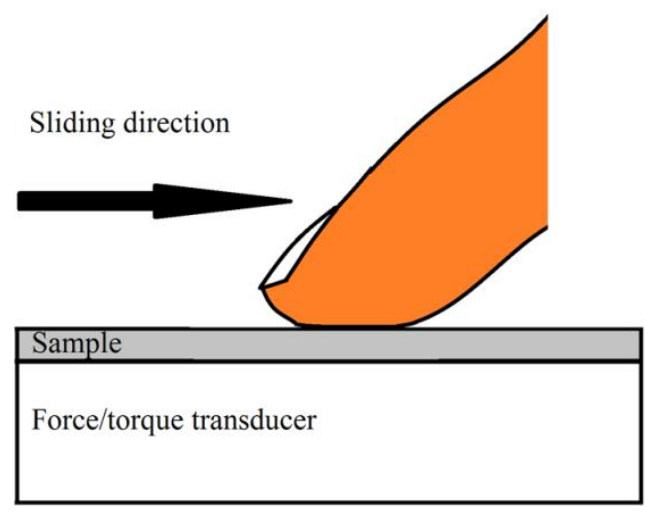

(b)

Fig 4.1 (a) Three-axis force/torque transducer (ATI Industrial Automation, Apex, NC, USA); (b) skin friction measurement.

\subsubsection{Textural Design of Geometry}

Surface textures are widely applied in studies on dynamic friction to reduce the adhesive component of friction, and most of them were carried out under unidirectional sliding conditions (Braun et al., 2014; Kang et al., 2015). However, the orientation effect has great influence on the skin friction between fingertip and textured counter-surface (Zhang et al., 2015). In this paper, the objective is to design one surface texture which not only decrease the friction but also eliminates the orientation effect. The textural design was based on three types, as shown in Fig 4.2: grooved channel as a semi-symmetric pattern (Z001), Hilbert curve as an asymmetric fractal pattern (Z002), grid as a symmetric pattern (Z003) and stochastic sample as the reference (Z000).

The grooved channel pattern is expected to be influenced by the orientation effect. The distribution of geometric structures is different in the perpendicular sliding direction compared to the parallel and $45^{\circ}$ sliding directions, as shown in Fig 4.2 (a). The area in contact changes accordingly. The change of pattern layout in different sliding direction is able to alter the contact 
area and friction between the skin and grooved channel texture. Unlike the grooved channel pattern, the Hilbert curve (asymmetric fractal pattern) demonstrates the ability to contain the entire two-dimensional unit space by a peculiar geometric structure which expands in all directions (Butz, 1968; Butz, 1969; Griffiths, 1985; Peano, 1890; Hilbert, 1891). As shown in Fig 4.2 (b), the areas in contact with different sliding directions have the similar pattern layout. In this research, the stroke length is approximately the length of the sample size which is 40 $\mathrm{mm}$. With this stroke length, the overall encountered peaks and valleys are self-similar across different direction which gives the ability to minimize the effect of orientation. On the other hand, the grid texture is a symmetric geometric structure which has an identical pattern distribution in $\mathrm{x}$-axis and $\mathrm{y}$ - axis directions. As shown in Fig 4.2 (c), the total amount of grids in contact were nearly same for all three sliding directions. The parallel sliding direction has approximately 33 counts of grids in contact; the $45^{\circ}$ sliding direction has approximately 34 grids in contact; the horizontal sliding direction has approximately 34 grids in contact with the same unit of contact length (refer to Fig $4.2 \mathrm{c}$ ). Since the differences of all three directions are very low in the number of grids in contact. Therefore, the effect of orientation is expected to be insignificant. 

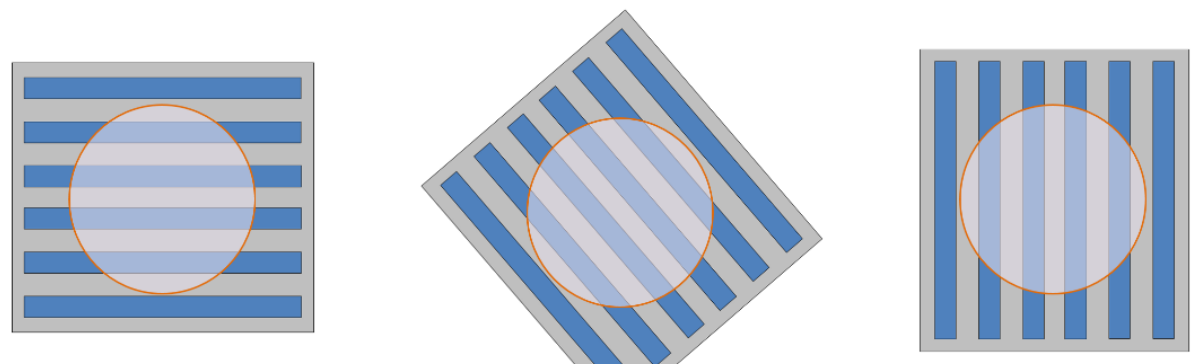

(a)
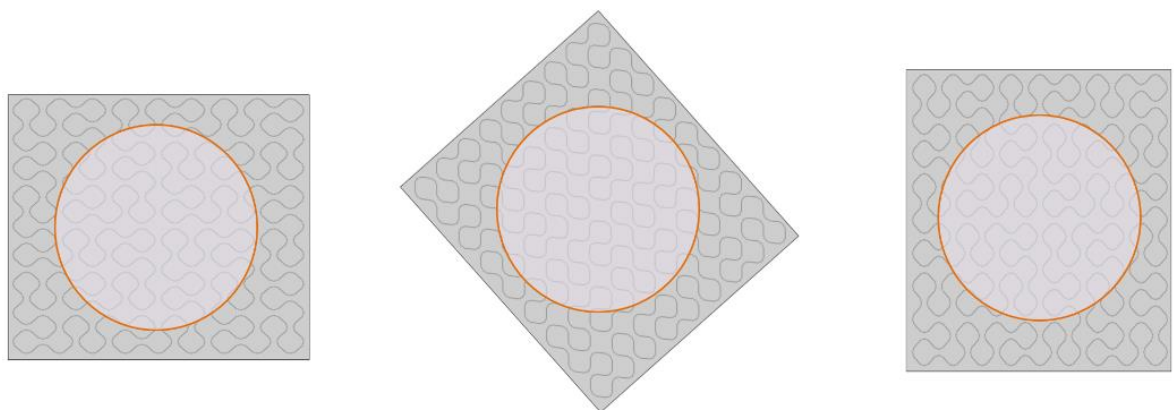

(b)
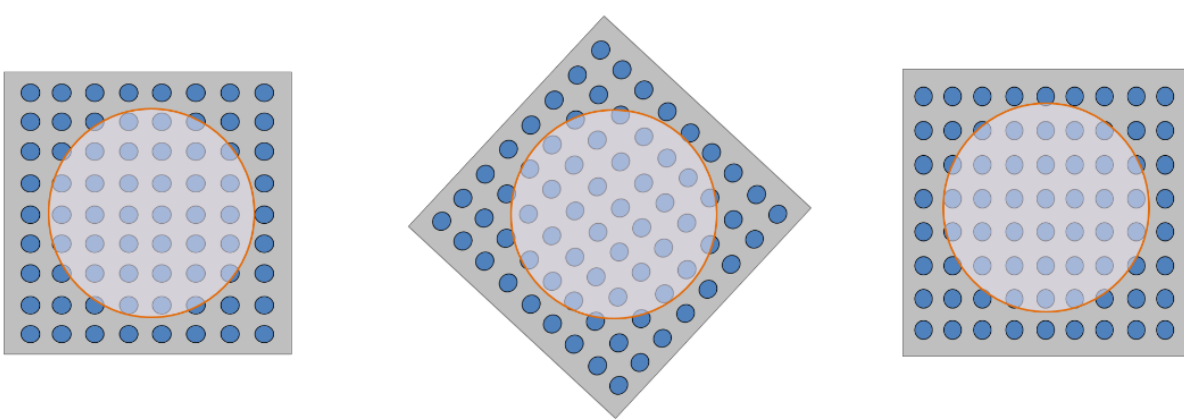

(c)

Fig 4.2 Perpendicular, $45^{\circ}$ and parallel sliding direction on (a) grooved channel, (b) Hilbert curve, and (c) grid texture.

\subsubsection{Material and Fabrication}

The textures were created in stainless steel EN-1.4301 samples with dimension of $40 \mathrm{~mm} \times 40$ mm. All the textures were produced by pulsed laser surface texturing (LST), with a picosecond laser in $400 \mathrm{kHz}$ pulse rate with maximum 50 Watts power. In addition, the stochastic reference sample was produced by cold rolling in conventional $2 \mathrm{G}$ finish. The surface examinations were 
conducted by SEM and confocal microscopy as shown in Fig 4.3. The parameters of the samples are shown in the schematic diagrams (refer to Fig 4.4) and details are tabulated in Table 4.1.

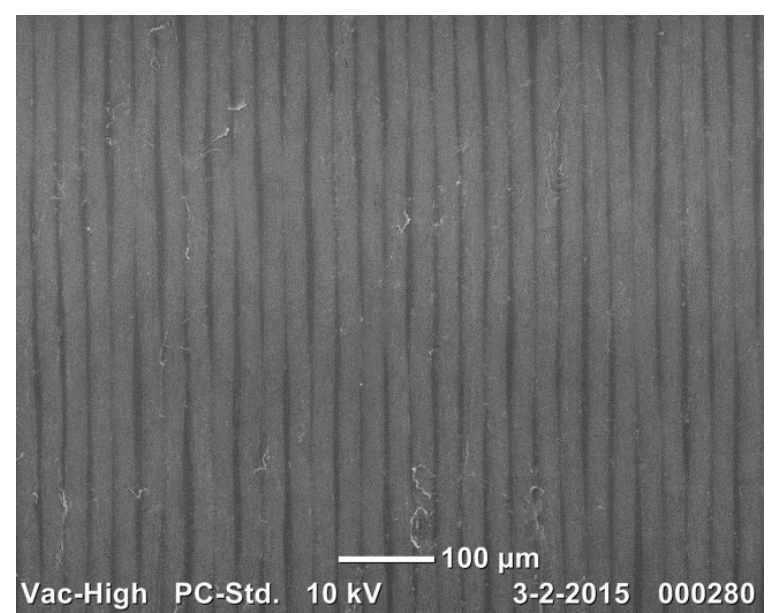

(a)

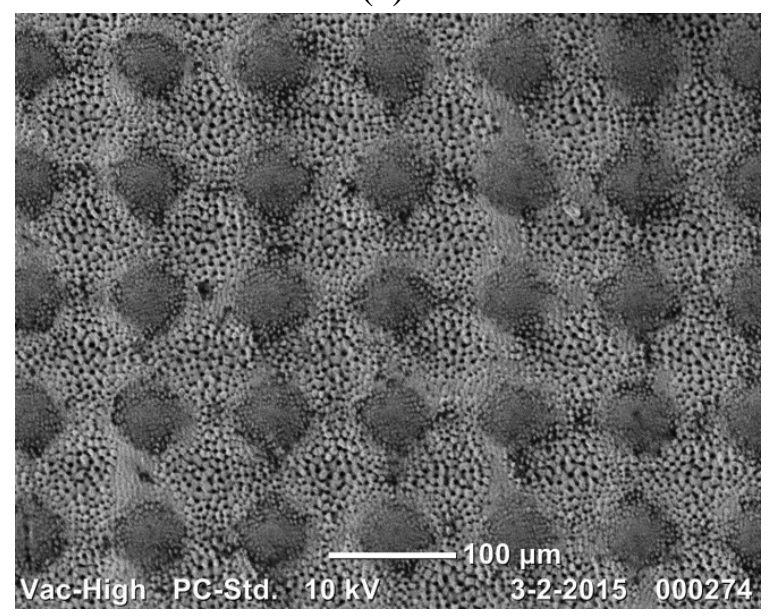

(c)

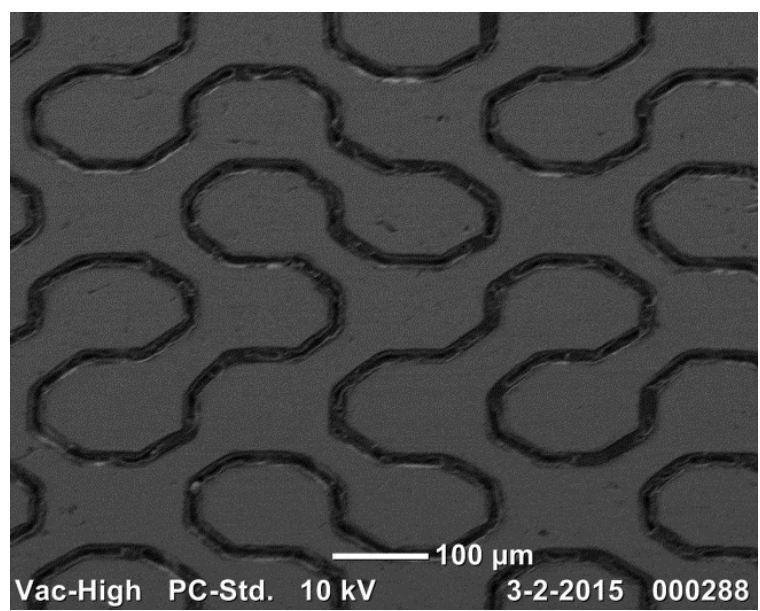

(b)

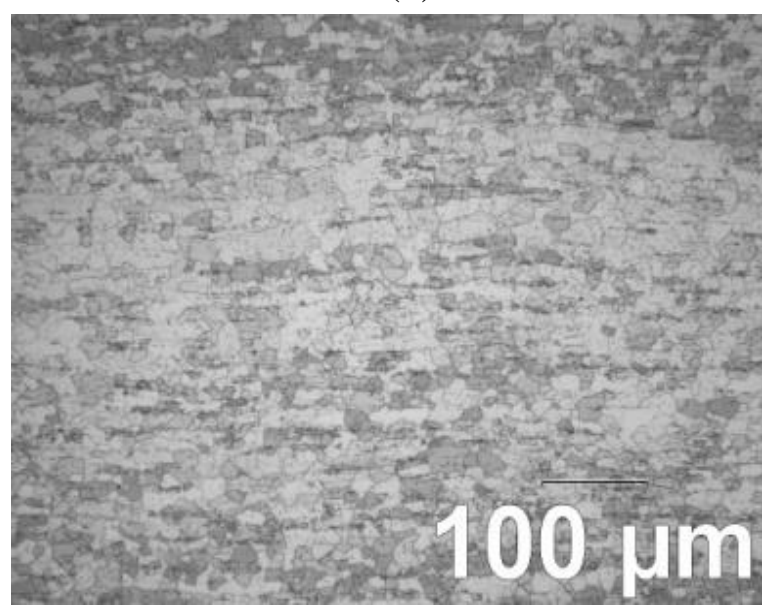

(d)

Fig 4.3 Textures (a) grooved channel (Z001); (b) Hilbert curve (Z002); (c) grid (Z003) examined by SEM and (d) reference surface with rolling direction from left to right (Z000) examined by confocal microscopy. 


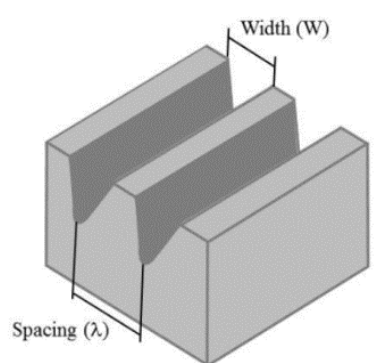

(a)

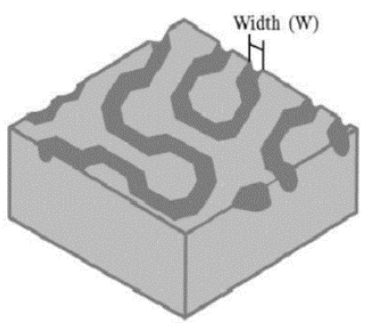

(b)

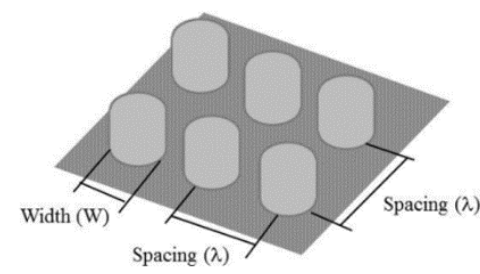

(c)

Fig 4.4 Schematic drawings and parameters of (a) grooved channel, (b) Hilbert curve, and (c) grid texture.

Table 4.1 Selected surface parameters of the samples: 3D surface roughness (Sa), Depth or Height (D), spacing $(\lambda)$, width $(W)$ and grid radius ( $r$ ) were measured by Laser Scanning Microscope (Keyence, VK-9700, USA).

\begin{tabular}{ccccccc}
\hline $\begin{array}{c}\text { Sample } \\
\text { Name }\end{array}$ & Surface Texture & $\begin{array}{c}\text { Sa } \\
{[\mu \mathrm{m}]}\end{array}$ & $\begin{array}{c}\text { Depth D } \\
{[\mu \mathrm{m}]}\end{array}$ & $\begin{array}{c}\text { Width W } \\
{[\mu \mathrm{m}]}\end{array}$ & $\begin{array}{c}\text { Spacing } \lambda \\
{[\mu \mathrm{m}]}\end{array}$ & $\begin{array}{c}\text { Radius r } \\
{[\mu \mathrm{m}]}\end{array}$ \\
\hline $\mathbf{Z 0 0 1}$ & Grooved Channel & 1.21 & 10 & 20 & 25 & - \\
$\mathbf{Z 0 0 2}$ & Hilbert Curve & 3.43 & 15 & 20 & - & - \\
$\mathbf{Z 0 0 3}$ & Grid & 4.69 & 15 & - & 80 & 60 \\
$\mathbf{Z 0 0 0}$ & Stochastic & 0.39 & - & - & - & - \\
& & & & & & \\
\hline
\end{tabular}




\subsection{Results and Discussion}

\subsubsection{The Orientation Effect of the Surface Geometry}

The values of COF for each sample were calculated from five friction cycles with one sliding movement in the direction towards the subject's body. The average COF and its corresponding standard deviation were calculated from the data obtained from five strokes and tabulated in Table 4.2. Fig 4.5 shows an overview of COF measured against dry skin with all samples in three directions, $45^{\circ}$, parallel and perpendicular, with respect to the surface structure. The mean value of dynamic $\mathrm{COF}$ is calculated under three different normal loads of $0.2 \mathrm{~N}, 0.4 \mathrm{~N}$ and 1.0 $\mathrm{N}$. The ranges of COF were $0.27 \sim 0.61,0.24 \sim 0.59$ and $0.24 \sim 0.57$ for all samples (including reference sample) in the $45^{\circ}$, parallel and perpendicular sliding directions accordingly (refer to Fig 4.6). The standard deviation indicates the variations between sliding cycles with the range from 0.01 to 0.09 .

Fig 4.5 shows the variations of COF associated with the sliding directions on all samples. Based on the analyzed data, the COFs of the samples Z000 (reference), Z001 (grooved channel) and Z002 (Hilbert curve) were influenced with the sliding directions, especially the samples Z000 and Z001. However, the COF of the sample Z003 (grid) revealed insignificant variations with the sliding directions compared to the other samples. In other words, the sample Z003 (grid) was proved to be orientation independent, and the other samples were orientation dependent. When the fingertip was sliding on the sample Z003 (grid), the tactile friction was mainly influenced by the number of grids in contact with skin instead of the sliding direction. The pattern layout of grid is symmetric and identical in all directions with enough stroke length. In this case, the number of grids in contact had a great influence of the real contact area and was determined by the texture parameters (asperity radius and spacing) and the contact radius of 
fingertip. According to the texture design of grid pattern (refer to Section 2.1), the estimated number of grids in contact of fingertip with all three sliding directions are very close.

In the case of perpendicular sliding against grooved channel, the friction between the skin and texture increased compared to the parallel and $45^{\circ}$ sliding direction in all three different normal loads (refer to Fig 4.5). This particular phenomenon is caused by the contribution of deformation component of friction in form of hysteresis (Tomlinson et al., 2009). Based on the previous study of sliding direction against a grooved channel on tool steel (Zhang et al., 2015), the resulting hysteresis force $\left(F_{\text {hys }}\right)$ and the normal force $\left(F_{N}\right)$ applied on the leading edge can be determined as follows:

$F_{\text {hys }}=\int_{0}^{s} \int_{0}^{a} p \cdot L \cdot \cot \theta \cdot d t \cdot d s=\frac{F_{N}}{2} \cot \theta$

$F_{N}=\int_{0}^{s} 2 \int_{0}^{a} p \cdot L \cdot d t \cdot \cot \theta \cdot d s$

Where $p$ is the pressure along the contact area of the ridge and skin; $L$ is the length of the ridge in contact; $\mathrm{dt}$ is the distance from the central axis $(\mathrm{t})$; $\mathrm{ds}$ is the distance of the apparent contact width (refer to Fig 4.7).

According to the studies of skin friction at the volar forearm in contact with spherical probes (Adams et al., 2007; Kwiatkowska et al., 2009), the contribution of hysteresis to the COF ranges from 0.04 to 0.06 in the order of magnitude. Other study shows that contributions to the friction coefficient between finger and glass due to viscoelastic skin deformations can be up to 0.2 (Derler et al., 2009). Therefore, in the case of perpendicular sliding against grooved channel texture, the role of viscoelastic skin deformation cannot be neglected and will increase overall friction between the fingertip and the counter-surface. 


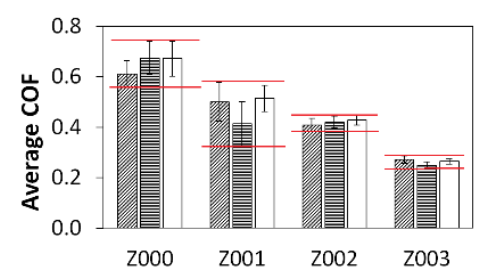

(a)

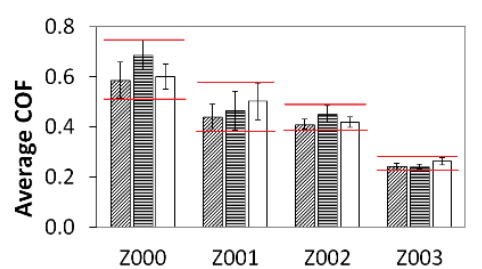

(b)

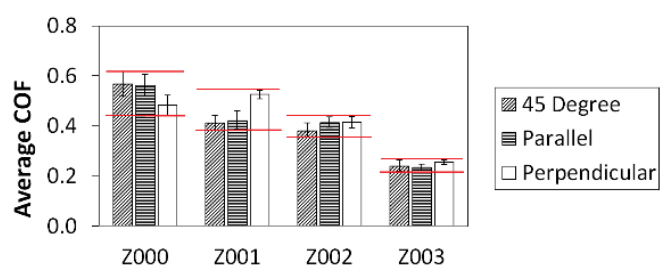

(c)

Fig 4.5 Overview of COF vs. sliding direction for each sample with different normal load (a) $0.2 \mathrm{~N}$, (b) $0.4 \mathrm{~N}$, and (c) $1.0 \mathrm{~N}$; Redline indicates the variation of COF with sliding directions.

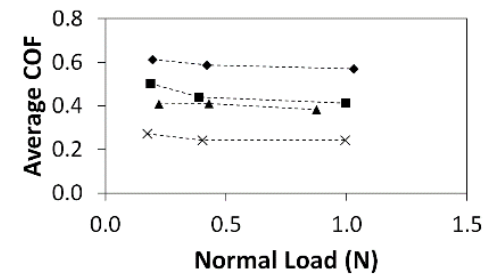

(a)

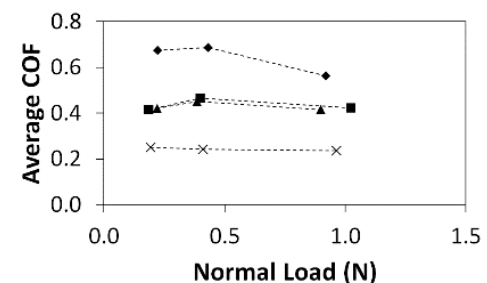

(b)

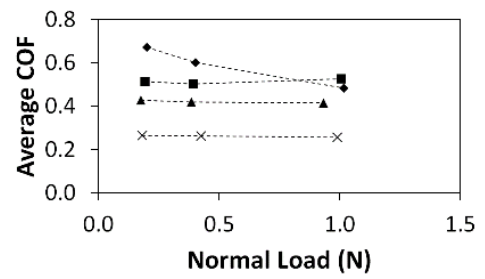

(c)

Fig 4.6 Values of COF vs. normal load for each sample in (a) $45^{\circ}$, (b) parallel, and (c) perpendicular sliding.

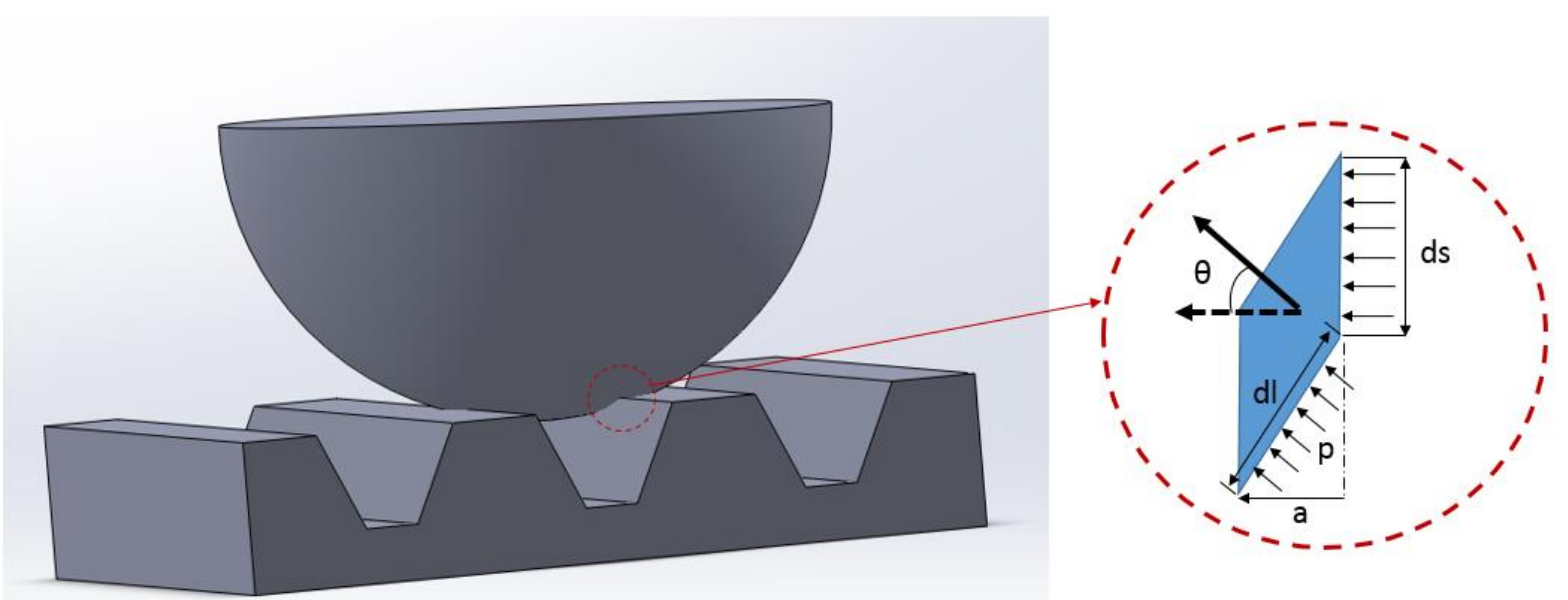

Fig 4.7 Schematic diagram of ridge-skin contact. 
Table 4.2 Experimental data of samples in $45^{\circ}$, perpendicular and parallel sliding direction

\begin{tabular}{|c|c|c|c|c|c|c|c|}
\hline $\begin{array}{l}\text { Sliding } \\
\text { motion }\end{array}$ & Sample & $\begin{array}{c}\text { Normal load } \\
{[N]} \\
\text { Mean } \pm \text { STD }\end{array}$ & $\begin{array}{c}\text { COF } \\
\text { Mean } \pm \text { STD }\end{array}$ & $\begin{array}{l}\text { Sliding } \\
\text { motion }\end{array}$ & Sample & $\begin{array}{c}\text { Normal } \\
\text { load [N] } \\
\text { Mean } \pm \text { STD }\end{array}$ & $\begin{array}{c}\text { COF } \\
\text { Mean } \pm \text { STD }\end{array}$ \\
\hline \multirow{12}{*}{$45^{\circ}$} & Z000 & $0.20 \pm 0.02$ & $0.61 \pm 0.05$ & \multirow{12}{*}{ Parallel } & Z000 & $0.22 \pm 0.04$ & $0.67 \pm 0.07$ \\
\hline & Z001 & $0.19 \pm 0.02$ & $0.50 \pm 0.01$ & & Z001 & $0.19 \pm 0.02$ & $0.41 \pm 0.09$ \\
\hline & Z002 & $0.22 \pm 0.04$ & $0.41 \pm 0.03$ & & Z002 & $0.22 \pm 0.04$ & $0.42 \pm 0.02$ \\
\hline & Z003 & $0.17 \pm 0.04$ & $0.27 \pm 0.01$ & & Z003 & $0.19 \pm 0.04$ & $0.25 \pm 0.01$ \\
\hline & Z000 & $0.42 \pm 0.04$ & $0.59 \pm 0.07$ & & Z000 & $0.43 \pm 0.07$ & $0.69 \pm 0.06$ \\
\hline & Z001 & $0.39 \pm 0.07$ & $0.44 \pm 0.05$ & & Z001 & $0.40 \pm 0.02$ & $0.47 \pm 0.08$ \\
\hline & Z002 & $0.43 \pm 0.04$ & $0.41 \pm 0.02$ & & Z002 & $0.39 \pm 0.07$ & $0.45 \pm 0.03$ \\
\hline & Z003 & $0.40 \pm 0.05$ & $0.24 \pm 0.01$ & & Z003 & $0.41 \pm 0.07$ & $0.24 \pm 0.01$ \\
\hline & Z000 & $1.03 \pm 0.05$ & $0.57 \pm 0.05$ & & Z000 & $0.92 \pm 0.12$ & $0.56 \pm 0.04$ \\
\hline & Z001 & $1.00 \pm 0.07$ & $0.41 \pm 0.03$ & & Z001 & $1.02 \pm 0.04$ & $0.42 \pm 0.04$ \\
\hline & Z002 & $0.88 \pm 0.09$ & $0.38 \pm 0.03$ & & Z002 & $0.90 \pm 0.09$ & $0.42 \pm 0.02$ \\
\hline & Z003 & $1.00 \pm 0.15$ & $0.24 \pm 0.02$ & & Z003 & $0.99 \pm 0.13$ & $0.26 \pm 0.01$ \\
\hline \multirow{12}{*}{ Perpendicular } & Z000 & $0.20 \pm 0.02$ & $0.67 \pm 0.07$ & & & & \\
\hline & Z001 & $0.19 \pm 0.01$ & $0.51 \pm 0.05$ & & & & \\
\hline & Z002 & $0.18 \pm 0.03$ & $0.43 \pm 0.02$ & & & & \\
\hline & Z003 & $0.18 \pm 0.04$ & $0.26 \pm 0.01$ & & & & \\
\hline & Z000 & $0.40 \pm 0.03$ & $0.60 \pm 0.05$ & & & & \\
\hline & Z001 & $0.39 \pm 0.01$ & $0.50 \pm 0.07$ & & & & \\
\hline & Z002 & $0.39 \pm 0.07$ & $0.42 \pm 0.02$ & & & & \\
\hline & Z003 & $0.43 \pm 0.05$ & $0.26 \pm 0.01$ & & & & \\
\hline & Z000 & $1.02 \pm 0.04$ & $0.48 \pm 0.04$ & & & & \\
\hline & Z001 & $1.01 \pm 0.04$ & $0.53 \pm 0.02$ & & & & \\
\hline & Z002 & $0.93 \pm 0.11$ & $0.41 \pm 0.02$ & & & & \\
\hline & Z003 & $0.99 \pm 0.13$ & $0.26 \pm 0.01$ & & & & \\
\hline
\end{tabular}




\subsubsection{The Geometric Effect of the Contact area}

As shown in Fig 4.6, all the textured samples (Z001, Z002, and Z003) generated less tactile friction compared to the non-textured sample (Z000), except sample Z001 in perpendicular sliding with the normal load of $1.0 \mathrm{~N}$ (the cause has been discussed in Section 3.1). This phenomenon was caused by the contact area between skin and counter-surface. According to the research, the reduction of the contact area can directly decrease the tactile friction (Prodanov et al., 2013). In addition, the real contact area can be influenced by the contact condition which is determined by the contact ratio. Westergaard developed a model to estimate the contact ratio between an elastic half-space and rigid wavy surface with spacing $(\lambda)$ and amplitude (depth or height of the structures) (Westergaard 1939). Study found that the Westergaard model also can be applied for a viscoelastic half-space including skin sliding on a rigid wavy surface (Menga et al, 2014) (Skedung et al., 2011) (Duvefelt et al., 2016). A modified contact model was proposed in the previous study to predict the contact ratio by calculating the average contact pressure $(\bar{p})$ and the pressure needed for the fingertip under the full contact condition $\left(p^{*}\right)$ (Zhang et al, 2015).

$\bar{p}=\frac{F_{N}}{\pi a^{2}}$

$p^{*}=\pi E^{*} \frac{D}{2 \lambda}$

$\frac{1}{E^{*}}=\frac{1-v_{\text {finger }}^{2}}{E_{\text {finger }}}+\frac{1-v_{\text {surface }}^{2}}{E_{\text {surface }}}$

$a=\sqrt[3]{\frac{3 R F_{N}}{4 E^{*}}}$

Where $F_{N}$ is the applied load; $a$ is the contact radius predicted by the Hertzian equation; $E^{*}$ is the effective Young's modulus; $D$ is the depth or height of the structures (amplitude); $v_{\text {finger }}$ and 
$v_{\text {surface }}$ are the Poisson ratio of finger and counter-surface accordingly; $R$ is the radius of curvature of the body.

When the average contact pressure $(\bar{p})$ is smaller than the pressure required for finger undergoing the full contact condition $\left(p^{*}\right)\left(\frac{\bar{p}}{p^{*}}<1\right)$, the contact condition is considered as in partial contact. Under the partial contact condition, the skin is not deformed enough to contact the sides and valley of the texture and less real contact area is conducted between the skin and counter-surface. On the contrary case $\left(\frac{\bar{p}}{p^{*}} \geq 1\right)$, the contact condition is considered as the full contact, and the real contact area is increased due to the combination area of the surface, sides and valley of the texture.

The effective Young's modulus $\left(E^{*}\right)$ was estimated by Eq 8 with the reported values of the Young's modulus and the Poisson ratios of skin and stainless steel (Dandekar et al., 2003; Shao et al., 2010; Greaves et al., 2011; Tomlinson et al., 2011) (refer to Table 4.2). The radius of fingertip in contact was measured to be $8 \mathrm{~mm}$. With the estimated value of the effective Young's modulus $\left(E^{*}\right)$, the contact radius between the skin and counter-surface was estimated $(\mathrm{a}=3.1$ $\mathrm{mm}$ ) by Eq (9). Combined with the surface parameters of textures tabulated in Table 4.1, the average contact contact pressure $(\bar{p})$ and the pressure needed for the fingertip under the full contact condition $\left(p^{*}\right)$ can be calculated by Eq (6) \& (7) accordingly. Finally, the contact ratios $\left(\frac{\bar{p}}{p^{*}}\right)$ of all textured samples were predicted and results were tabulated in Table $4.2(\mathrm{Z} 001=$ $0.24 ; \mathrm{Z} 002=0.48 ; \mathrm{Z} 003=0.51)$. Since the pressure ratios were less than 1 (refer to Table 4.2), therefore, the contact conditions can be considered as in partial contact. Under the partial contact condition, the maximum contact areas of grooved channel, Hilbert curve and grid textures can be derived as:

$$
A_{\text {Groove }}=\pi a^{2}-N w_{\text {groove }} \bar{l}_{\text {groove }}=N\left(\lambda-w_{\text {groove }}\right) \bar{l}_{\text {groove }}, \quad \text { for } \frac{\bar{p}}{p^{*}}<1
$$


$A_{\text {Hilbert }}=\pi a^{2}-w_{\text {Hilbert }} l_{\text {Hilbert }}, \quad$ for $\frac{\bar{p}}{p^{*}}<1$

$A_{\text {Grid }}=N \pi r_{\text {Grid }}^{2}, \quad$ for $\frac{\bar{p}}{p^{*}}<1$

Where $N$ is the number of grooves or grids in contact; $w_{\text {groove }}$ is the width of the grooved channel; $\bar{l}_{\text {groove }}$ is the average length of the grooves in contact; $w_{\text {Hilbert }}$ is the width of the Hilbert curve; $l_{\text {Hilbert }}$ is the length of Hilbert curve in contact; $r_{\text {Grid }}$ is the radius of grid pattern.

Now, a modified Westergaard model can be used to describe the contact width $2 a_{\text {westergaard }}$.

$2 a_{\text {westergaard }}=\frac{2 \lambda}{\pi} \sin ^{-1}\left(\frac{\bar{p}}{p^{*}}\right)^{1 / 2}$

Where $\lambda$ is spacing (or wavelength); $\bar{p}$ is mean surface pressure; $p^{*}$ is the pressure needed for full continuous contact.

With the value of contact ratio $\left(\frac{\bar{p}}{p^{*}}\right)$ (refer to Table 4.2) and known spacing $\lambda$ of each texture (refer to Table 4.1), the contact width $2 a_{\text {westergaard }}$ can be calculated. As the result, the contact area of each textured samples need to be calculated (refer to Eq 10, 11 \& 12). According to Eq 3, the functional forms of COF between the skin and textured counter-surface can be calculated by inputting the values of the intrinsic interfacial shear strength $\tau_{0}$ and the pressure coefficient $\alpha$ which are reported in the literature as $5.5 \mathrm{kPa}$ and 0.23 accordingly (refer to Table 4.2) (Tomlinson et al., 2011) (Derler et al., 2013). The normal loads $\left(F_{N}\right)$ were $0.2 \mathrm{~N}, 0.4 \mathrm{~N}$ and 1.0 $\mathrm{N}$, and the results of estimated COF were charted. As shown in Fig 4.8, the values of estimated COF corresponds well with the range of COF obtained from friction measurements for the all samples, especially for the sample Z003 (grid). For example, under the normal load of $0.2 \mathrm{~N}$, the estimated COF of the sample Z003 was 0.28 compared with the calculated COF from the friction measurements $\left(0.27\right.$ for $45^{\circ}, 0.25$ for parallel, and 0.26 for the perpendicular sliding direction) (refer to Fig $4.8 \mathrm{c}$ ). 
Overall, the sample Z003 (grid) showed a better performance compared to the other samples in friction reduction from both experimental and analytical results (refer to Fig $4.6 \& 4.8$ ). Moreover, based on the experimental results, the sample Z003 (grid) was orientationindependent while the other samples were orientation-dependent in $45^{\circ}$, parallel and perpendicular sliding directions. With the respect to the texture designs based on the friction model and orientation effect, the grid pattern showed superior performance compared to the grooved channel and Hilbert curve pattern and reference sample.

Table 4.2 Parameters from literature were used to calculate the pressure ratios and COF of textured samples (Dandekar et al., 2003; Shao et al., 2010; Greaves et al., 2011; Tomlinson et al., 2011), the normal load $F_{N}$ (maximum value) was obtained from the skin friction measurements.

\begin{tabular}{llll}
\hline Material Property & Values & Sample & $\begin{array}{l}\text { Pressure } \\
\text { Ratio }\end{array}$ \\
\hline & & & \\
$\boldsymbol{E}_{\text {finger }}$ & $0.2 \mathrm{MPa}$ & $\mathrm{Z} 001$ & 0.24 \\
$\boldsymbol{E}_{\text {surface }}$ & $150 \mathrm{GPa}$ & $\mathrm{Z} 002$ & 0.48 \\
$\boldsymbol{v}_{\text {finger }}$ & 0.48 & & 0.51 \\
$\boldsymbol{v}_{\text {surface }}$ & 0.3 & & \\
$\boldsymbol{F}_{\boldsymbol{N}}$ & $1.0 \mathrm{~N}$ & \\
Finger Radius, $\boldsymbol{R}$ & $8 \mathrm{~mm}$ & \\
Pressure Coefficient $\boldsymbol{\alpha}$ & 0.23 & & \\
Intrinsic interfacial shear strength & $\boldsymbol{\tau}_{\mathbf{0}}$ & $5.5 \mathrm{kPa}$ & \\
& & & \\
\hline
\end{tabular}




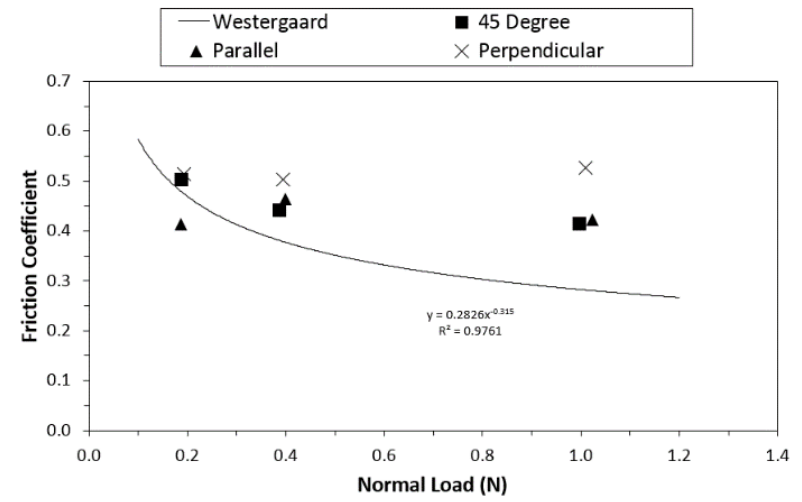

(a)

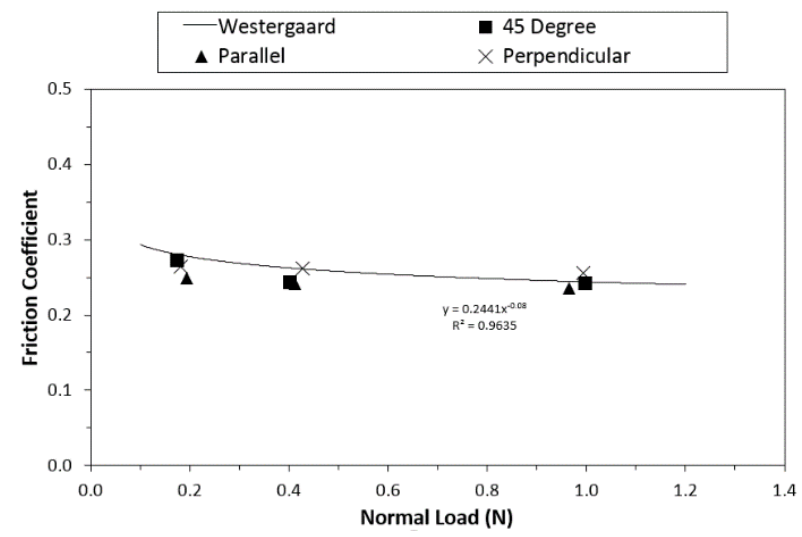

(c)

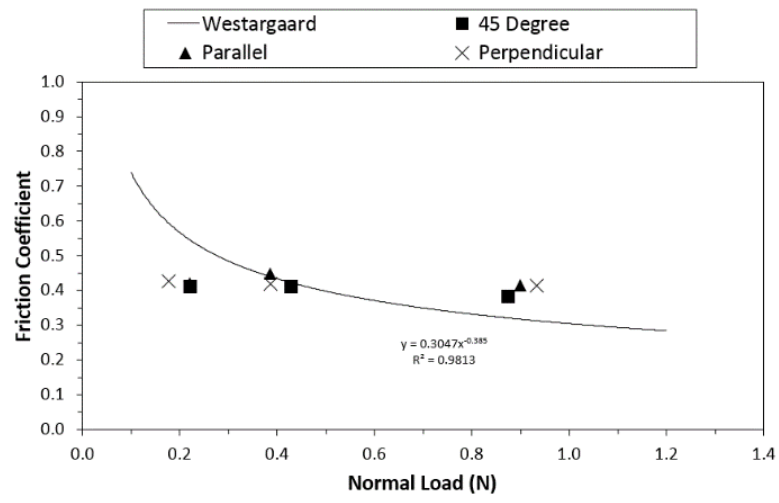

(b)

Fig 4.8 Values of COF (both experimental and analytical results) vs. normal load for (a) sample Z001 (grooved channel), (b) sample Z002 (Hilbert curve), and (c) sample Z003 (grid).

\subsection{Conclusions}

Based on the experimental results (under the normal loads of $0.2 \mathrm{~N}, 0.4 \mathrm{~N}$ and $1.0 \mathrm{~N}$ ), less friction forces were observed on the textured stainless steel samples (Z001, Z002, Z003) compared to non-textured sample in three sliding directions (perpendicular, parallel and $45^{\circ}$ ) except sample Z001 in perpendicular sliding with the normal load of $1.0 \mathrm{~N}$. In the concern of friction reduction, the grid (Z003) texture has the advantage over Hilbert curve and grooved channel textures in decreasing the friction force under the partial contact condition $\left(\frac{\bar{p}}{p^{*}}<1\right)$. From the analytical approach, the grid (Z003) also showed lower values of COF compared to the other samples, which was consistent with the experimental results. 
Furthermore, the influence of orientation effect was insignificant for grid (Z003) textures due to the geometrical advantage. However, the sliding directions affected other samples, especially the perpendicular sliding for the grooved channel (Z001) and stochastic surface (Z000). In the case of sample Z001 in perpendicular sliding, the resulting hysteresis force was able to increase the deformation component of friction between the skin and the leading edges of countersurface, as the result, the overall friction was increased.

From both the experimental and analytical approaches, the grid pattern was proved to be the optimal textural design in the concern of friction reduction and orientation effect (refer to Table 4.3). The grid structure can greatly reduce the dynamic friction between the skin and countersurface without the influence of sliding directions $\left(45^{\circ}\right.$, parallel and perpendicular) compared to the other samples.

Table 4.3 Conclusions based on the estimated COF, measured friction and orientation effect.

\begin{tabular}{cccccc}
\hline $\begin{array}{c}\text { Sample } \\
\text { Name }\end{array}$ & Texture Type & $\begin{array}{c}\text { Estimated } \\
\text { COF }\end{array}$ & $\begin{array}{c}\text { Measured } \\
\text { Friction }\end{array}$ & $\begin{array}{c}\text { Orientation } \\
\text { Effect }\end{array}$ & Rank \\
\hline Z000 & None & Highest & Highest & Highly Dependent & low \\
$\mathbf{Z 0 0 1}$ & Grooved Channel & Medium & Median & Highly Dependent & medium \\
$\mathbf{Z 0 0 2}$ & Hilbert Curve & Low & Low & Less Dependent & high \\
$\mathbf{Z 0 0 3}$ & Grid & Lowest & Lowest & Least Dependent & Optimal \\
& & & & & \\
\hline
\end{tabular}




\section{REFERENCES}

[1] Adams, M.J., Briscoe, B.J., Johnson, S.A., Friction and lubrication of human skin. Tribology Letters, 2007, 26(3): 239-253.

[2] Butz, A.R., Space filling curves and mathematical programming. Information and Control, 1968, 12: 314-330.

[3] Butz, A.R., Convergence with Hilbert's space filling curve. Journal of Computer and System Sciences, 1969, 3: 128-146.

[4] Chen, X., Bames, C.J., Childs, T.H.C., Henson, B., Shao, F., Materials' tactile testing and characterization for consumer products' affective packaging design. Materials \& Design, 2009, 30(10): 4299-4310.

[5] Braun, D., Greiner, C., Schneider, J., Gumbsch, P., Efficiency of laser surface texturing in the reduction of friction under mixed lubrication. Tribology International, 2014, 77: 142-147.

[6] Dandekar, K., Raju, B. I., Srinivasan, M. A., 3-D finite-element models of human and monkey fingertips to investigate the mechanics of tactile sense. Journal of Biomechanical EngineeringTransactions of the ASME, 2003, 125(5): 682-691.

[7] Derler, S., Gerhardt, L.-C., Tribology of skin: review and analysis of experimental results for the friction coefficient of human skin. Tribology Letters, 2012, 45:1-27.

[8] Derler, S., Gerhardt, L.-C., Lenz, A., Bertaux, E., Hadad, M., Friction of human skin against smooth and rough glass as a function of the contact pressure. Tribology International, 2009, 42: 15651574 .

[9] Derler, S., Huber, R., Feuz, H.P., Hadad, M., Influence of surface microstructure on the sliding friction of plantar skin against hard substrates. Wear, 2009, 267(5-8): 1281-1288.

[10] Derler, S., Suess, J., Rao, A., Rotaru, G.-M., Influence of variations in the pressure distribution on the friction of the finger pad. Tribology International, 2013, 63: 14-20.

[11] Duvefelt, K., Olofsson, U., Johannesson, C.M., Skedung, L., Model for contact between finger and sinusoidal plane evaluate adhesion and deformation component of friction. Tribology International, 2016, 96: 389-394.

[12] Greenwood, J.A., Tabor, D., The friction of hard sliders on lubricated rubber: the importance of deformation losses. Proceedings of the Physical Society, 1958, 71: 989-1001.

[13] Griffiths, J.G., Table-driven algorithms for generating space-filling curves. Computer-Aided Design, 1985, 17: 37-41.

[14] Greaves, G.N., Greer, A.L., Lakes, R.S., Rouxel, T., Poisson's ratio and modern materials. Nature Materials, 2011, 10: 823-837.

[15] Hilbert, D., Ueber die stetige Abbildung einer Linie auf ein Flaechenstueck, Mathematische Annalen. 1891, 38: 459-460.

[16] Johnson, K.L., Greenwood, J.A., Higginson, J.G., The contact of elastic regular wavy surface. International Journal of Mechanical Sciences, 1985, 6: 383-396. 
[17] Kang, M., Park, Y.M., Kim, B.H., Seo, Y.H., Micro- and nanoscale surface texturing effects on surface friction. Applied Surface Science, 2015, 345: 344-348.

[18] Kim, M.S., Kim, I.Y., Park, Y.K., Lee, Y.Z., The friction measurement between finger skin and material surfaces. Wear, 2013, 301: 338-342.

[19] Kwiatkowska, M., Franklin, S.E., Hendriks, C.P., Kwiatkowski, K., Friction and deformation behaviour of human skin. Wear, 2009, 267(5-8): 1264-1273.

[20] Lewis, R., Carre, M.J., Tomlinson, S.E., Skin friction at the interface between hands and sports equipment. Procedia Engineering, 2014, 72: 611-617.

[21] Maeno, T., Kobayashi, K., Yamazaki, N., Relationship between the structure of human finger tissue and the location of tactile receptors. JSME International Journal Series C-Mechanical Systems Machine Elements and Manufacturing, 1998, 41(1): 94-100.

[22] Menga, N., Putignano, C., Carbone, G., Demelio, G.P., The sliding contact of a rigid wavy surface with a viscoelastic half-space. Proceedings of the Royal Society A: Mathematical Physical \& Engineering Sciences, 2014, 470: 1-14.

[23] Pasumarty, S.M., Johnson, S.A., Watson, S.A., Adams, M.J., Friction of the human finger pad: influence of moisture, occlusion and velocity. Tribology Letters, 2011, 44: 117-137.

[24] Prodanov, N., Gachot, C., Rosenkanz, A., Muchlich, F., Muser, M.H., Contact mechanics of lasertextured surfaces. Tribology Letters, 2013, 50: 41-48.

[25] Peano, G., Sur une coube, qui remplit toute une aire plaine. Mathematische Annalen, 1890, 36: 157-160.

[26] Prokopovich, P., Perni, S., Adhesion models: from single to multiple asperity contacts. Colloids and Surfaces A: Physicochemical and Engineering Aspects, 2011, 383: 95-101.

[27] Schreiner, S., Rechberger, M., Bertling, J., Haptic perception of friction - correlating friction measurements of skin against polymer surfaces with subjective evaluations of the surfaces' grip. Tribology International, 2013, 63: 21-28.

[28] Shao, F., Childs, T.H.C., Barnes, C.J., Henson, B., Finite element simulations of static and sliding contact between a human fingertip and textured surfaces. Tribology International, 2010, 43: $2308-2316$.

[29] Skedung, L., Danerlov, K., Olofsson, U., Johannesson, C.M., Aikala, M., Kettle, J., Arvidsson, M., Berglund, B., Rutland, M.W., Tactile perception: Finger friction, surface roughness and perceived coarseness. Tribology International, 2011, 44: 505-512.

[30] Soneda, T., Nakano, K., Investigation of vibrotactile sensation of human finger-pads by observation of contact zones. Tribology International, 2010, 43: 210-217.

[31] Suh, M., Chae, Y., Kim, S., Hinoki, T., Kohyama, A., Effect of geometrical parameters in microgrooved crosshatch pattern under lubricated sliding friction. Tribology International, 2010, 43: $1508-1517$.

[32] Tagami, H., Yoshikuni, K., Interrelationship between water-barrier and reservoir functions of pathologic stratum corneum. Archives of Dermatology, 1985, 121: 642-645.

[33] Tomlinson, SE., Carre, MJ., Lewis, R., Franklin, SE., Human finger contact with small, triangular ridged surfaces. Wear, 2011, 271: 2346-53. 
[34] Tomlinson, S.E., Lewis, R., Carre, M.J., The effect of normal force and roughness on friction in human finger contact. Wear, 2009, 267(5-8): 1311-1318.

[35] Van Kuilenburg, J., Masen, M.A., Groenendijk, M.N.W., Bana, V., van der Heide, E., An experimental study on the relation between surface texture and tactile friction. Tribology International, 2012, 48: 15-21.

[36] Westergaard, H.M., Bearing pressures and cracks. Journal of Applied Mechanics - Transactions of the ASME, 1939: 49-53.

[37] Wolfram, L.J., Friction of skin. Journal of the Society of Cosmetic Chemists, 1983, 34(8): 465476.

[38] Yuan, Y., Verma, R., Measuring microelastic properties of stratum corneum. Colloids and Surfaces B: Biointerfaces, 2006, 48: 6-12.

[39] Zhang, S., Rodriguez Urribarri, A., Morales Hurtado, M., Zeng, X., van der Heide, E., The role of the sliding direction against a grooved channel texture on tool steel: an experimental study on tactile friction. International Journal of Solids and Structures, 2015, 56-57: 53-61. 


\section{Chapter 5}

\section{Texture Design for Light Touch Perception*}

This study focused on active light touch with predefined textures specially-designed for tactile perception. The counter-body material is stainless steel sheet. Three geometric structures (grid, crater and groove) were fabricated by pulsed laser surface texturing. A total number of twenty volunteers participated in the research which contains two parts: perception tests and skin friction measurements. The perception tests focused mainly on the participants' perceptual attributes: perceived roughness and perceived stickiness. For the skin friction measurements, a multi-axis force/torque transducer was used to measure the normal force and friction force between skin and countersurface along with the fingertip position. The results of the predefined textures showed the ability to reduce skin friction due to the reduction of contact area. Moreover, the participants' perceptual attributes were greatly influenced by the predefined microstructures in the light touch regime.

*S. Zhang, X. Zeng, D.T.A. Matthews, A. Igartua, E. Rodriguez-Vidal, J. Contreras Fortes and E. van der Heide, Texture design for light touch perception, Tribology International, Under Review, 03/2016 


\subsection{Introduction}

Tactile perception of surfaces is an essential aspect of our daily life and has a profound importance for our well -being (Etzi et al., 2014). The introduction of haptic interfaces that rely on texture discrimination tasks might enhance this importance greatly. As such, it is highly relevant to develop knowledge for the design of surface textures that we like to touch (Etzi et al., 2014), give pleasure (Klatzky et al, 2013) and that e.g. enables us to perform touch based control tasks in reliable way (Mizuhara et al, 2013).

The human hand for example, is innervated by more than 600 nerve fibers per $\mathrm{mm}^{2}$, (Kelly et al, 2005) in (Maricich, 2012), conveying cutaneous stimuli that are represented and processed in the spinal cord and brain to touch perceptions (Zimmerman et al, 2014). The main part of the nerve fibers consists of low threshold mechanoreceptive A $\beta$-fibers with sensory axon terminals, associated non-neuronal components and contacts between them and the surrounding cells of the skin (Zimmerman et al, 2014) (Lederman, 1981) (Lawson and Djouhri, 2004). The underlying principles that govern transduction at axon terminals in the skin have only recently been revealed and show that Merkel cells - a non-neuronal component - are essential in texture discrimination (Maricich et al, 2009). Future research on specific deletion of subclasses of cutaneous mechanoreceptors might clarify which functional assignment is to be associated with which specific parts of the cutaneous somatosensory system (Maricich et al, 2012).

From a mechanistic point of view, the tactile and haptic experiences with materials and surfaces essentially rely on the interactions between the human skin and objects. New insights of surface topographical modifications of both skin (abraded) and counter-surfaces due to friction are analyzed (Derler et al., 2015). One form of tactile perception that is of particular relevance, is the light (Maricich et al, 2009) or gentle (Zimmerman et al, 2014) regime of touch, which is essential for the discrimination of surface structures without skin abrading. Light touch perception is associated with sliding of the glabrous skin that is found on the hands and feet of 
most mammals (Zimmerman et al, 2014), relative to and in contact with surfaces at a certain normal load. The mechanism of light touch is characterized by dynamic skin deformations or static skin indentations in the micro- to nano- meter range (Maricich et al., 2009) and typically involves normal loads between $0.1 \mathrm{~N}$ to $1.0 \mathrm{~N}$ with respect to the exploratory procedure for an human fingertip (Lackner et al., 1999; Delhaye et al., 2014). The required relevant level of detail of surface roughness for texture discrimination at light touch conditions, can only be reached in a deterministic way based on modern fabrication techniques, of which pulsed laser surface texturing (Li, 2015) (Van Kuilenburg et al., 2012) (Scarragi et al., 2014) is selected in this work.

Related studies on textural perception of deterministic surfaces are focusing on the perception of form, size, spatial period and spacing of the textures, as for example shown in (van Kuilenburg et al., 2012) (Chen, 2009). Recently, experimental research was presented on the effect of the sliding direction and applied normal force of the finger (Zhang et al., 2015).

This research focusses on the relationships among tactile perception, sub-micron surface roughness features and friction at light touch conditions, with the general aim to discover design principles that enhance tactile perception. An experimental approach was adopted in this work based on two perspectives: 1) a panel test with a questionnaire that subjectively rates touch perception of roughness and of slipperiness, and 2) in vivo friction measurements and area roughness measurements as objective ratings of the touch system. The correlation of the two is expected to provide design tools for texture design of future product surfaces. 


\subsection{Subjects and Objects}

\subsubsection{Texture design}

Tactile perception does not depend on the textural stimuli only. For example, the perceived temperature or cold/warm dimension and the perceived softness or hard/soft dimension might influence the texture related rough/smooth and sticky/slippery dimensions (Kawasegi et al., 2013) (Van Kuilenburg, 2015). To avoid cross over from this it is decided to use stainless steel EN-1.4301, well suited for pulsed laser surface texturing processing. The textural stimulus of hard/soft remains therefore the same, because all samples were made from the same stainless steel sheet material. Also, the textural stimulus of warm/cold is considered constant, given the minimum amount of frictional heat that is produced during sliding at low velocity and at low normal load (van der Heide and Schipper, 2004) and given the constant thermal properties of the interacting surfaces. As such, the perceptions including rough/smooth and sticky/slippery are two subjective dimensions which are expected to be modified by the texture design. The surface roughness has the ability of modifying the perceived roughness and perceived stickiness. Moreover, study shows that the friction force generated between metals and skin decreases when surface roughness increases (Hendriks and Franklin, 2010).

Surface roughness parameter $R a$, related to the center line average of the local surface heights, is a well-defined and frequently used parameter to evaluate the surface quality. Yet, line measurements conducted on deterministic surfaces are influenced by the length of the measurement and by the angle relative to the texture. The areal form of this parameter $(S a)$ is able to evaluate the surface quality with less dependence on the actual location at the surface see e.g. (Wang et al., 2015). The surface roughness $S a$ of the texture designs can be calculated by Eq. (1). 
$S_{a}=\frac{1}{M N} \sum_{k=0}^{M-1} \sum_{l=0}^{N-1}\left[\left|z\left(x_{k}, y_{l}\right)\right|\right]$

Where variable $z\left(x_{k}, y_{l}\right)$ denotes the vertical deviation of the surface at location $\left(x_{k}, y_{l}\right)$

The surface roughness $S a$ of these patterns will be greater when the structures have proportionately deeper depth (refer to Fig 5.2 a \& b). However, to avoid negative influences like interlocking effects, the depth cannot be too large when a threshold level of roughness is reached (Tomlinson et al., 2011). Since the criteria of texture design is focused on the surface roughness, therefore, the leading parameter is the depth (or height) based on the geometric shape of surface features. Three geometric shapes were designed, referred to as crater (concave), groove (concave) and grid (convex) structures with different parameters including width, depth and spacing (see Fig 5.1a, $1 \mathrm{~b}$ and 1c, respectively). These patterns are able to change the surface roughness in deterministic way and can be fabricated by pulsed laser surface texturing (Scaraggi et al., 2014; Luo et al., 2014; Van Kuilenburg, 2012). For the crater structure, the overlapping spots need to be considered due to the fabrication process (refer to Fig 5.2 c).

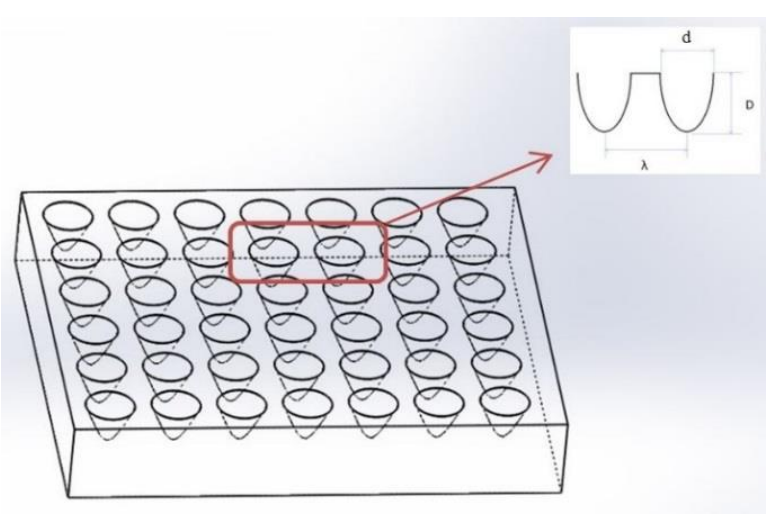

(a)

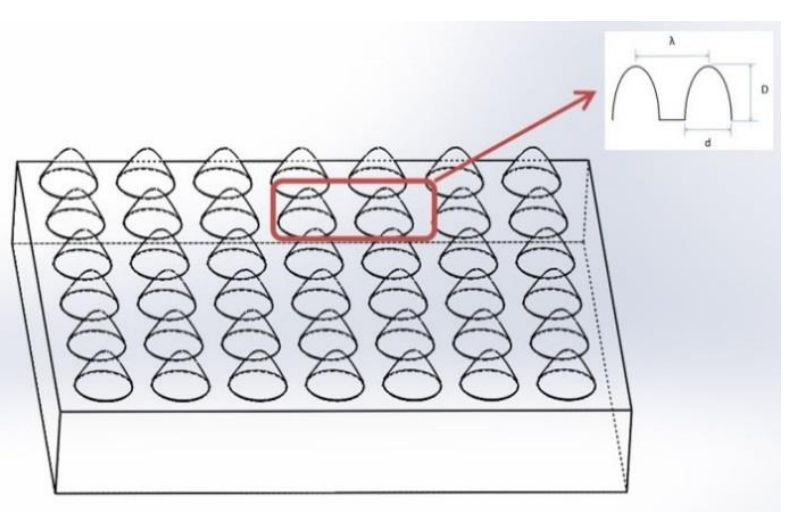

(b) 


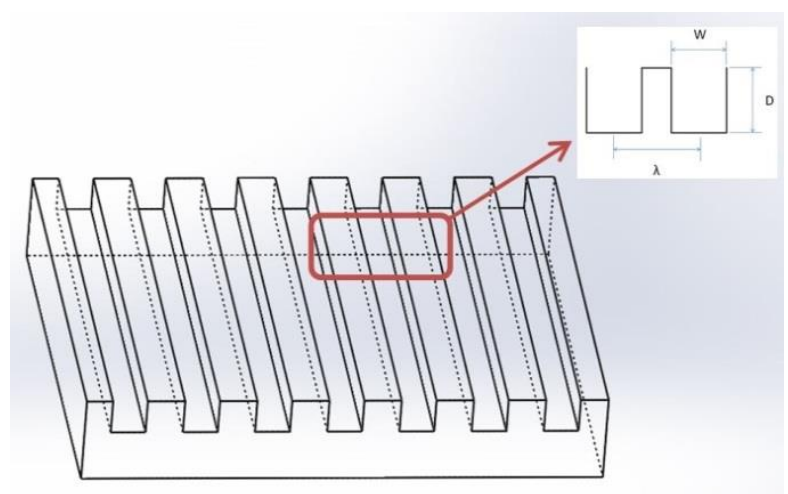

(c)

Fig 5.1 Schematic profile of (a) crater, (b) grid, and (c) groove structures.

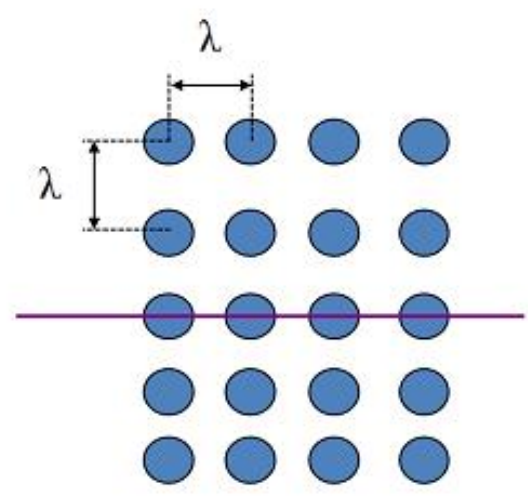

(a)

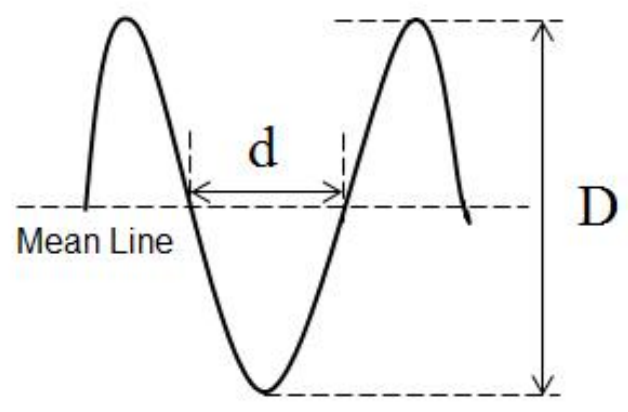

(b)

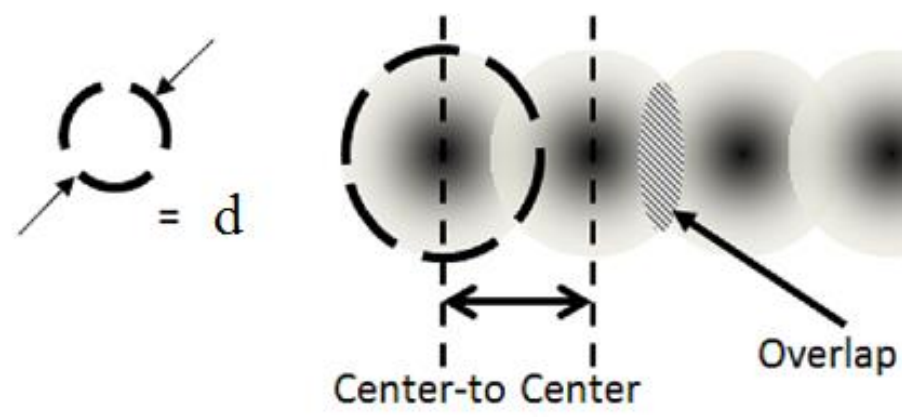

(c)

Fig 5.2 Objective schematic profile of (a) crater array, (b) a single crater, and (c) overlapping spots. 


\subsubsection{Fabrication of textures}

In this work, six textured samples and one non-textured sample each of dimension $35 \mathrm{~mm} \times 35$ $\mathrm{mm} \times 1 \mathrm{~mm}$ were used. The same stainless steel sheet material EN-1.4301 was used for all samples. Two grid structures (picosecond laser), two crater structures (nanosecond laser) and two groove structures (nanosecond laser) were fabricated by pulsed laser surface texturing (LST) (refer to Fig 5.3) with different surface parameters. The power of the picosecond laser is $0.151 \mathrm{~W}$ with frequency of $250 \mathrm{kHz}$. The speed was set at $750 \mathrm{~mm} / \mathrm{s}$ with 20 tracks. For the nanosecond laser, the power is $9.5 \mathrm{~W}$ with $41 \mathrm{kHz}$ as frequency. The speed was $3280 \mathrm{~mm} / \mathrm{s}$ with 10 tracks (refer to Fig 5.3 b). The surface parameters of the samples are tabulated in Table 5.1 and examined by SEM and confocal microscopy as shown in Fig 5.4. In addition, one conventionally finished sample ( $2 \mathrm{G}$ finish) produced by cold rolling was conducted in the same experiments as a reference for comparison.

Table 5.1. Selected surface parameters of the samples: depth (D), diameter of crater and grid (d), width $(W)$, spacing $(\lambda)$ and calculated surface roughness $(\mathrm{Sa})$.

\begin{tabular}{lccccccc}
\hline $\begin{array}{c}\text { Sample } \\
\text { Name }\end{array}$ & $\begin{array}{c}\text { Fabrication } \\
\text { Method }\end{array}$ & $\begin{array}{c}\text { Surface } \\
\text { Texture }\end{array}$ & $\begin{array}{c}\text { Depth D } \\
{[\mu \mathrm{m}]}\end{array}$ & $\begin{array}{c}\text { Diameter d } \\
{[\mu \mathrm{m}]}\end{array}$ & $\begin{array}{c}\text { Width W } \\
{[\mu \mathrm{m}]}\end{array}$ & $\begin{array}{c}\text { Spacing } \boldsymbol{\lambda} \\
{[\boldsymbol{\mu m}]}\end{array}$ & $\begin{array}{c}\text { Calculated } S a \\
{[\mu \mathrm{m}]}\end{array}$ \\
\hline C-2 & LST - NS & Crater & 15 & 60 & - & 80 & 3.79 \\
C-3 & LST - NS & Crater & 30 & 60 & - & 80 & 7.58 \\
LDG-1 & LST - NS & Groove & 15 & - & 100 & 115 & 1.98 \\
LDG-3 & LST - NS & Groove & 30 & - & 100 & 115 & 3.97 \\
HDG-2 & LST - PS & Grid & 15 & 75 & - & 90 & 2.53 \\
HDG-3 & LST - PS & Grid & 30 & 75 & - & 90 & 5.06 \\
2G & Cold Rolling & - & - & - & - & - & -
\end{tabular}




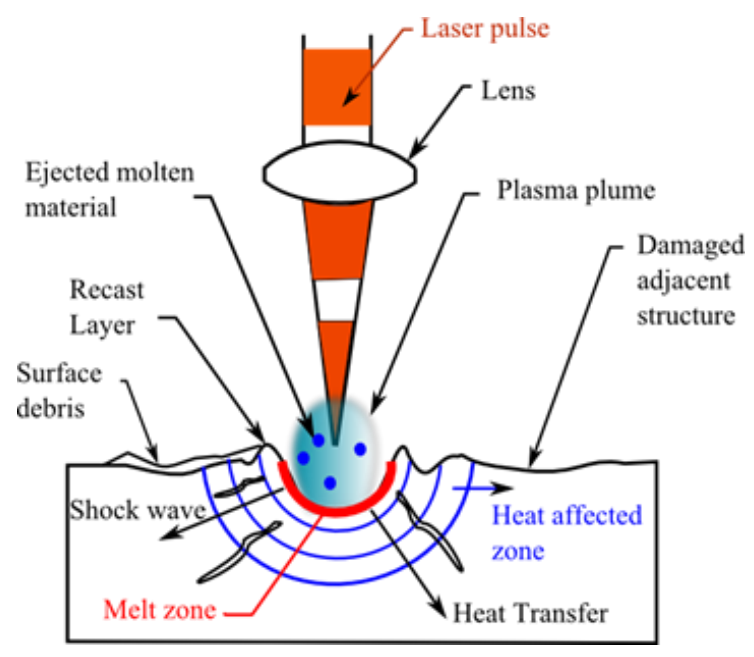

(a)

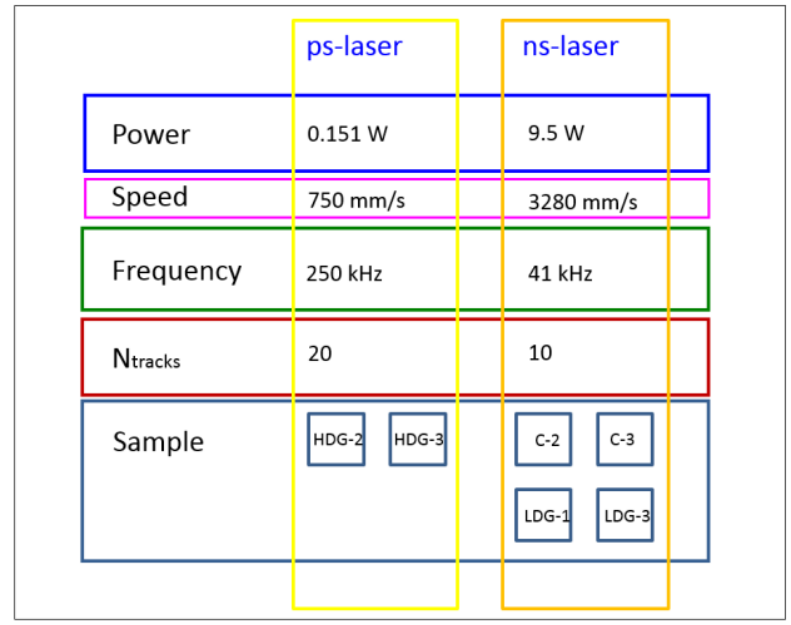

(b)

Fig 5.3 (a) Schematic of pulsed laser ablation; (b) Fabrication methods, power, frequency, speed and number of tracks ( $\mathrm{N}_{\text {tracks }}$ ).

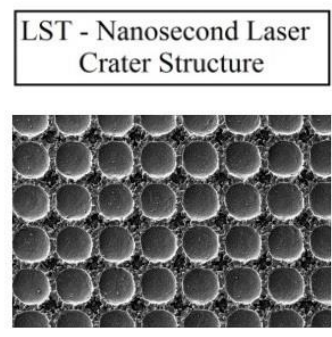

(a)

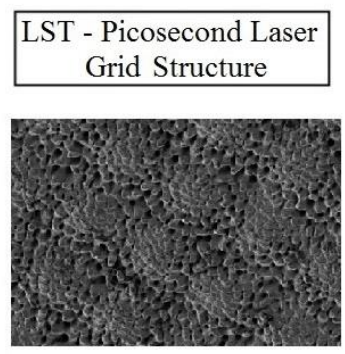

(e)

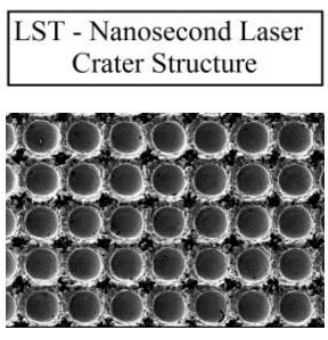

(b)
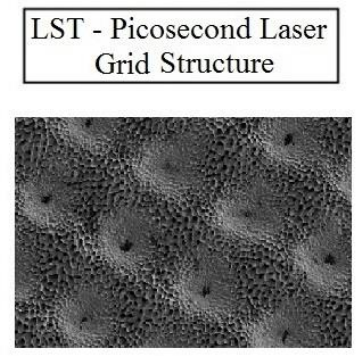

(f)
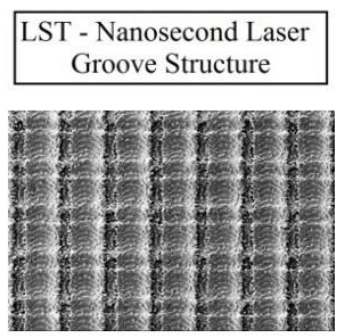

(c)

Reference Finish

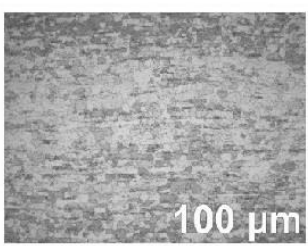

(g)

Fig 5.4 SEM images of samples (a) C-2 (crater), (b) C-3 (crater), (c) LDG-1 (groove), (d) LDG-3 (groove), (e) HDG-2 (grid), (f) HDG-3 (grid); confocal microscope image (50x) of sample (g) $2 \mathrm{G}$ (reference). Measured surface roughness $S a$ was conducted by a 3D areal confocal ( $\mu$ SURFmobile, NanoFocus AG, Germany). 


\subsubsection{Participants and Conditions}

An influential factor of textural perception is the state of the skin. As a multi-layered biological material, skin behaves in a viscoelastic, non-homogeneous, nonlinear and anisotropic manner. Moreover, the state and properties of skin are depending on the body region, age, degree of hydration and nutritional conditions (Ramalho et al., 2007; Pailler-Mattei et al., 2008; Zajpiamo et al., 2011).

Two mutually exclusive experiments were conducted with a panel that consisted of twenty participants aged from 20 to 30 years old, see Table 5.2. The perceptual fingertips were the middle fingers of the non-dominant hands. The hydration levels of the skins were measured by a corneometer (CM 825, Courage+Khazaka GmbH, Germany), and the fingertips were cleaned with alcohol and air-dried before tests. All experiments were conducted in a controlled laboratory with an ambient temperature of $20 \pm 1{ }^{\circ} \mathrm{C}$ and relative humidity of $50 \pm 10 \%$. 
Table 5.2 List of the participants performing the perception experiment and the finger hydration measurements (M: Male; F: Female).

\begin{tabular}{cccccc}
\hline Participant & Gender & $\begin{array}{c}\text { Hand } \\
\text { (non- } \\
\text { dominant) }\end{array}$ & $\begin{array}{c}\text { Finger } \\
\text { (non-dominant) }\end{array}$ & $\begin{array}{c}\text { Normal } \\
\text { Load } \\
\text { (N) }\end{array}$ & $\begin{array}{c}\text { Hydration Level } \\
\text { of the Fingertip } \\
\text { [AU] }\end{array}$ \\
1 & M & Left & Middle & 0.15 & 75.9 \\
2 & F & Left & Middle & 0.13 & 61.6 \\
3 & M & Left & Middle & 0.13 & 62.4 \\
4 & M & Left & Middle & 0.27 & 66.7 \\
5 & M & Left & Middle & 0.37 & 119.7 \\
6 & M & Left & Middle & 0.33 & 95.5 \\
7 & F & Left & Middle & 0.19 & 97.3 \\
8 & F & Left & Middle & 0.31 & 87.1 \\
9 & F & Left & Middle & 0.63 & 102.6 \\
10 & M & Left & Middle & 0.14 & 95.1 \\
11 & F & Left & Middle & 0.20 & 110.6 \\
12 & F & Left & Middle & 0.18 & 70.8 \\
13 & M & Left & Middle & 0.15 & 102.1 \\
14 & F & Right & Middle & 0.28 & 111.2 \\
15 & F & Left & Middle & 0.26 & 83.7 \\
16 & F & Left & Middle & 0.22 & 95.9 \\
17 & M & Left & Middle & 0.21 & 73.7 \\
18 & M & Left & Middle & 0.39 & 68.2 \\
19 & F & Left & Middle & 0.21 & 98.7 \\
20 & M & Left & Middle & 0.14 & 78.6 \\
\hline
\end{tabular}




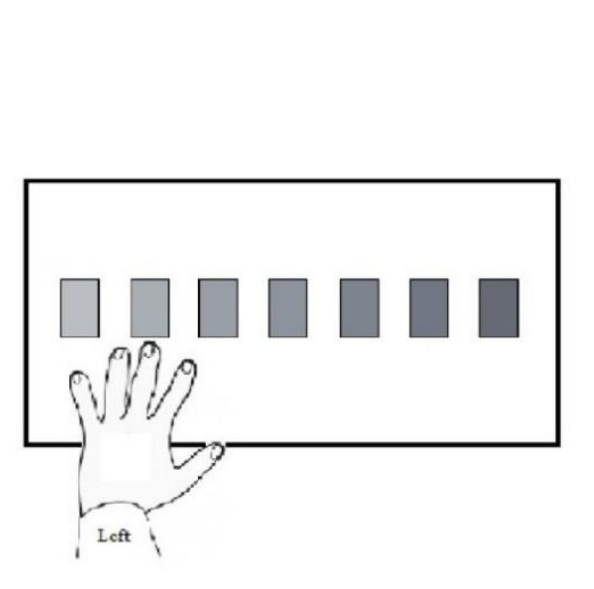

(a)

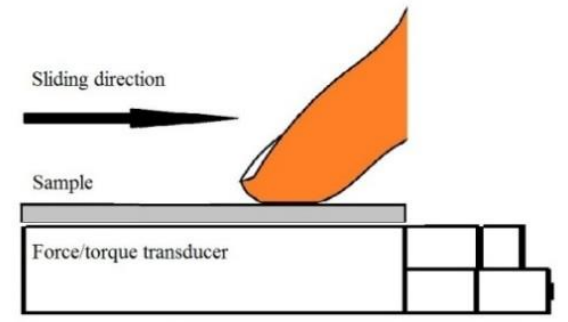

(b)

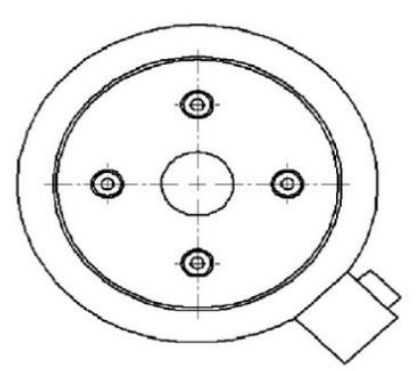

(c)

Fig 5.5 Schematics of (a) panel tests for the perception experiment, (b) skin friction measurement, and (c) multi-axis force/torque transducer (ATI Industrial Automation, Apex, NC, USA).

\subsection{Experiments}

\subsubsection{Perception Experiment}

The perception experiments were conducted by a panel test method to identify the perceptual attributes: perceived stickiness and perceived roughness (refer to Fig 5.5 a). The participants were blindfolded to ensure the action of textural perception was independent without visual interference (Whitaker et al., 2008). A training session was used to allow the participants to get familiar with the blind touch and be comfortable with the tests to avoid perceptual bias from emotional intensity. In the actual perception experiments, the subjects were requested to perform sliding motion along the sample surface toward their bodies. The samples were explored in a random order. The subjective ratings from 0 to 10 were graded by each participant in light, active touch. The lower number means less perceptual recognition. For example, the 
lower number in perceived roughness indicated smoother sensation from the sample surface, while the higher number indicated the rougher sensation in perception.

\subsubsection{Friction and Surface Roughness Measurements}

A multi-axis force/torque transducer (ATI Industrial Automation, Apex, NC, USA) was used to measure the normal force in $\mathrm{z}$-direction (resolution of force measurement: $25 \mathrm{mN}$ ) and friction force in xy-plane (resolution of force measurement: $15 \mathrm{mN}$ ) generated by the interaction of skin and sample surface (refer to Fig 5.5 b \& c). In addition, the surface roughness $S a$ of all samples were measured by a 3D areal confocal ( $\mu$ SURF-mobile, NanoFocus AG, Germany) (refer to Table 5.3). The testing samples were fixated to the top of force transducer by using a double sided tape. Each participant sat comfortably next to the measurement apparatus with the fingertip on the sample surface. The same finger from the perception tests were used to measure the friction force. In order to let the participants to have a good control of steady sliding velocity, a few habituated practices were conducted before the friction measurements. The final measurements consisted of five repetitions with no additional external load. During the sliding, the normal force $\left(F_{N}\right)$ and friction force $\left(F_{f}\right)$ were recorded along with the fingertip position. The coefficient of friction COF was calculated for each measurement point as the quotient of friction force and normal force. The same procedure was repeated for all twenty participants on the same samples from experiment \#1 until the finish. 


\subsection{Results and Discussion}

The surface roughness $S a$ of the designs were calculated by the vertical deviations of the designed structures by using Equation (1) with the textural parameters from Table 5.1. The relationship between the measured surface roughness $S a$ and the calculated surface roughness $S a$ was found to be weak $\left(\mathrm{R}^{2}=0.2073\right.$ ) (refer to Fig 5.6). This was caused by the bias of fabrication technique. In this research, all the fabricated samples were from a large set of microstructured samples based on the topographical quality of the texture produced in an EU project (van der Heide et al., 2014). Laser surface texturing was used as the fabrication technique, which is an accurate micro-fabrication method. However, pile up, overlapping and other problems can appear during the fabrication process to affect the accuracy. Moreover, the material itself contained surface roughness before the fabrication, which can influence the results of texture fabrication as well.

The ratio scale of the perceived roughness and perceived stickiness by the participants ranged from 0 to 10 based on the intensity of impression towards the stimulus. The larger numeric range (from 0 to 10) compared to the smaller ratio scale, gave wider perceptual intensity to the individual participants to better describe their natural perception towards the stimulus. In our case, the data of perceptions were normalized into the geometric mean, which is more precise for larger numeric range compared to the arithmetic mean (Skedung et al., 2011). With a data set of $\{a 1, a 2, \ldots, a n\}$, the geometric mean (GM) can be calculated as:

$\left(\prod_{i=1}^{n} a_{i}\right)^{1 / n}=\sqrt[n]{a_{1} \cdot a_{2} \cdots a_{n}}$

where $\mathrm{n}$ is the number of estimations.

The overall data from the perception tests were normalized into the geometric mean and plotted in Fig 5.7. From the perceived stickiness tests, the reference sample $2 \mathrm{G}$ had the highest average 
value of geometric mean with 5.72 (refer to Fig 5.7 a \& Table 5.3). All the textured samples revealed a great reduction of the perceived stickiness. In the comparison of textured samples, the groove patterns LDG-1 and LDG-3 showed the geometric mean of perceived stickiness with 2.96 and 2.78 accordingly, which are slightly smaller than other textured samples ranged from 3.21 to 3.84 (refer to Fig 5.7 a \& Table 5.3). This strongly validated that the designed textures were able to reduce the perceptual attribute of stickiness greatly.

According to the literature, the human skin can perceive the surface roughness in micro-scale level and is sensitive in perceiving a series of fabricated surfaces with wrinkle wavelengths ranging from $300 \mathrm{~nm}$ to $90 \mu \mathrm{m}$ and amplitudes between $7 \mathrm{~nm}$ to $4.5 \mu \mathrm{m}$ (Skedung et al., 2013). In our research. The perceived roughness experiments illustrated that the textured samples have larger perceived roughness ratings from the participants (GM from 3.24 to 5.47) compared to the reference sample $2 \mathrm{G}$ (GM of 1.9) (refer to Fig $5.7 \mathrm{~b}$ ). The depth of surface structure has significant effects on the perceived roughness for the grooved patterns (convex). For the groove patterns with same width ( $\mathrm{W}=100 \mu \mathrm{m}$ ), the sample LDG-1 with depth of $15 \mu \mathrm{m}$ has the GM value of 4.35 for the perceived roughness; for the sample LDG-3 with depth of $30 \mu \mathrm{m}$, the GM value of the perceived roughness increased to 5.47. Same phenomenon was found with the crater samples, the GM values of the perceived roughness on the crater samples increased from 3.83 with depth of $15 \mu \mathrm{m}(\mathrm{C}-2)$ to 5.25 with depth of $30 \mu \mathrm{m}(\mathrm{C}-3)$. For the raised pattern like the grid samples (convex), the height of the surface structure has less effect on the GM values of the perceived roughness, it increased from 3.24 with height of $15 \mu \mathrm{m}$ (HDG-2) to 3.55 with height of $30 \mu \mathrm{m}$ (HDG-3) (refer to Fig $5.7 \mathrm{~b} \&$ Table 5.3).

The normal load is an important factor in both the perception experiments and the friction measurements. In this study, the average normal load of all twenty participants were measured, which ranged from $0.13 \pm 0.03$ to $0.63 \pm 0.22 \mathrm{~N}$ (refer to Fig 5.8 a). This range is consistent with the light touch regime (Delhaye et al., 2014). The average values of coefficient of friction 
(COF) are plotted in Fig 5.8 (b). Overall, the textured samples with designed surface structures significantly decreased the values of $\mathrm{COF}$, which ranged from 0.92 to 1.31 . And, the reference sample $2 \mathrm{G}$ has the highest COF with value of 2.95 (refer to Table 5.3). Moreover, after combining the results of both perception experiments (subjective) and friction/roughness measurements (objective), the relationships between these aspects were revealed. According to Fig 5.9 (a), the perceived stickiness and COF had a strong relationship with a positive polynomial trendline $\left(\mathrm{R}^{2}=0.9543\right)$. In the relationship between COF and the perceived roughness, a negative polynomial correlation is revealed with determination coefficient of 0.9809 (refer to Fig 5.9 b). The textured sample group demonstrated the ability to affect the perceptual attributes of roughness and stickiness associated with less COF compared to the reference sample. From all above, we can conclude that the designed textures in this research have the ability to reduce the friction between the skin and counter-surface under the light touch condition. Also, the perceptual attributes of stickiness and roughness can be influenced significantly (refer to Table 5.3).

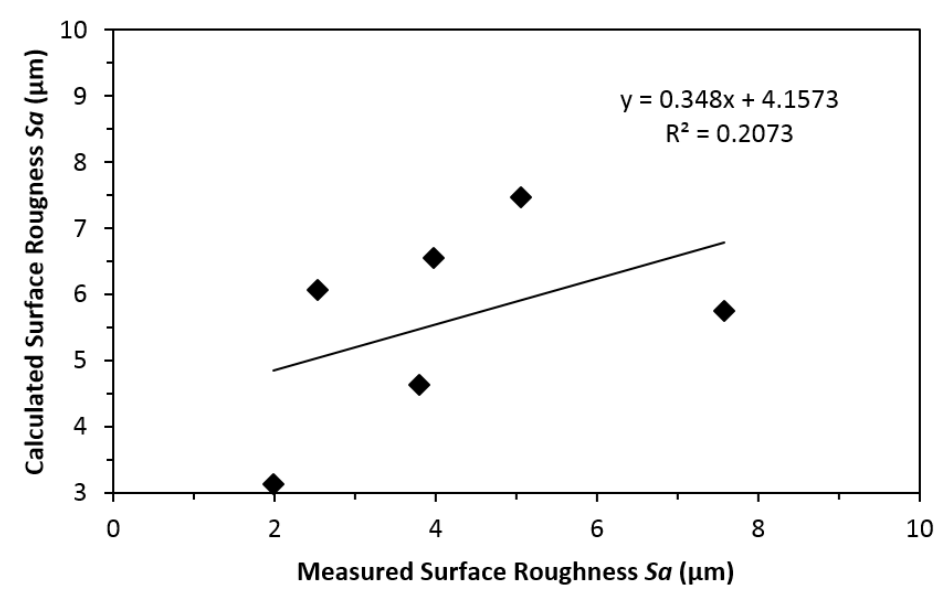

Fig 5.6 Measured surface roughness $S a$ vs. calculated surface roughness $S a$. 


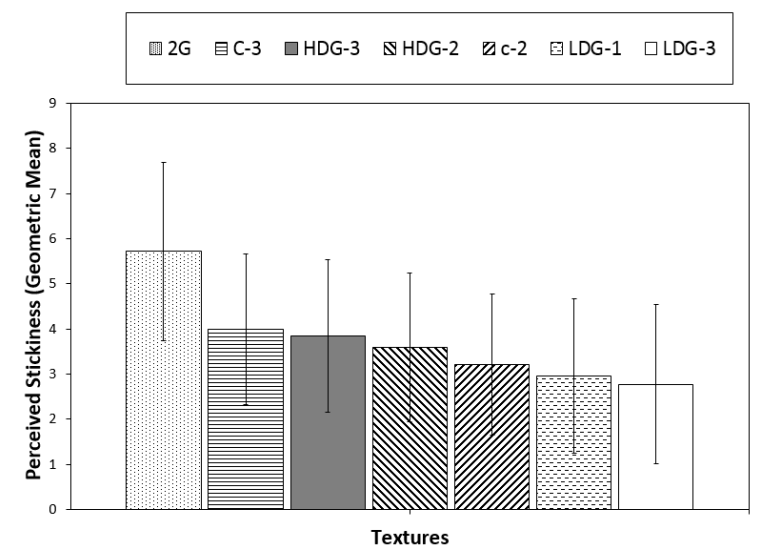

(a)

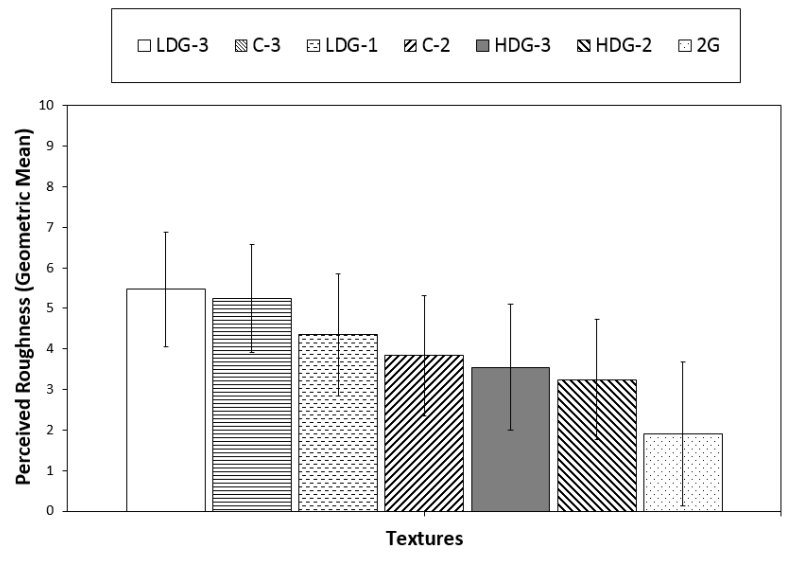

(b)

Fig 5.7 Geometric mean from the perception tests of all samples, (a) perceived stickiness, and (b) perceived roughness.

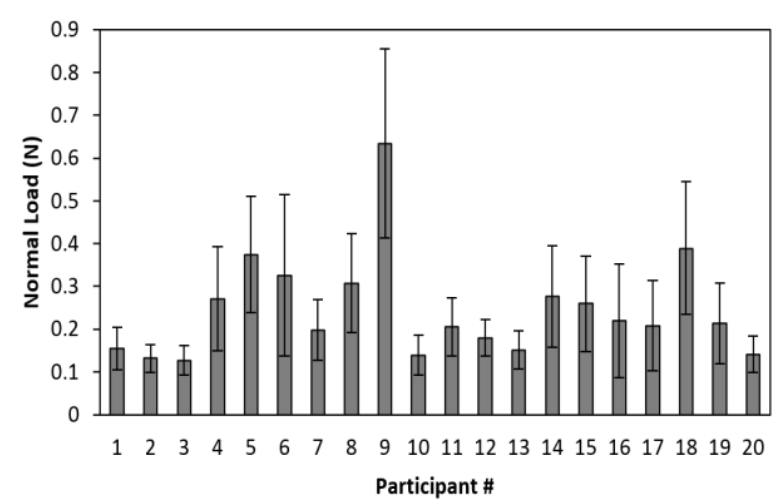

(a)

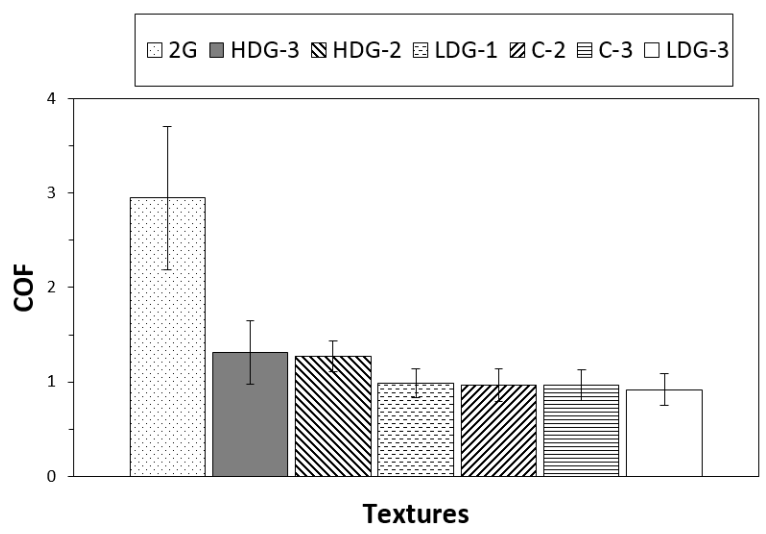

(b)

Fig 5.8 Friction measurements of the participants on the stainless steel samples, average values of (a) normal loads, (b) COF. 


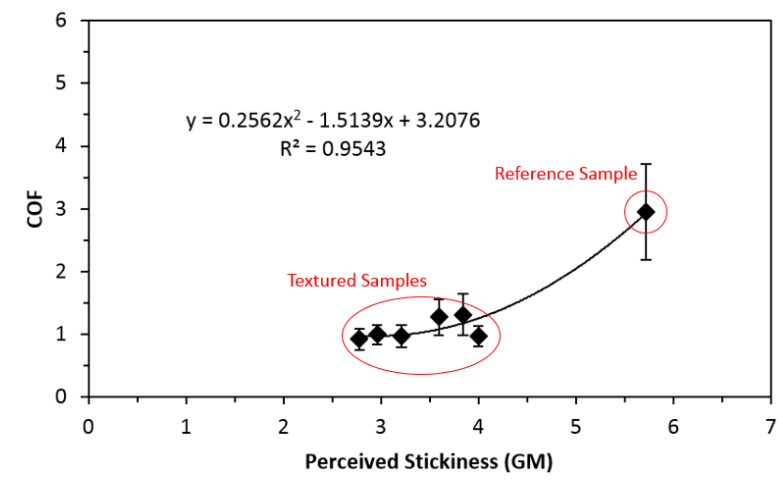

(a)

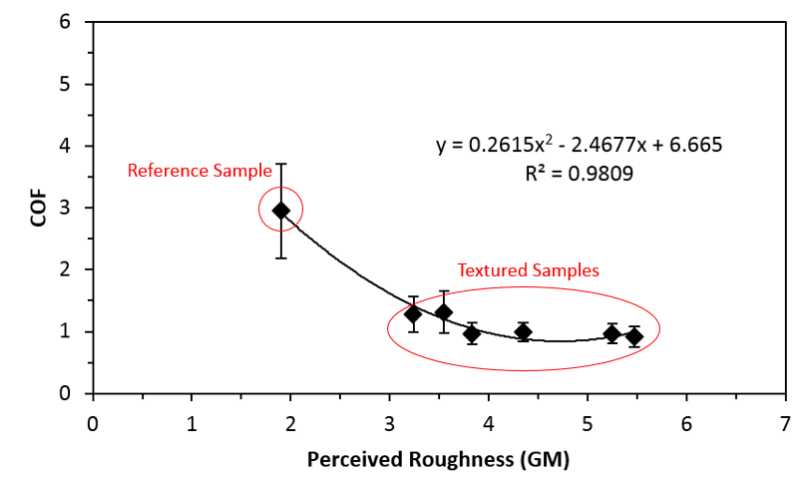

(b)

Fig 5.9 (a) Perceived stickiness (GM) vs. COF; (b) perceived roughness (GM) vs. COF.

Table 5.3. The geometric mean of perceived stickiness, perceived roughness, comfort level of sixteen participants from perception experiments; The average values of surface roughness $S a$ measured by $3 D$ areal confocal ( $\mu$ SURF-mobile, NanoFocus AG, Germany); the average values of COF with standard deviations from friction measurements by a multi-axis force/torque transducer (ATI Industrial Automation, Apex, NC, USA).

\begin{tabular}{lccccc}
\hline \multicolumn{1}{c}{ Sample Name } & $\begin{array}{c}\text { Perceived } \\
\text { Stickiness }\end{array}$ & $\begin{array}{c}\text { Measured } \\
\text { Perceived } \\
\text { Roughness }\end{array}$ & $\begin{array}{c}\text { Surface } \\
\text { Roughness } \boldsymbol{S a} \\
(\boldsymbol{\mu m})\end{array}$ & COF & $\begin{array}{c}\text { Standard } \\
\text { Deviation }\end{array}$ \\
\hline C-2 (Crater) & 3.21 & 3.83 & 4.63 & 0.97 & 0.41 \\
C-3 (Crater) & 4.00 & 5.25 & 5.75 & 0.96 & 0.30 \\
LDG-1 (Groove) & 2.96 & 4.35 & 3.13 & 0.99 & 0.34 \\
LDG-3 (Groove) & 2.78 & 5.47 & 6.56 & 0.92 & 0.30 \\
HDG-2 (Grid) & 3.60 & 3.24 & 6.07 & 1.27 & 0.71 \\
HDG-3 (Grid) & 3.84 & 3.55 & 7.47 & 1.31 & 0.74 \\
2G (Reference) & 5.72 & 1.90 & 0.13 & 2.95 & 1.29 \\
& & & & & \\
\hline
\end{tabular}


In all cases presented above, the friction was generated between the skin and the counter-body during the sliding motion. Through the skin friction, the participants were able to distinguish the degree of perceived stickiness and perceived roughness. According to the research of skin friction, COF is composed of the deformation and adhesion component (Adams et al., 2007; van Kuilenburg et al., 2012).

$\mu=\mu_{d e f}+\mu_{a d h}$

During tactile exploration, the movement of a fingertip against a counter-body is usually at a small normal load (Adams et al., 2012). In this case, the adhesion component is the dominant component over deformation and the friction coefficient can be described by Eq. (4) (Bowden and Tabor, 1986):

$\mu_{a d h}=\frac{\tau A_{\text {real }}}{F_{N}}$

where $A_{\text {real }}$ is the real contact area; $\tau$ is the intrinsic interfacial shear strength; $F_{N}$ is the applied normal load. During the friction measurement experiments, the real contact area between the fingertip and the counter-body cannot be measured. However, the apparent contact area can be predicted and used as a preliminary indicator for the real contact area.

In the light touch regime, skin is exploring the counter-body under the partial contact condition (refer to Fig 5.10). For the partial contact, the apparent contact area $A_{\text {app }}$ consists mainly of the surface area of the contacted zone. Therefore $A_{a p p}$ in contact with the textured counter-body is less compared to the reference sample with no geometric structures (refer to Fig 5.10). Since the real contact area is the fraction of the apparent contact area $\left(A_{\text {real }}<A_{\text {app }}\right)$. As the results show, the real contact area is reduced when the apparent contact area decreases. According to Eq. 4, less contact area between the skin and the counter-body generates less friction force 
during the sliding motion. The apparent contact areas of groove, grid and crater structures can be approximated by Eqs. (5), (6) and (7) respectively:

$A_{\text {app }, \text { groove }}=\pi a^{2}-N w \bar{l}=N(\lambda-w) \bar{l}$

$A_{\text {app }, \text { Grid }}=N \pi r_{\text {grid }}^{2}$

$A_{\text {app }, \text { crater }}=\pi a^{2}-N \pi r_{\text {crater }}^{2}$

$a=\sqrt[3]{\frac{3 R F_{N}}{4 E^{*}}}$

$\frac{1}{E^{*}}=\frac{1-v_{\text {finger }}^{2}}{E_{\text {finger }}}+\frac{1-v_{\text {surface }}^{2}}{E_{\text {surface }}}$

Where $a$ is the contact radius of fingertip in contact with counter-surface predicted by Hertz equation; $N$ is the number of groove, grid or crater structures in contact; $W_{\text {groove }}$ is the width of the groove; $l$ is the length of groove's top portion in contact; $r_{\text {grid }}$ is the radius of grid tip; $r_{\text {crater }}$ is the radius of crater bottom. $E^{*}$ is the effective Young's modulus; $v_{\text {finger }}$ and $v_{\text {surface }}$ are the Poisson ratio of finger and counter-surface accordingly; $R$ is the radius of fingertip. 


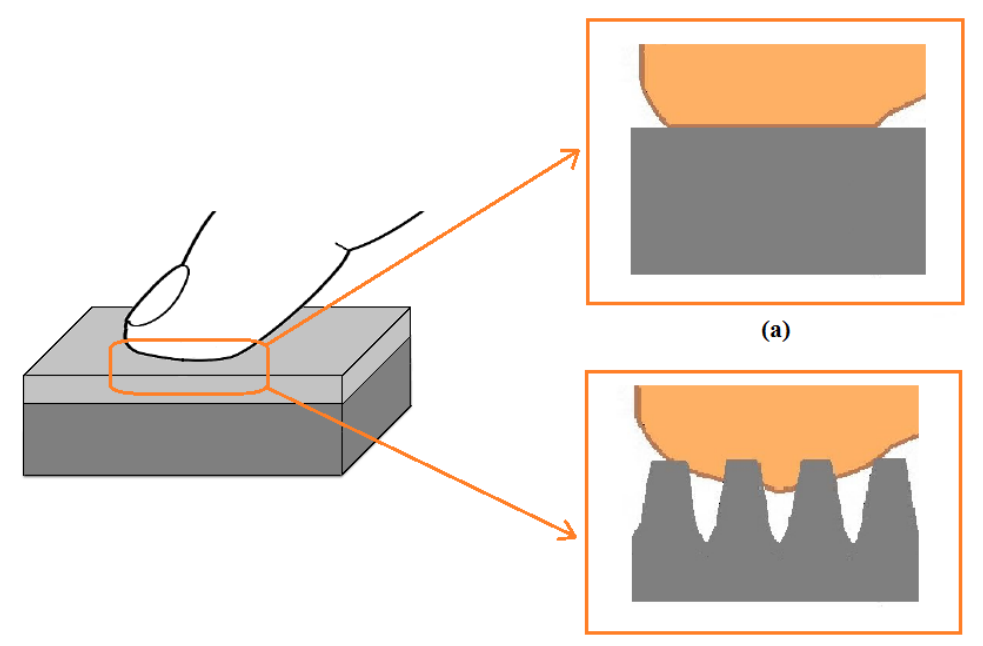

(b)

Fig 5.10 Schematic of the contact between fingertip and (a) the reference sample with no geometric structures; (b) the textured counter-body under the partial contact condition.

In order to further understand the role of apparent contact area in skin friction, $A_{a p p}$ is calculated by using Equations (5), (6), (7), (8) and (9) with the textural parameters from Table 5.1. The average radius of fingertip is approximately $8 \mathrm{~mm}$. In addition, other parameters $\left(\mathrm{E}_{\text {finger }}=0.2\right.$ $\left.\mathrm{MPa}, \mathrm{E}_{\text {stainless_steel }}=150 \mathrm{GPa}, \mathrm{v}_{\text {finger }}=0.48, \mathrm{v}_{\text {stainless_steel }}=0.3\right)$ used in the estimation are from literature (Maeno et al., 1998) (Shao et al., 2010). As shown in Fig 5.11, the estimated apparent contact areas of textured samples are smaller than the reference sample. Also, less skin friction was generated between the skin and the textured samples.

From the literature, convex and concave patterns are generally preferred by humans and able to change the tribological characteristics of the materials (Kawasegi et al., 2013). In this research, the crater and groove textures are designed as concave patterns, and the grid textures are designed as convex pattern. All of designed textures, especially concave patterns (C-2, C-3, LDG-1, LDG-3), revealed the ability to reduce the perceived stickiness and COF due to the decreased contact area. These designed textures have higher surface roughness compared to the non-textured reference sample. With higher surface roughness, lesser contact area is conducted between the fingertip and counter-surface. Furthermore, both the convex and concave textures 
intruded into the fingerprint which inducing the rough sensation during the tactile exploration. Accordingly, the perceived roughness on the textured samples increased which is consistent with the measured surface roughness $S a$.

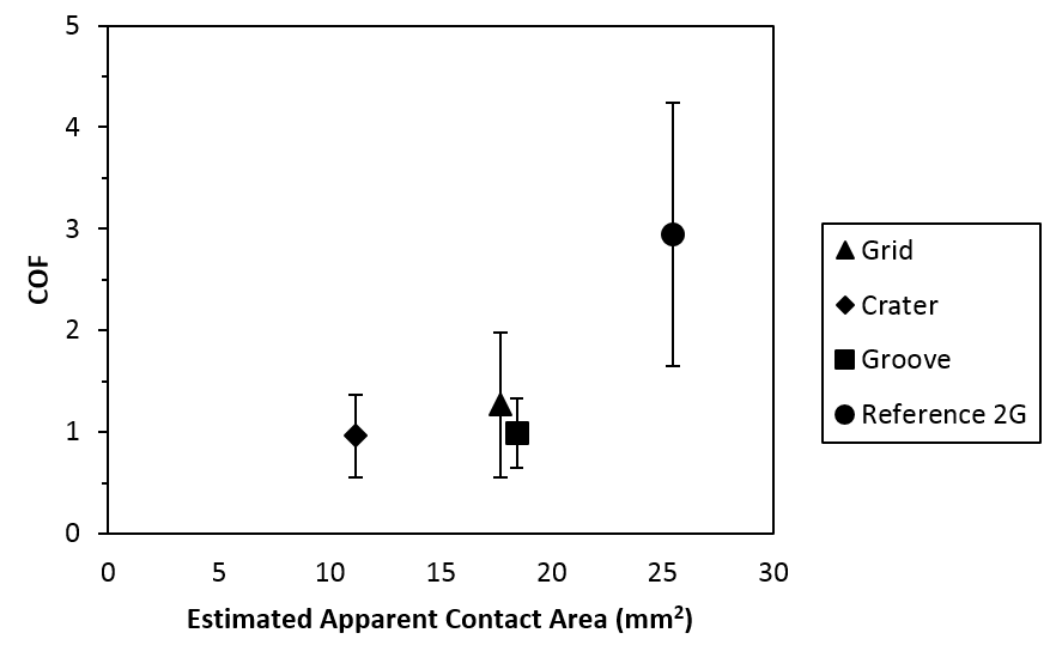

Fig 5.11 COF vs. estimated apparent contact area.

\subsection{Conclusion}

The tactile perception related texture design was investigated in both perception experiments and skin friction measurements under light touch condition. Based on the observed results, textured surfaces with predefined micro-structures were able to influence the participants' perceptual attributes including perceived stickiness and perceived roughness. Both concave (crater, groove) and convex (grid) patterns reduced the perceived stickiness, while on the other hand, the perceived roughness increased.

From the friction study, less skin friction was generated between the textured samples and skin due to the reduction of contact area compared to the reference sample. Concave patterns like 
groove and crater have more advantages of the friction reduction due to less contact area compared to the convex pattern like grid.

Therefore, the geometric type, surface roughness and apparent contact area are important elements of the preliminary textural design for the light touch perception. 


\section{References}

Adams, M.J., Briscoe, B.J., Johnson, B.A., Friction and lubrication of human skin. Tribology Letters, 2007, 263: 239-253.

Adams, M.J., Johnson, S.A., Levere, P., Levesque, V., Haywar, V., Andre, T., Thonnard, J., Finger pad friction and its role in grip and touch. Journal of the Royal Society Interface, 2012, 10(80): 20120467.

Bowden, F.P., Tabor, D., The friction and lubrication of solids, Oxford Science Press, UK, 1986, Chapter 1: 5-32.

Chen X., Barnes, C.J., Childs, T.H.C., Henson, B., Shao, F., Materials' tactile testing and characterization for consumer products' affective packaging design. Materials \& Design, 2009, 30: 4299-4310.

Delhaye, B., Lefevre, P., Thonnard, J.L., Dynamics of fingertip contact during the onset of tangential slip. Journal of The Royal Society Interface, 2014, 11(100): 20140698.

Derler, S., Preiswerk, M., Rotaru, G.-M., Kaiser, J.-P., Rossi, R.M., Friction mechanisms and abrasion of the human finger pad in contact with rough surfaces. Tribology International, 2015, 89:119127.

Etzi, R., Spence, C., Gallace, A., Textures that we like to touch: An experimental study of aesthetic preferences for tactile stimuli. Consciousness and Cognition, 2014, 29: 178-188.

Hendriks, C.P., Franklin, S.E., Influence of surface roughness, material and climate conditions on the friction of human skin. Tribology Letters, 2010, 37: 389-399.

Lackner, J.R., Dizio, P., Jeka, J., Horak, F., Krebs, D., Rabin, E., Precision contact of the fingertip reduces postural sway on individuals with bilateral vestibular loss. Experimental Brain Research, 1999, 126: 459-466.

Lederman, S.J., The perception of surface roughness by active and passive touch. Bull Psychonomic Soc 1981, 18: 253-255.

Lewis, R., Carre, M.J., Tomlinson, S.E., Skin friction at the interface between hands and sports equipment. Procedia Engineering, 2014, 72: 611-617.

Li, Y., Cui, Z., Wang, W., Lin, C., Tsai, H., Formation of linked nanostructured-textured mound-shaped microstructures on stainless steel surface via femtosecond laser ablation. Applied Surface Science, 2015, 324: 775-783.

Luo, K.Y., Wang, C.Y., Li, Y.M., Luo, M., Hua, X.J., Lu, J.Z., Effects of laser shock peening and groove spacing on the wear behavior of non-smooth surface fabricated by laser surface texturing. Applied Surface Science, 2014, 313: 600-606.

Maeno, T., Kobayashi, K., Yamazaki, N., Relationship between the structure of human finger tissue and the location of tactile receptors. JSME International Journal Series C-Mechanical Systems Machine Elements and Manufacturing, 1998, 41(1): 94-100. 
Kawasegi, N., Fujii, M., Shimizu, T., Sekiguchi, N., Sumioka, J., Doi, Y., Evaluation of the human tactile sense to microtexturing on plastic molding surfaces. Precision Engineering, 2013, 37: 433-442.

Kelly, E.J., Terenghi, G., Hazari, A., Wiberg, M., Nerve fibre and sensory end organ density in the epidermis and papillary dermis of the human hand. Br J Plast Surg, 2005, 58:774-779

Klatzky R.L., Pawluk, D., Peer, A., Haptic perception of material properties and implications for applications. Proceedings of the IEEE, 2013, 101: 2081-2092.

Maricich M. S., Wellnitz, A.S., Nelson M. A., Lesniak, R. D., Gerling, J. G., Lumpkin, A. E., Zoghbi, Y. H., Merkel cells are essential for light-touch responses. Science, 2009, 324(5934): 15801582.

Maricich, S.M., Morrison, K.M., Mathes, E.L., Brewer, B.M., Rodents rely on Merkel cells for texture discrimination tasks, The Journal of Neuroscience, 2012, 32 (10):3296-3300.

Mizuhara, K., Hatano, H., Washio, K., The effect of friction on the usability of touchpad, Tribology International 2013, 65:326-335

Pailler-Mattei, C., Bec, S., Zahouani, H., In vivo measurements of the elastic mechanical properties of human skin by indentation tests. Medical Engineering \& Physics, 2008, 30: 599-606.

Ramalho, A., Silva, C.L., Pais, A.A.C.C., Sousa, J.J.S., In vivo friction study of human skin: influence of moisturizers on different anatomical sites. Wear, 2007, 263: 1044-1049.

Scaraggi, M., Mezzapesa P.F., Carbone, G., Ancona, A., Sorgente, D., Mario Lugara, P., Minimize friction of lubricated laser-microtextured-surfaces by tuning microholes depth. Tribology International, 2014, 75: 123-127.

Shao, F., Childs, T.H.C., Barnes, C.J., Henson, B., Finite element simulations of static and sliding contact between a human fingertip and textured surfaces. Tribology International, 2010, 43: 2308-2316.

Skedung, L., Arvidsson, M., Chung, J.Y., Stafford, C.M., Berglund, B., Rutland, M.W., Feeling small: exploring the tactile perception limits. Scientific Reports, 2013, 3: 1-6.

Skedung, L., Danerlov, K., Olofsson, U., Johannesson, C.M., Aikala, M., Kettle, J., Arvidsson, M., Berglund, B., Rutland, M.W., "Tactile perception: Finger friction, surface roughness and perceived coarseness," Tribology International, 2011, 44: 505-512.

Sutu, A., Meftah, E., Chapman, C.E., Physical determinants of the shape of the psychophysical curve relating tactile roughness to raised-dot spacing: implications for neuronal coding of roughness. Journal of Neurophysiology, 2012, 109: 1403-1415.

Tomlinson, S.E., Carre, M.J., Lewis, R., Franklin, S.E., Human finger contact with small, triangular ridged surfaces. Wear, 2011, 271: 2346-2353.

Van Kuilenburg, J., Masen, M.A., Groenendijk, M.N.W., Bana, V., van der Heide, E., An experimental study on the relation between surface texture and tactile friction. Tribology International, 2012, 48: $15-21$.

Van Kuilenburg, J. Masen, M.A., Van der Heide, E.. A review of fingerpad contact mechanics and friction and how this affects tactile perception. Proceedings of the IMechE Part J: Journal of Engineering Tribology, 2015, 229(3): 243-258. 
Van der Heide, E. Schipper, D.J., On frictional heating in single summit contacts: towards failure at asperity level in lubricated systems. ASME Journal of Tribology, 2004, 126 (2): 275-280.

Van der Heide, E., Saenz de Viteri, V., Rodringuez-Vidal, E., Pagano, F., Wadman, B., Wiklund, D., Matthews, D.T.A., Contreras Fortes, J., Zhang, S., Steel sheet surfaces with enhanced tactile feel, European Commission Research Programme of the Research Fund for Coal and Steel, RFSR-CT-2011-00022, 2011-2014.

Wang, T., Xie, L., Wang, X., Shang, T., 2D and 3D milled surface roughness of high volume fraction $\mathrm{SiCp} / \mathrm{Al}$ composites. Defence Technology, 2015, 11: 104-109.

Whitaker, T., Simoes-Franklin, C. Newell, N. F., Vision and touch: independent or integrated systems for the perception of Texture. Brain Research, 2008, 1242: 59-72.

Zahouani, H. Boyer, G., Pailler-Mattei, C., Ben Tkaya, M.B., Vargiolu, R., Effect of human ageing on skin rheology and tribology. Wear, 2011, 271: 2364-2369.

Zimmerman, A., Bai, L., Ginty, D.D., The gentle touch receptors of mammalian skin. Science, 2014, 346 (6212): 950-953

Zhang, S., Rodriguez Urribarri, A., Morales Hurtado, M., Zeng, X., van der Heide, E., The role of the sliding direction against a grooved channel texture on tool steel: An experimental study on tactile friction. International Journal of Solids and Structures, 2015, 56-57: 53-61. 


\title{
Chapter 6
}

\section{Finger Pad Friction and Tactile Perception of Laser Treated, Stamped and Cold Rolled Micro-structured Stainless Steel Sheet Surfaces*}

\begin{abstract}
Tactile perception is a complex system, which depends on frictional interactions between skin and counter-body. The contact mechanics of tactile friction is governed by many factors such as the state and properties of skin and counter-body. The question is: what is the connection between perception and tactile friction? And, how is it related to pleasant touch? In order to solve the puzzle, both perception experiments (subjective) and tactile friction measurements (objective) were performed in this research. The perception experiments were carried out by using a panel test method to identify the perceived roughness, perceived stickiness and perceived comfort level from the participants. For the friction experiments, tactile friction was measured by a multiaxis forceltorque transducer in vivo. The perceived stickiness was illustrated as an affective subjective stimulus, which has a negative correlation to the comfort perception. No significant evidence was revealed to the connection between the perceived roughness and comfort perception. Furthermore, the dynamic tactile friction was concluded as an objective stimulus to the comfort perception with a negative correlation.
\end{abstract}




\subsection{Introduction}

Tactile comfort, a concept with a mechanical, physiological and a psychological perspective, is of particular concern to industry and academia. The hedonic attributes of tactile comfort are influential to our daily life like wearing clothes, using personal care products, holding tool handles or in domestic appliances [1], [2], [3]. In the case of designing hand tools, the relationships of comfort descriptors and comfort factors with users' experiences have been investigated, and the relation with skin friction to enhance the comfort level of products is described in detail [4], [5] [6]. In a more prosaic case, the degree of comfort in tactile contact between the skin and stainless steel surface for domestic appliances greatly affects the quality of our daily life. Stainless steel is one of the most common materials used in automobile, architecture, kitchenware, medical applications, etc. However, the study of perception and friction on stainless steel material is limited. The enhancement of tactile comfort in daily interaction with stainless steel products can directly increase the customers' satisfaction by the stimulation of the somatosensory system in a positive way. A higher added value could be created by understanding the stimulus parameters and pleasantness factors [7] validated by an experimental approach for stainless steel sheet material.

A basic understanding of the skin anatomy is important to tactility-related research. The skin has a complicated structure composed of three main layers: epidermis, dermis and hypodermis [8]. Each layer has a different composition, thickness, hydration degree and mechanical properties [9]. In addition, the state and properties are a function of the body region, age, degree of hydration or nutritional condition as well [10], [11], [12], [13], [14], [15]. Overall, the skin behaves in a viscoelastic, non-homogeneous, nonlinear and anisotropic manner under load. 
From the psychological perspective, humans are able to distinguish multidimensional textural stimuli including sensations of roughness versus smoothness, hardness versus softness, stickiness versus slipperiness, and warmth versus coolness. However, the overall textural perception of a counter surface is essentially determined by the following three surface properties: hardness, roughness and stickiness [16]. In this work, stainless steel sheet samples were used with the same thermal properties and within the same hardness range, therefore, only roughness and stickiness were variables in this research.

In total, five surface textures are analyzed: four deterministic surface textures with specific geometric shapes, designed for this research, and one conventionally finished sample (2G finish) as reference. Three different surface fabrication methods, i.e. laser surface texturing, stamping (or pressing) and cold rolling were used to produce the experimental surface textures on stainless steel samples. This combination of production technologies is unique and not reported before in surface haptic related research. The objective of this research is to investigate the relationship between tactile comfort and friction, specifically for stainless steel sheet surfaces. 


\subsection{Methods}

\subsubsection{Subjects and Conditions}

The finger friction measurements and perception experiments were performed in a controlled laboratory having an ambient temperature of $20 \pm 1{ }^{\circ} \mathrm{C}$ and relative humidity of $50 \pm 10 \%$. The total number of subjects were sixteen (eight female and eight male volunteers) aged from 20 to 30 years with no known skin disease. All tests were conducted on the middle finger of the nondominant hand to avoid any bias, because the dominant finger (index finger) of the dominant hand can have more wear of the finger ridges due to frequent daily use. No external skin care was used prior to the experiments. The fingertips were cleaned with alcohol and air-dried for ten minutes before testing. A Corneometer CM 825 (Courage+Khazaka GmbH, Germany) was used to measure the hydration level of the skin before the experiments. The range of hydration level of all subjects was $62 \sim 120$ AU. The evaluation of hydration related skin types can be categorized by arbitrary units (AU) into: very dry skin (<30 AU), dry skin ( $30 \sim 40 \mathrm{AU})$, normal skin $(40 \sim 100 \mathrm{AU})$, wet skin $(100 \sim 120 \mathrm{AU})$, very wet skin (>120 AU) [41].

\subsubsection{Testing Objects}

Five stainless steel EN-1.4301 plates, four textured and one conventionally finished surface $2 \mathrm{G}$, were used in the tests (see Table 6.1 and Figure $6.1 \& 2$ ). The $1 \mathrm{~mm} \times 1 \mathrm{~mm}$ area of each sample was measured by a three-dimensional (3D) areal confocal ( $\mu$ SURF-mobile, NanoFocus AG, Germany) with a $20 \mathrm{x}$ objective (height resolution $=63 \mathrm{~nm}$ ) and a $4 \mu \mathrm{m}$ filter. Research in the field of Engineering Technology suggests 3D roughness parameters give better information on the surface compared to two-dimensional (2D) roughness parameters on the flat surface structures [17]. Therefore, surface of the samples were measured in 3D surface roughness $S a$ in this work. 
All samples were using the same stainless steel sheet material EN-1.4301 with different surface texture produced by various fabrication methods and taken from a large set of microstructured samples based on the topographical quality of the texture produced in an EU project [44]. Sample 1HV90 was fabricated by a stamping method with tools that contain the negative of a crater pattern (see Figure 6.2 a). The grid pattern on sample 1HV90 with 1\% elongation was produced by cold rolling with rolls that contain the negative of the pattern (see Figure $6.2 \mathrm{~b}$ ). The low density grid pattern on sample LDG-3 (see Figure $6.2 \mathrm{~d}$ ) was produced by direct laser surface texturing with a nano-second laser, and the high density grid pattern on sample HDG-1 (see Figure $6.2 \mathrm{c}$ ) was fabricated by direct laser surface texturing (LST, pico-second laser). The sample $2 \mathrm{G}$, produced by cold rolling and subsequent skin pass rolling, was used as received condition and served as a reference specimen for comparison (see Figure $6.2 \mathrm{e}$ ). The samples 1HV90, LDG-3 and HDG-1 are specifically designed for touch perception, and produced for the first time. 
Table 6.1 The surface parameters of the samples with depth (D), spacing ( $\lambda)$, width $(W), 3 D$ surface roughness $(S a)$ were measured by $3 D$ areal confocal ( $\mu S U R F$-mobile, NanoFocus AG, Germany).

\begin{tabular}{lccccccc}
\hline $\begin{array}{c}\text { Sample } \\
\text { Name }\end{array}$ & $\begin{array}{c}\text { Fabrication } \\
\text { Method }\end{array}$ & $\begin{array}{c}\text { Surface } \\
\text { Texture }\end{array}$ & $\begin{array}{c}\text { Sample Size } \\
{[\mathbf{m m}]}\end{array}$ & $\begin{array}{c}\text { Depth D } \\
{[\boldsymbol{\mu} \mathbf{m}]}\end{array}$ & $\begin{array}{c}\text { Width W } \\
{[\boldsymbol{\mu m}]}\end{array}$ & $\begin{array}{c}\text { Spacing } \lambda \\
{[\boldsymbol{\mu m}]}\end{array}$ & $\begin{array}{c}\text { Sa } \\
{[\boldsymbol{\mu m}]}\end{array}$ \\
\hline $\mathbf{1 H V 9 0}$ & Stamping & Crater & $35 \times 65 \times 1$ & 20 & 50 & 50 & 0.49 \\
$\mathbf{1 H V 9 0 - 1 \%}$ & Cold Rolling & Grid & $35 \times 65 \times 1$ & 20 & 50 & 60 & 1.34 \\
HDG-1 & LST & Grid & $35 \times 35 \times 1$ & 30 & 75 & 90 & 4.02 \\
LDG-3 & LST & Grid & $35 \times 35 \times 1$ & 30 & 100 & 115 & 6.56 \\
$\mathbf{2 G}$ & Cold Rolling & - & $35 \times 65 \times 1$ & - & - & - & 0.13 \\
& & & & & & & \\
\hline
\end{tabular}

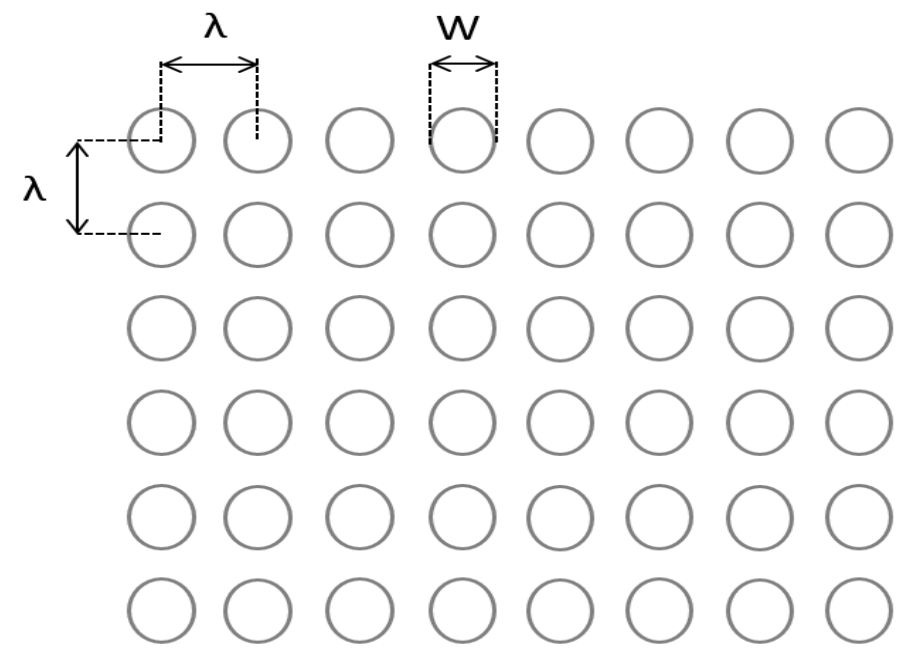

Fig 6.1 Texture parameters for crater and grid structures. 


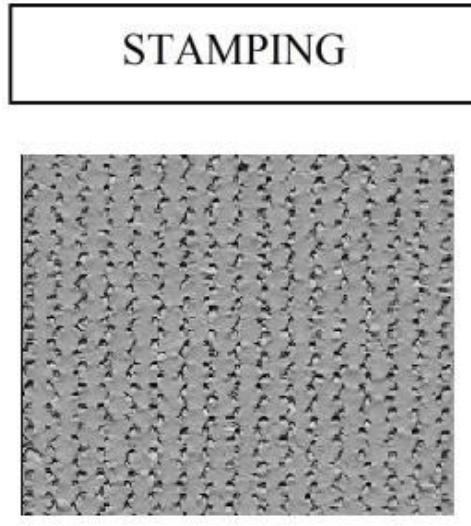

(a)

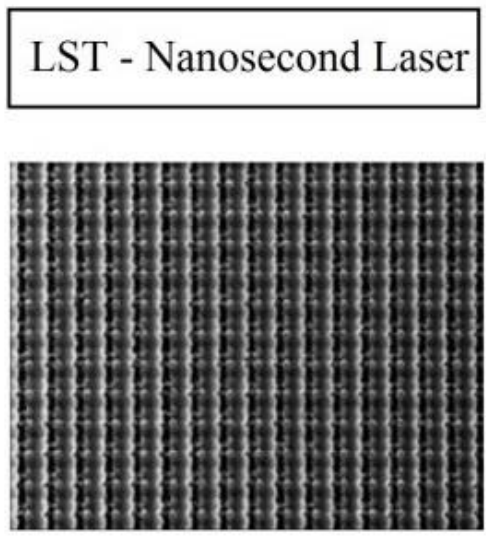

(d)
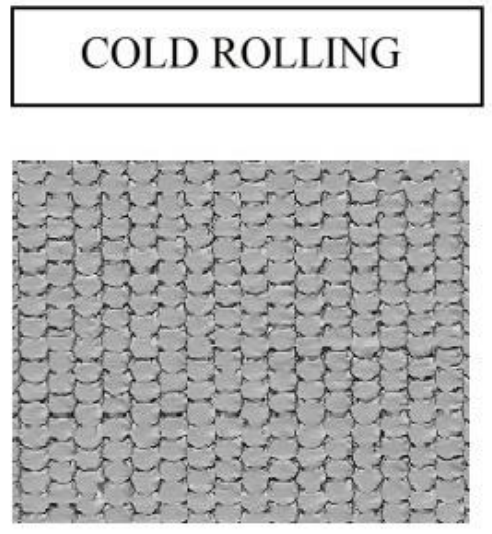

(b)
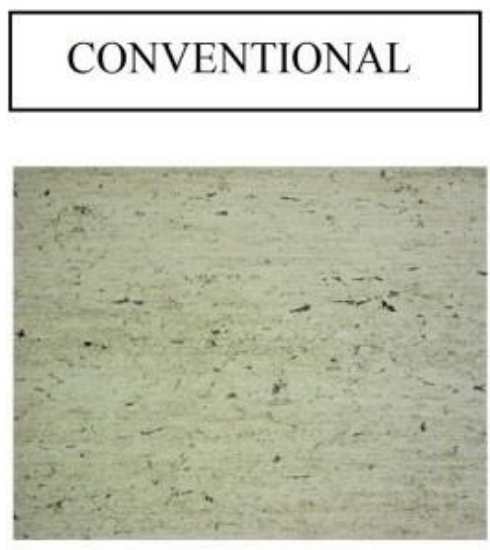

(e)

\section{LST - Picosecond Laser}

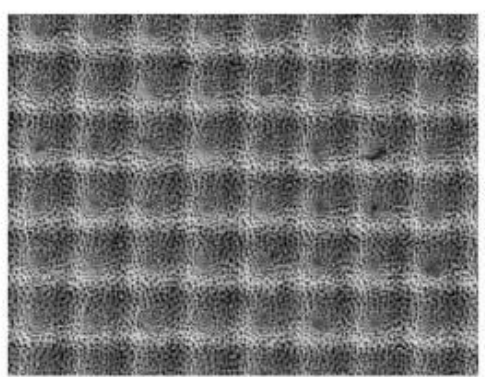

(c)

Fig 6.2 Confocal microscope images of sample (a) 1HV90 (stamping), (b) 1HV90-1\% (cold rolling), and (e) 2G (reference); SEM images of sample (c) HDG-1 and (d) LDG-3. Measured 3D surface roughness Sa were conducted by 3D areal confocal ( $\mu$ SURF-mobile, NanoFocus AG, Germany) 


\subsubsection{Testing Methods}

The experiments were conducted in two parts: perception experiments (subjective rating) and tactile friction measurements (objective measurement). First, the perception experiments were carried out by using a panel test method to identify the perceived roughness, perceived stickiness and comfort level from the subjects (see Figure 6.3 a). The study of Witaker et al. shows both vision and touch are able to contribute information to the perception of texture in an independent but complementary manner [18]. The exposure of the object to a visual stimulus can increase or decrease the preference during the touch perception [19]. Therefore, all the participants were blindfolded to avoid vision interference on perception and focus on touch perception only. Before the perception experiments, the participants (all master students from an English-based course) were explained by the author in English, and any rising questions were answered to clear the doubts. The four samples having designed textures and one reference stainless steel samples were presented to the subjects in random order. The subjects were requested to use the middle finger of their non-dominant hand to touch and slide along the sample surface toward the body. The same sliding direction was performed in the friction measurements. According to the previous study, the sliding direction to the texture can alter the dynamic tactile friction between the fingertip and the counter-surface [24]. During the perception tests, the subject had unlimited time to explore the sample before reporting a judgment. The ratings from 0 to 10 were graded by each subject to describe the level of perceived roughness, perceived stickiness and perceived comfort. The lower number in perceived roughness indicated the least touch perception of surface roughness, on the contrary, the higher number indicated the greater roughness perception. The same ten-point scale was used for the perception of surface stickiness and comfort level. In addition, the subjects may touch and slide the samples more than one time before the grades were given. 
For the friction experiments, a multi-axis force/torque transducer (ATI Industrial Automation, Apex, NC, USA) was used to measure dynamic skin friction in vivo (see Figure $6.3 \mathrm{~b}$ ). This apparatus, described in full detail in [24], is able to measure the outputting forces and torques from all three Cartesian coordination ( $\mathrm{x}, \mathrm{y}$, and $\mathrm{z}$ ) with the resolution of $25 \mathrm{mN}$ in normal direction and $12.5 \mathrm{mN}$ in tangential direction. Double sided tape was used to firmly fix the testing samples to the top of the force transducer. The same fingers used during the perception tests were used to perform sliding motion on the samples towards the body. Each friction measurement consisted of five repetitions of sliding motion. All participants were instructed to slide in a stable and natural way with no external load. The range of the resulting average normal force was from 0.12 to $0.63 \mathrm{~N}$ which can be regarded as light touch conditions $(<1 \mathrm{~N})$ (see Figure 6.4) [20]. The stroke length was $30 \mathrm{~mm}$ for all samples. During the tests, the sliding velocity was kept as constant as possible. The sliding velocity of each friction measurement was recorded by the force transducer. In this manner, the data of friction force and normal load were acquired with a sampling rate of $100 \mathrm{~Hz}$. The values of friction coefficient (COF) were calculated as the ratio of friction force $F_{f}$ and normal load $F_{N}\left(C O F=\frac{F_{f}}{F_{N}}\right)$ accordingly. 


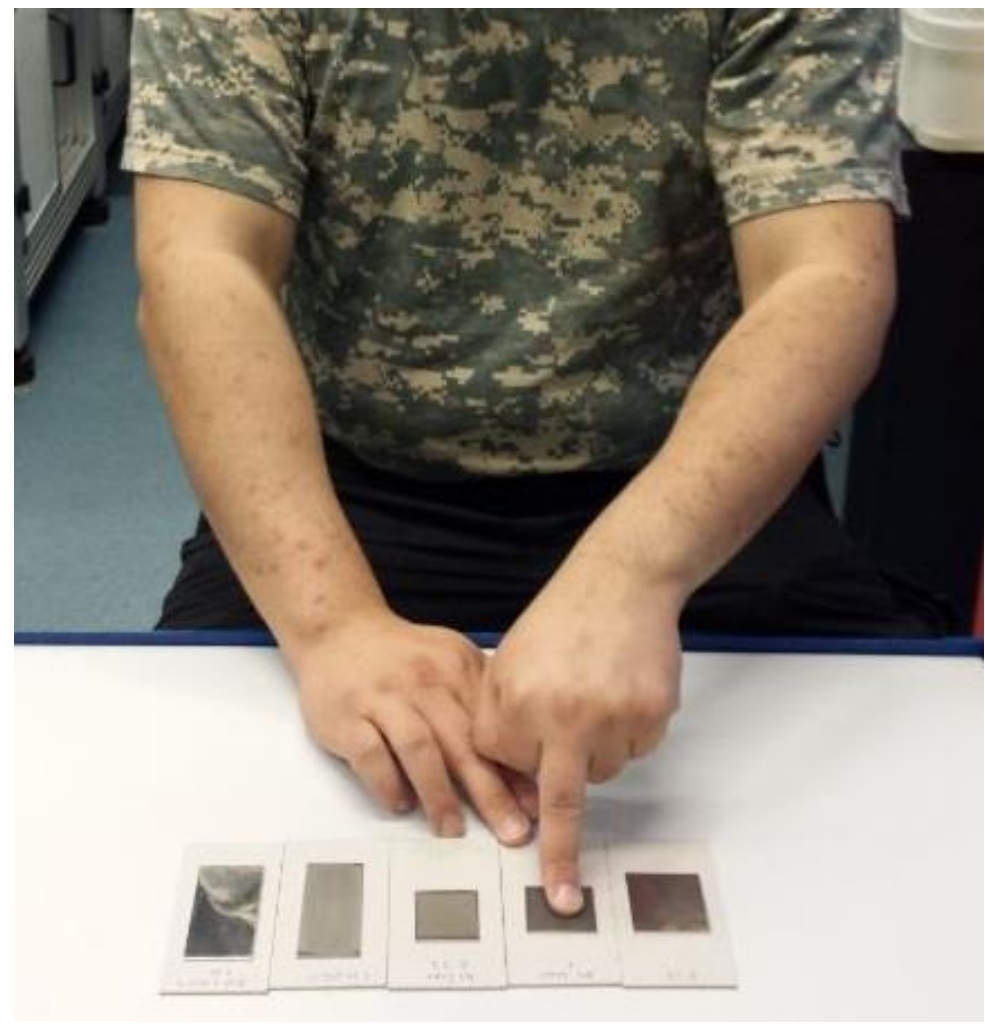

(a)

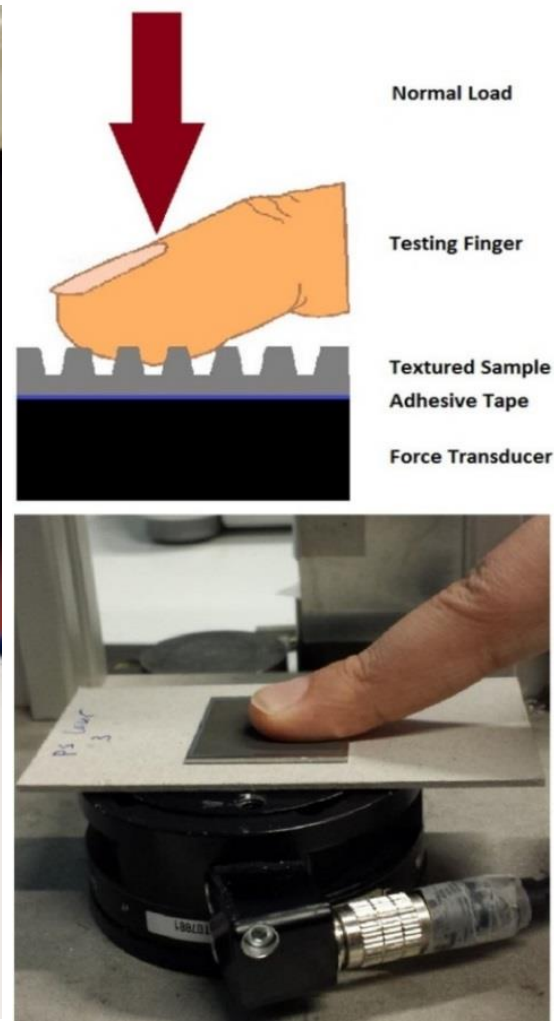

(b)

Fig 6.3 (a) Perception experiment (blindfolded); (b) Friction measurement set-up. 


\subsection{Results and discussion}

\subsubsection{Friction Measurements}

The dynamic friction measurements of all sixteen participants on the stainless steel samples are plotted in the Fig 6.5, and the average values of COF for the five samples were sorted in decreasing order in the Fig 6.6. From Fig 6.5 it shows that certain participants slide their finger pad with higher values of the friction force than other participants, although the counter surface has the same topography. This phenomenon is related to the system dependence of friction, which could be caused by many factors including the resulting contact area, hydration level of skin, and applied load. These factors can be understood from the well-described two-term friction model, for skin friction, which consists of both an adhesive and a deformation component of friction [21]. Related studies show that adhesive component of friction plays the dominant role in skin friction and greatly depends on the real contact area [22], [23].

$F_{f, a d h}=\tau \cdot A_{\text {real }}$

Where $A_{\text {real }}$ is the real contact area; $\tau$ is the shear strength of the interface.

According to the study, the contact radius (a) of the fingertip in contact with counter-surface can be predicted by the Hertzian equation for a point contact [24].

$a=\sqrt[3]{\frac{3 R F_{N}}{4 E^{*}}}$

$\frac{1}{E^{*}}=\frac{1-v_{\text {finger }}^{2}}{E_{\text {finger }}}+\frac{1-v_{\text {surface }}^{2}}{E_{\text {surface }}}$

Where $F_{N}$ is the normal load; $E^{*}$ is the effective Young's modulus; $R$ is the radius of the fingertip; $v_{\text {finger }}$ and $v_{\text {surface }}$ are the Poisson ratio of finger and counter-surface accordingly. 
With the concern of fingerprint structure, a modified Westergaard model can be used to describe the contact width $2 a$ [42].

$$
\begin{aligned}
& 2 a=\frac{2 \lambda}{\pi} \sin ^{-1}\left(\frac{\bar{p}}{p^{*}}\right)^{1 / 2} \\
& p^{*}=\pi E^{*} \Delta / \lambda
\end{aligned}
$$

Where $\lambda$ is spacing (or wavelength); $\bar{p}$ is mean surface pressure; $p^{*}$ is the pressure needed for full continuous contact; $\Delta$ is the amplitude. The aspect ratio and real contact area depends on the interaction between the fingerprints and the surface structure. For reasons of simplicity, however, the effect of fingerprint was not taken into account in this paper.

The hydration level is another important element of skin friction. Related studies suggest that the increased hydration level of skin can increase the values of COF [26], [27], [28]. With the same real contact area, the moist skin is getting softer with a lower elastic modulus, which leads to the increase of the adhesive component of friction [29]. In our case, the hydration level of all participants ranged from $62 \mathrm{AU}$ to $120 \mathrm{AU}$ with an average value of $90.9 \pm 17.8 \mathrm{AU}$.

Furthermore, the relationship between the normal load and COF needs to be discussed. In the literature, a linear relationship was found over the load range of $1 \mathrm{~N}$ [25] [35]. In our case, the overall normal load ranged from $0.13 \mathrm{~N}$ to $0.63 \mathrm{~N}$ with an average normal load of $0.25 \pm 0.12$ $\mathrm{N}$, and the lower normal loads were slightly employed with the higher values of COF (see Figure 6.7). Moreover, the sliding velocity can affect the frictional response as well. The force transducer recorded the sliding velocity of each friction measurement, and the variation of sliding velocity is not too large for each participant. For instance, participant \#1 has an average sliding velocity of $27.7 \pm 12.7 \mathrm{~mm} / \mathrm{sec}$. However, the sliding velocity of all participants ranged from $24.5 \mathrm{~mm} / \mathrm{sec}$ to $123.8 \mathrm{~mm} / \mathrm{sec}$. According to the research conducted by Tang et al., as the sliding velocity increases, the dynamic tactile friction increases accordingly due to the 
hysteretic friction with more energy lost in elastic hysteresis [43]. Therefore, the variations of dynamic skin friction from Fig 6.5 can be explained by contact area, hydration level and sliding velocity of each subject. From Fig 6.6, it shows that even with the influence described above, certain texture shows higher average value of COF, for example, the texture 1HV90 (crater) has the highest COF compared to others.

More importantly, the surface roughness of the counter-surface was investigated. The measured values of the 3D surface roughness $S a$ are listed in Table 6.1 which shows that the laser surface textured samples in general are rougher than both the stamped samples and the reference sample. The 3D surface roughness $S a$ of the texture denotes the average vertical deviation at the location of the measured surface area, and is greatly influenced by the height of pattern. Compared to the line roughness $R a$, the $3 \mathrm{D}$ surface roughness $S a$ is conducted in a areal measurement which is more accurate to describe the surface characteristic in roughness. In this research, the reference stainless steel sample (2G) had the lowest 3D surface roughness $\mathrm{Sa}$. As shown in Fig 6.8, a significant reduction in $C O F$ is observed with the sample of higher surface roughness, and illustrating that higher 3D surface roughness $S a$ result in lower tactile friction with a determination coefficient of 0.8313 . A similar phenomenon is found in the study of Derler [29], that the adhesive component of skin friction is reduced when sliding against a rough glass surface. When in contact with the rougher surface, the skin has a smaller real contact area, and lower friction force is generated. Under a constant normal force, the coefficient of friction is reduced significantly, in the current case with $250 \%$. 


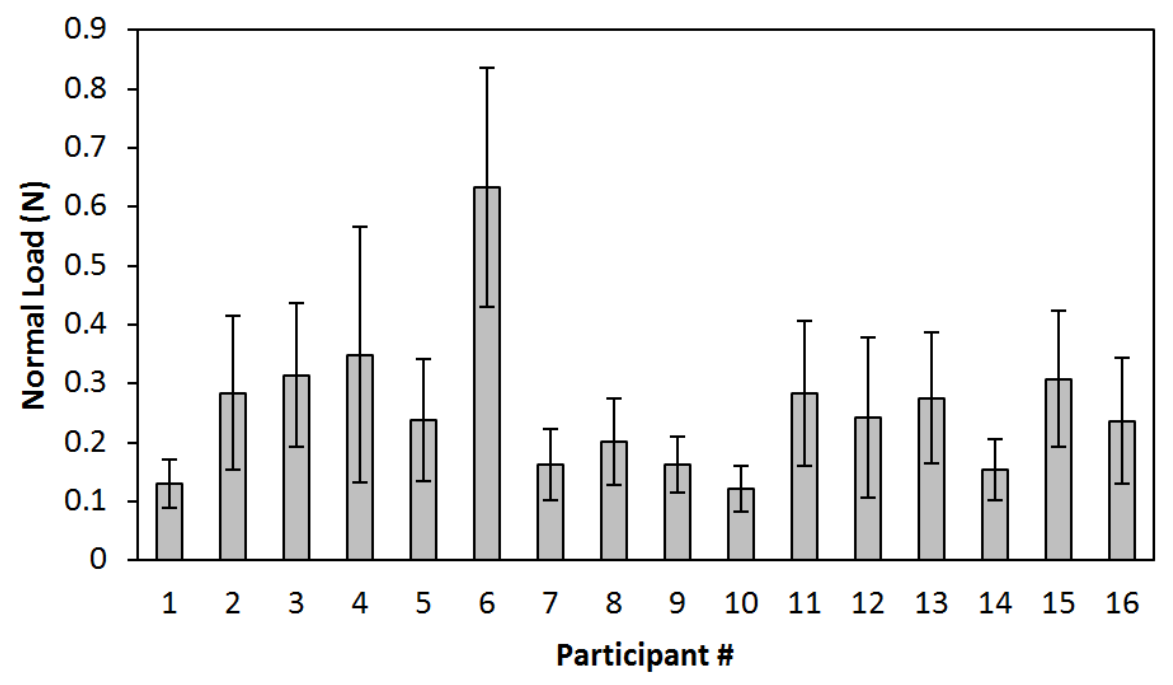

Fig 6.4 The average applied normal load (with standard deviation) of each participant during friction measurements.

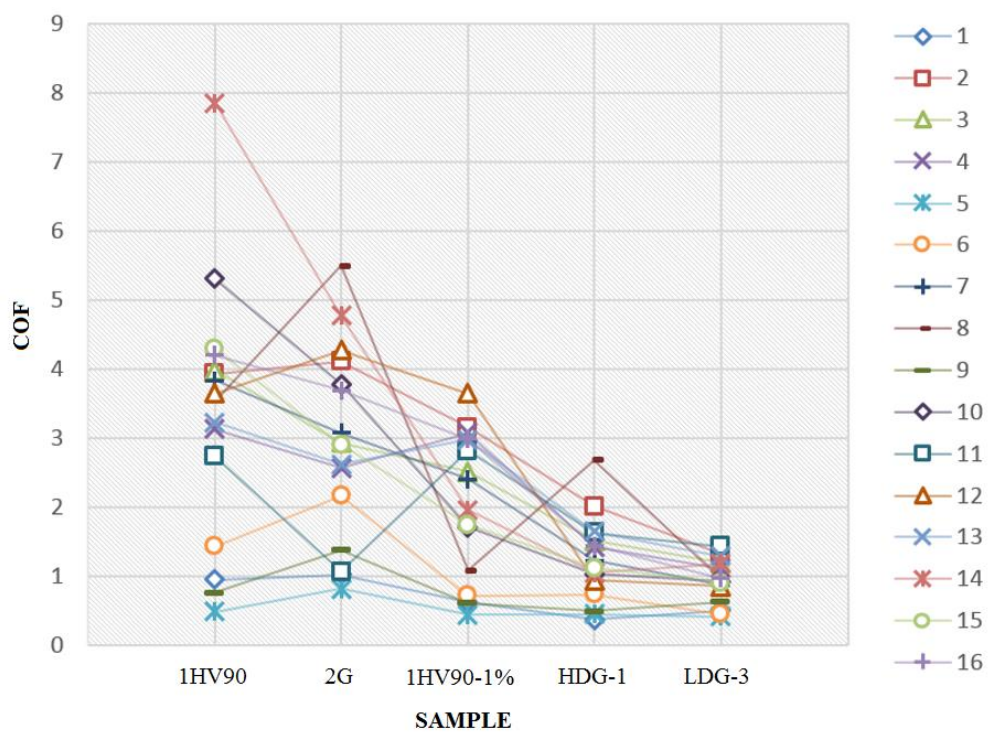

Fig 6.5 Finger friction measurements of the participants on the stainless steel samples. 


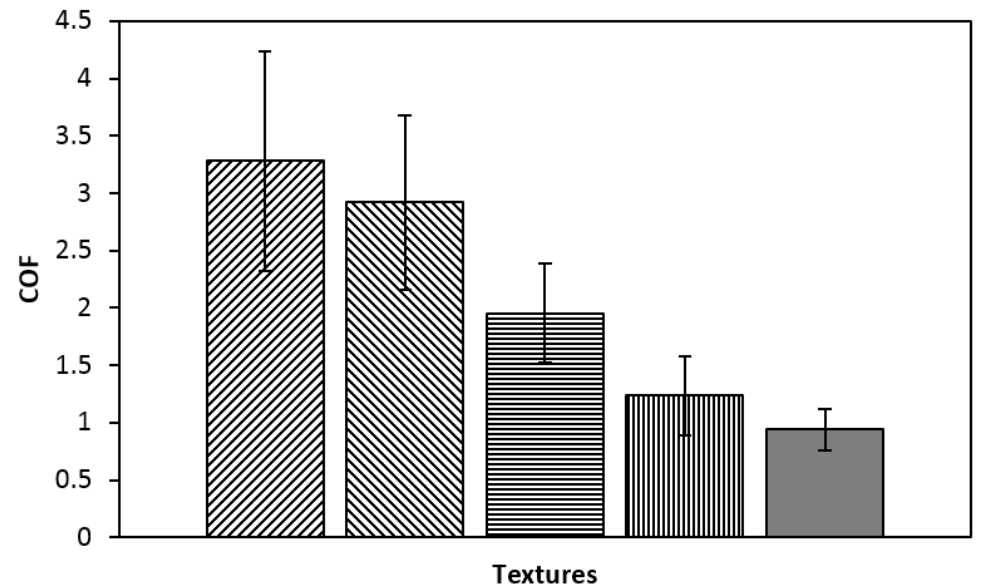

Fig 6.6 The average values of COF of the dynamic friction measurments (five sliding cycles) for the 5 samples, sorted in decreasing order.

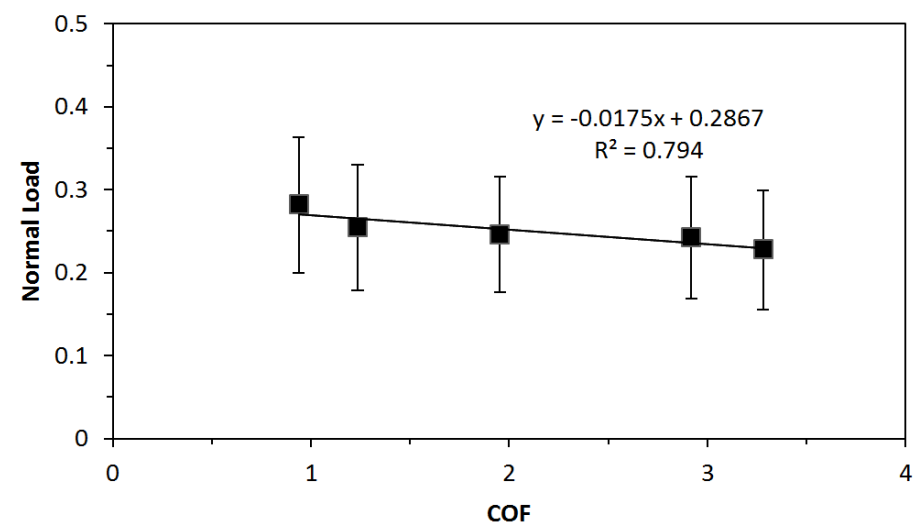

Fig 6.7 The average normal load versus COF.

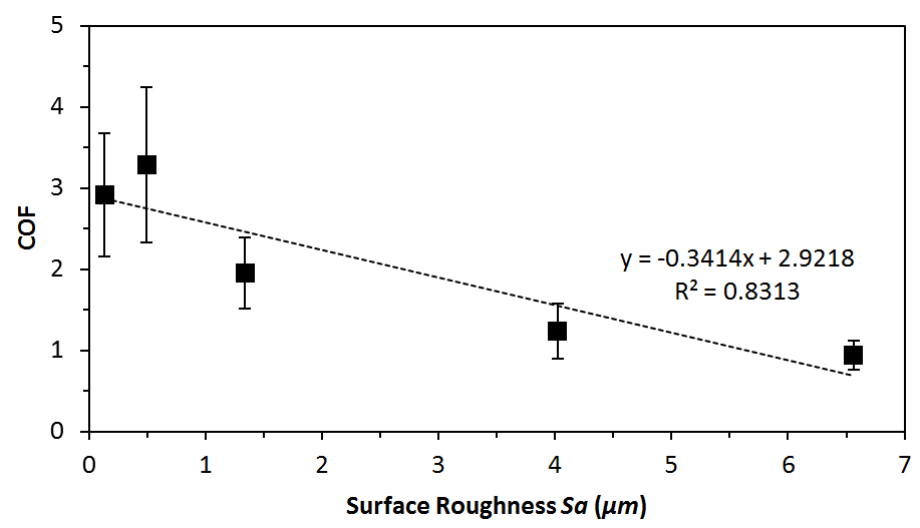

Fig 6.8 COF vs. measured 3D surface roughness $S a$. 


\subsubsection{Perceived Roughness \& Stickiness}

The magnitude estimation method is considered as one of the most common psychophysical methods for the perception experiments [34]. In our case, the perceived roughness and perceived stickiness were ratio scaled by the participants from 0 to 10 based on the intensity of impression towards the stimulus. Compared to the smaller ratio scale like from 1 to 5 , the larger numeric range (from 0 to 10 ) gave wider perceptual intensity to the individual participants to better describe their natural perception towards the stimulus. In addition, the estimations were then normalized and calculated into the geometric mean. Compared to the arithmetic mean, the geometric mean is more precise, especially for larger numeric range [34]. With a data set of $\{\mathrm{a} 1, \mathrm{a} 2, \ldots, \mathrm{an}\}$, the geometric mean can be calculated as:

$\left(\prod_{i=1}^{n} a_{i}\right)^{1 / n}=\sqrt[n]{a_{1} \cdot a_{2} \cdots a_{n}}$

Where $n$ is the number of estimations.

The perceptual properties of roughness and stickiness are two important elements that contribute to the perception of texture. In this research, the goals of perceived roughness and perceived stickiness were conducted in two parts: (a), perceptual separability; and (b), the influence of dynamic tactile friction. As the part (a), we first need to determine whether the participants were able to distinguish the perceptual stimuli like the perceived roughness and perceived stickiness. In fact, from the literature, the most separable perceptual stimulus and dimension-pairs are the ones including perceived stickiness [38]. In our case, the subjects were able to discriminate the perceived stickiness of the samples, and the relationship between the perceived stickiness and 3D surface roughness $S a$ is in a negative correlation $\left(R^{2}=0.8001\right)$ (see Figure $6.9 \mathrm{~b}$ ). Moreover, the perceived roughness is consistent with measured 3D surface roughness $S a$, and a positive correlation was found $\left(R^{2}=0.7434\right)$ (see Figure 6.9 a). The results show that the participants can distinguish a set of stainless steel samples in terms of stickiness 
and roughness. Early research found that subjects were able to discriminate pattern height with difference of $1 \mu \mathrm{m}$ to discriminate the perceived roughness of sandpaper and ridged stainless steel samples with different surface roughness [36]. According to the recent research conducted by Skedung et al., the tactual perception of human finger is able to perceive features of surface textures as small as submicron in both wavelength and amplitude [30]. In our case, the 3D surface roughness Sa was ranged from $0.49 \mu \mathrm{m}$ to $6.56 \mu \mathrm{m}$.

The influences of dynamic tactile friction were also concerned in this study. Fig 6.9 (c) reveals the negative correlation of perceived roughness with the values of $C O F$ from the friction measurements $\left(R^{2}=0.7312\right)$. According to the research conducted by Smith et al., the sensation of roughness (perceived roughness) is a reflection of variation in tangential force [37]. The changes of spacing and height would contribute to the variations in dynamic tactile friction, which ultimately affect the perception of roughness. In Fig 6.9 d, the perceived stickiness was found to have a positive correlation with $C O F\left(R^{2}=0.96\right)$. The results revealed that the perceived stickiness was significantly influenced by the variation of friction, and similar phenomenon was found in the study of Hollins et al. [38] 


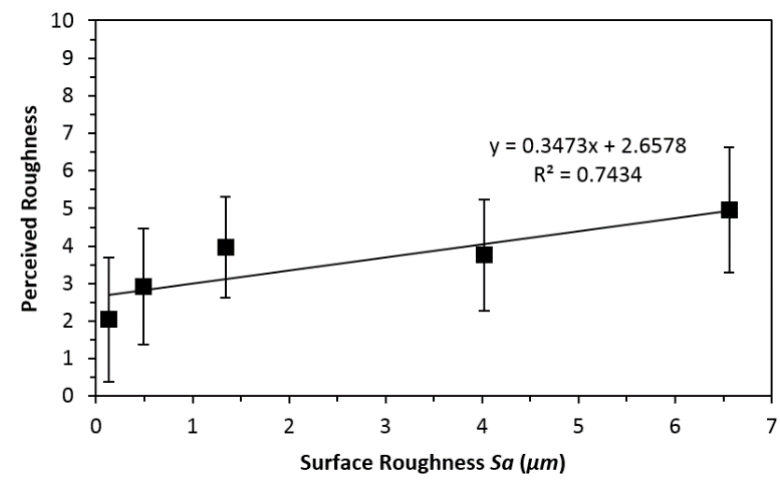

(a)

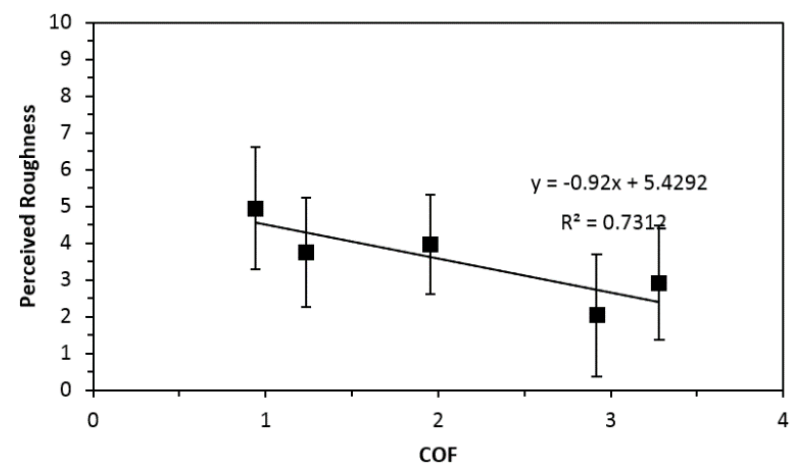

(c)

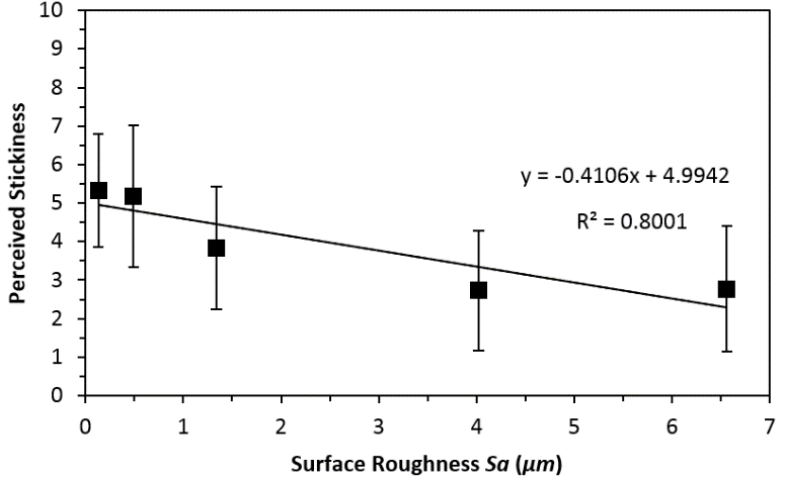

(b)

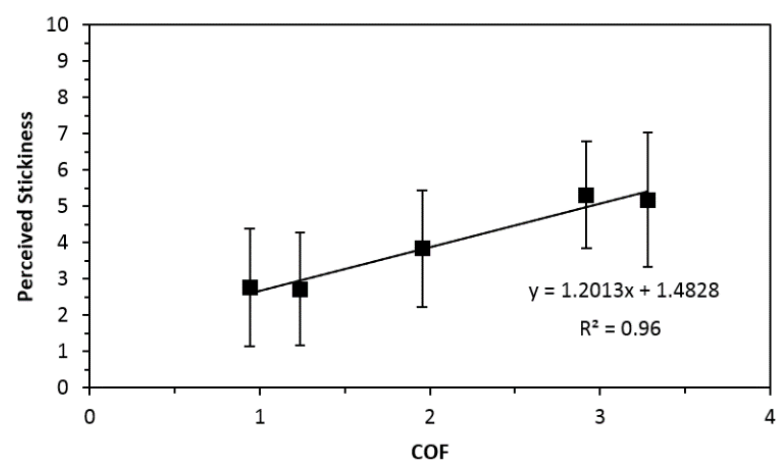

(d)

Fig 6.9 Geometric mean of perceived roughness versus (a) 3D surface roughness Sa, and (c) COF; and geometric mean of perceived stickiness versus (b) surface roughness $s_{a}$, and (d) COF.

\subsubsection{Comfort Level}

The impression and emotional feeling of an object is appeared through sensation, perception and cognition by touch [31]. Moreover, the perception of pleasantness (comfort) is individual, subjective and closely related to the properties of counter-body. From research on multidimensional subjective experience of surface texture, perceptual stimuli of cold - warm, hard -soft, smooth - rough and slippery - sticky can be extracted as four principal subjective dimensions [34, 39, 40]. Stainless steel EN-1.4301 was used as the material for all samples, therefore, the perceptual dimension of hard-soft did not apply to this study. Same for the 
perceptual stimuli of cold - warm, which is same for the same material. In addition, one important physical dimension of dynamic tactile friction was concerned. As such, it becomes possible to explore the relation between the physical stimulus of finger pad friction, and the perceptual stimuli of roughness and stickiness to comfort (or pleasant) touch.

Based on the perception experiments, the relationship between the comfort level and perceived roughness is shown in a weak correlation with determination coefficient of 0.2473 (see Figure 6.10 a). This indicates that the perceived roughness is an insignificant stimulus for pleasant touch. According to the literature, the relationship between comfort level and perceived roughness can be biased upon subjects' experiences in tactile sensation [32]. In another study of Barnes et al. [33] on surface and touch, the influence of perception with measured roughness was investigated and no clear relationship was found between roughness and feeling. However, the perceived stickiness shows a negative influence on comfort perception with a rather high coefficient of determination $\left(R^{2}=0.7214\right)$ (see Figure $6.10 \mathrm{~b}$ ). Based on the results, the sample HDG-1 and sample LDG-3 showed the highest comfort level when the perceived stickiness decreased (See Table 6.2). It appears that the perceived stickiness is a dominant perceptual stimulus to affect the level of comfort on the same type of material (same hardness). However, the perceived roughness did not align a meaningful dimension in the comfort level of perception.

In the study on the physical factors influencing pleasant touch, reference [7] shows that participants rated comfort level based on the comparison of the friction forces during the perception experiments. In the current case, friction was used as a physical stimulus to the comfort level, based on a crater and grid texture design. From the results, the geometry of grid can change the surface roughness greatly and had a better effect in reducing the dynamic skin friction compared to the crater structure and reference sample. A clear negative correlation was found between the level of comfort and the $C O F$ with the determination coefficient of 0.7128 
(see Figure $6.10 \mathrm{c}$ ). The comfort level increases when the tactile friction between the skin and counter-surface decreases which is consistent with the experimental results of Klöcker et al. [7]. Therefore, the dynamic tactile friction can be concluded as a physical stimulus to predict the comfort feeling based on the experimental data. And grid structure is one unique and desired texture to create high comfort touch conditions.

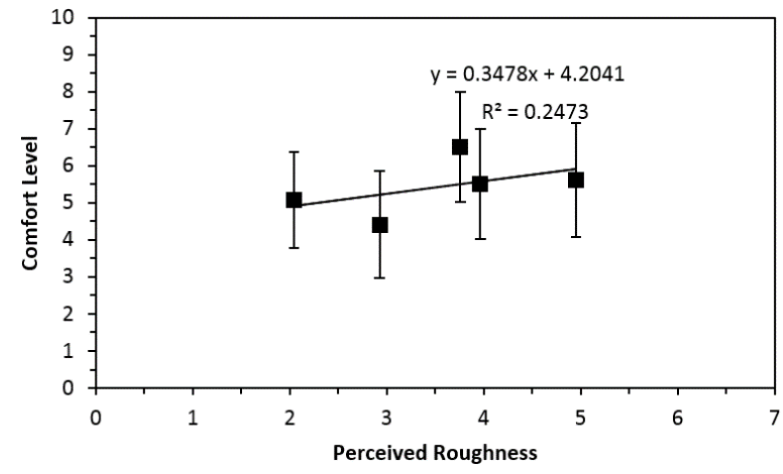

(a)

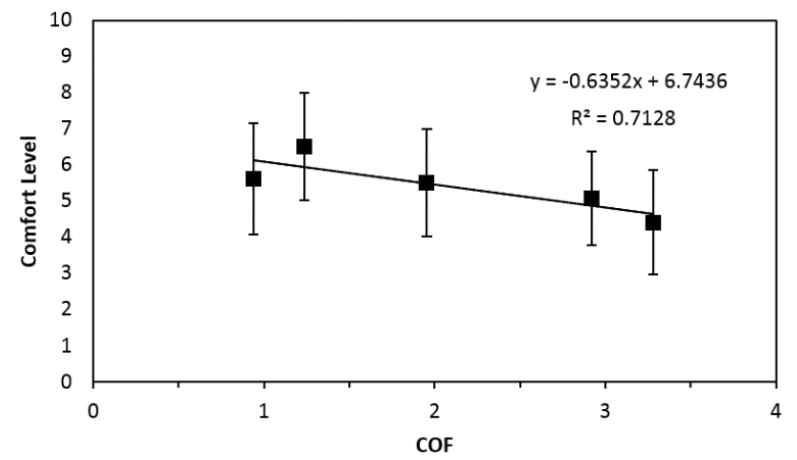

(c)

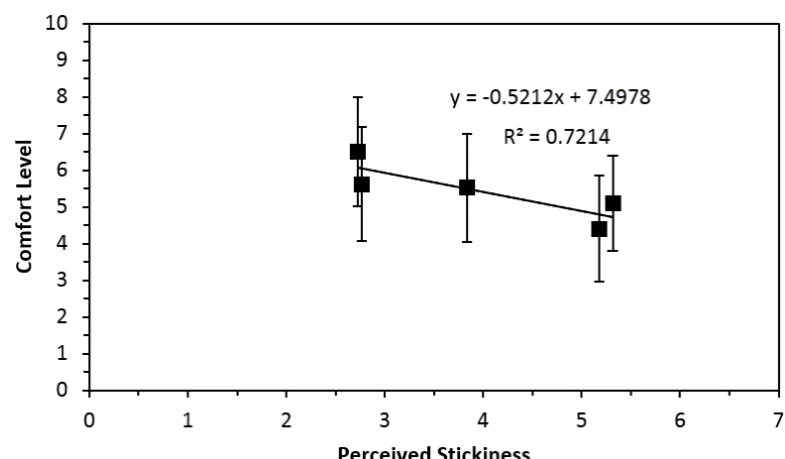

(b)

Fig 6.10 Geometric mean of (a) Comfort level versus perceived roughness; (b) comfort level versus perceived stickiness; (c) comfort level versus COF. 
Table 6.2 The geometric mean of perceived stickiness, perceived roughness, comfort level of sixteen participants from perception experiments; the average values of COF with standard deviations from friction measurements.

\begin{tabular}{|c|c|c|c|c|c|}
\hline $\begin{array}{c}\text { Sample } \\
\text { Name }\end{array}$ & $\begin{array}{c}\text { Comfort } \\
\text { Level }\end{array}$ & $\begin{array}{l}\text { Perceived } \\
\text { Stickiness }\end{array}$ & $\begin{array}{l}\text { Perceived } \\
\text { Roughness }\end{array}$ & COF & $\begin{array}{l}\text { Standard } \\
\text { Deviation }\end{array}$ \\
\hline HDG-1 & 6.5 & 2.7 & 3.8 & 1.24 & 0.34 \\
\hline LDG-3 & 5.6 & 2.8 & 5.0 & 0.94 & 0.18 \\
\hline 1HV90-1\% & 5.5 & 3.8 & 4.0 & 2.03 & 0.49 \\
\hline $2 G$ & 5.1 & 5.3 & 2.0 & 2.92 & 0.76 \\
\hline 1HV90 & 4.4 & 5.2 & 2.9 & 3.28 & 0.96 \\
\hline
\end{tabular}

\subsection{Conclusions}

In this research, subjective and objective measurements were performed by sixteen participants on five different stainless steel samples with designed microstructured surfaces. Based on the results of perception tests (subjective measurements) and friction measurements (objective measurements), the conclusions can be summarized as follows:

(1) The participants had the ability to distinguish the perceived roughness and stickiness of the counter-surface by sliding on the surfaces of objects. The perceived roughness was consistent with $3 \mathrm{D}$ surface roughness $\mathrm{Sa}$ in a positive correlation. And the perceived stickiness was found to correlate in a negative relationship with 3D surface roughness Sa. In addition, both perception of stickiness and roughness can be influenced by the variation of dynamic tactile friction.

(2) From the subjective perspective, the perceived stickiness was illustrated as a perceptual stimulus which was able to influence the comfort level of perception in a negative 
correlation. However, the effect of the perceived roughness was insignificant in the connection to the perception of comfort.

(3) From the objective perspective, the dynamic tactile friction was proved to be an affective physical stimulus which has a negative correlation to the comfort perception.

The results of this study can be beneficial to understand the tactility related research and product developments in the future. 


\section{REFERENCES}

[1] Schreiner, S., Rechberger, M., Bertling, J., Haptic perception of friction - correlation friction measurements of skin against polymer surfaces with subjective evaluations of the surfaces'grip, Tribology International, 2011, 63: 21-28.

[2] Tang, W., Bhushan, B., Adhesion, friction and wear characterization of skin and skin cream using atomic force microscope. Colloids and Surfaces B: Biointerfaces, 2010, 76: 1-15.

[3] Harih, G., Dolsak, B., Tool-handle design based on a digital human hand model. International Journal of Industrial Ergonomics, 2013, 43(4): 288-295.

[4] Kuijt-Evers, L.F.M., Groenesteijn, L., de Looze, M.P., Vink, P., Identifying factors of comfort in using hand tools. Applied Ergonomics, 2004, 35: 453-458.

[5] Kuijt-Evers, L.F.M., Vink, P., de Looze, M.P., Comfort predictors for different kinds of hand tools: Differences and similarities. International Journal of Industrial Ergonomics, 2006, 37: 7384.

[6] Ramalho, A. Szekeres, P., Fernandes, E., Friction and tactile perception of textile fabrics. Tribology International, 2013, 63: 29-33.

[7] Klöcker, A. Oddo, C.M., Camboni, D., Penta, M., Thonnard, J., Physical factors influencing pleasant touch during passive fingertip stimulation, PLOSONE, 2014, 9(7).

[8] Haggard, P., Sensory neuroscience: from skin to object in the somatosensory cortex. Current Biology, 2006, 20: 884-886.

[9] Morales Hurtado, M., Zeng X., and van der Heide, E., The human skin and hydration, hydrated materials: applications in biomedicine and the environment. Edited by Yoshitaka Nakanishi, Copyright (C) 2015 Pan Stanford Publishing Pte. Ltd. ISBN 978-981-4316-31-6

[10] Lapière, C.M., The ageing dermis: the main cause for the appearance of 'old' skin. British Journal of Dermatology, 1990, 122: pp. 5-11.

[11] Hendriks, C. P., Franklin, S. E., Influence of surface roughness, material and climate conditions on the friction of human skin. Tribology Letters, 2010, 37: 361-373.

[12] Derler, S., Huber, R., Feuz, H. P., Hadad, M., Influence of surface microstructure on the sliding friction of plantar Skin against hard substrates. Wear, 2009, 267: 1281-1288.

[13] Diridollou, S., Vabre, V., Berson, M., Vaillant, L., Black, D., Lagarde, J. M., Grégoire, J. M., Gall, Y., Patat, F., Skin ageing: changes of physical properties of human skin in vivo. International Journal of Cosmetic Science, 2001, 23: 353-62.

[14] Cua, A. B., Wilhelm, K. P., Maibach, H. I., Frictional properties of human skin: relation to age, sex and anatomical region, stratum corneum hydration and trans epidermal water loss. British Journal of Dermatology, 1990, 123: 473-479.

[15] Veijgen, N. K., Masen, M. A., van der Heide, E., Relating friction on the human skin to the hydration and temperature of the skin, Tribology Letters, 2013, 49: 251-261. 
[16] Bensmaia, S., Manfredi, L., The sense of touch. Encyclopedia of Human Behavior, 2012, 2: 379-386.

[17] Durakbasa, M.N., Osanna, P.H., Demircioglu, P., The factors affecting surface roughness measurements of the machined flat and spherical surface structures - The geometry and the precision of the surface. Measurement, 2011, 44(10): 1986-1999.

[18] Whitaker, T., Simoes-Franklin, C. Newell, N. F., Vision and touch: independent or integrated systmens for the perception of Texture. Brain Research, 2008, 1242: 59-72.

[19] Hilsenrat, M., Reiner, M., The impact of subliminal haptic perception on the preference discrimination of roughness and compliance. Brain Research Bulletin, 2011, 85: 267-270.

[20] Lackner, J.R., Dizio, P., Jeka, J., Horak, F., Krebs, D., Rabin, E., Precision contact of the fingertip reduces postural sway on individuals with bilateral vestibular loss. Experimental Brain Research, 1999, 126: 459-466.

[21] Adams, M. J., Briscoe, B. J., Johnson, S. A., Friction and Lubrication of Human Skin, Tribology Letters, 2007, 26 (3):239-253.

[22] Greenwood, J. A., Tabor, D., The Friction of Hard Sliders on Lubricated Rubber: The Importance of Deformation losses. Proceedings of the Physical Society, 1958, 71(6): 989-1001.

[23] Johnson, S. A., Gorman, D. M., Adams, M. J., Briscoe, B. J., The Friction and Lubrication of Human Stratum Corneum, In: Proceedings 19th Leeds-Lyon Symposium on Tribology, Elsevier, 1993, ISBN: 9780444897893, 663-672.

[24] Zhang, S., Rodriguez Urribarri, A., Morales Hurtado, M., Zeng, X., van der Heide, E., The role of the sliding direction against a grooved channel texture on tool steel: An experimental study on tactile friction. International Journal of Solids and Structures, 2015, 56-57: 53-61.

[25] Childs T. H. C. and Henson B. Human tactile perception of screen-printed surfaces: self-report and contact mechanics experiments. Proc IMechE, Part J: J Engineering Tribology 2007; 221: $427-441$.

[26] El-Shimi, A.F., In vivo skin friction measurements. Journal of the Society of Cosmetic Chemists, 1977, 28:37-51.

[27] Comaish, S., Bottoms, E., The skin and friction: deviations from Amonton's laws, and the effects if hydration and lubrication. British Journal of Dermatology, 1971, 84: 37-43.

[28] Nacht, S., Close, J., Yeung, D., Gans, E.H., Skin friction coefficient: changes induced by skin hydration and emollient application and correlation with perceived skin feel. Journal of the Society of Cosmetic Chemists, 1981, 32: 55-65.

[29] Derler, S., Gerhardt, L.-C., Lenz, A., Bertaux, E., Hadad, M., Friction of human skin against smooth and rough glass as a function of the contact pressure. Tribology International, 2009, 42: $1565-1574$.

[30] Skedung, L., Arvidsson, M., Chung J.Y., Stafford, M. C., Berglund, B., Rutland, M., Feeling small: exploring the tactile perception limits. Scientific Reports, 2013, 3 DOI: $10.1038 /$ srep02617 
[31] Lui, X., Yue, Z., Cai, Z., Chetwynd, D.G., Smith, S.T., Quantifying touch-feel perception: tribological aspects. Measurement Science and Technology, 2008, 19(8): doi:10.1088/09570233/19/8/084007;

[32] Annett, J., Subjective rating scales: science or art. Ergonomics, 2002, 45: 966-987.

[33] Barnes, C.J., Childs, T.H.C., Henson, B., Southee, C.H., Surface finish and touch - a case study in a new human factors tribology. Wear, 2004, 257: 740-750.

[34] Skedung, L., Danerlov, K., Olofsson, U., Johannesson, C.M., Aikala, M., Kettle, J., Arvidsson, M., Berglund, B., Rutland, M.W., Tactile perception: Finger friction, surface roughness and perceived coarseness. Tribology International, 2011, 44: 505-512.

[35] Skedung, L., Danerlov, K., Olofsson, U., Aikala, M., Niemi, K., Kettle, J., Finger-friction measurements on coated and uncoated printing papers. Tribology letters, 2010, 37: 389-399.

[36] Miyaoka, T., Mano, T., Ohka, M., Mechanisms of fine-surface-texture discrimination in human tactile sensation. Journal of the Acoustical Society of America, 1999, 105: 2485-2492.

[37] Smith, A.M., Chapman, C.M., Deslandes, M., Langlais, J.-S., Thibodeau, M.-P., Role of friction and tangential force variation in the subjective scaling of tactile roughness. Experimental Brain Research, 2002, 144: 211-223.

[38] Hollins, M., Lorenz, F., Seeger, A., Taylor, R., Factors contributing to the integration of textural qualities: Evidence from virtual surfaces. Somatosensory and Motor Research, 2005, 22(3): 193-206.

[39] Hollins, M., Faldowski, R., Rao, S., Young, F., Perceptual dimensions of tactile surface texture: a multidimensional scaling analysis. Perception \& Psychophysics, 1993, 54: 697-705.

[40] D. Picard, D., C. Dacremont, D., D. Valentin, D., A. Giboreau, A., Perceptual dimensions of tactile textures. Acta Psychologica, 2003, 114: 165-184.

[41] Heinrich, U. Koop, U., Leneveu-Duchemin, M.-C., Osterrieder, K., Bielfeldt, S., Chkarnat, C., Degwert, J., Hantschel, D., Jaspers, S., Nissen, H.-P., Rohr, M., Schneider, G., Tronnier, H., Multicentre comparison of skin hydration in terms of physical-, physiological- and productdependent parameters by the capacitive method. International Journal of Cosmetic Science, 2003, 25: 45-53.

[42] Duvefelt, K., Olofsson, U., Johannesson, C.M., Skedung, L., Model for contact between finger and sinusoidal plan to evaluate adhesion and deformation component of friction. Tribology International, 2014, in press.

[43] Tang, W., Ge, S., Zhu, H, Cao, X., Li, N., The influence of normal load and sliding speed on frictional properties of skin. Journal of Bionic Engineering, 2008, 5: 33-38.

[44] Van der Heide, E., Saenz de Viteri, V., Rodringuez-Vidal, E., Pagano, F., Wadman, B., Wiklund, D., Matthews, D.T.A., Contreras Fortes, J., Zhang, S., Steel sheet surfaces with enhanced tactile feel, European Commission Research Programme of the Research Fund for Coal and Steel, RFSR-CT-2011-00022, 2011-2014. 


\section{Chapter 7}

\section{Conclusions and Recommendations}

\subsection{General Conclusions}

The thesis investigates and explores the knowledge and technology for texture design that is capable of enhancing the tactile perception and skin friction of stainless steel surfaces. The main findings of each chapter are listed as bullet points:

Chapter 2, Micro-fabrication Techniques for Surface Texturing, revealed:

- Micro-casting, Chemical Wet Etching, Plasma Etching, Laser Surface Texturing and 3D Printing are the major fabrication methods to produce predefined deterministic surface structures in micro scale detail.

- The mechanism and application of all five categories of surface texturing techniques are introduced. Moreover, the advantages and disadvantages of each method are discussed.

- LST is chosen to be the main fabrication method for producing the surface texture due to its accuracy and ability to fabricate on stainless steel sheet material. For large production, the industrial stamping and cold rolling processes can be used, based on imprinting the negative of the design, to lower the cost and fabrication time.

Chapter 3, the Role of the Sliding Direction against a Grooved Channel Texture on Tool Steel: An Experimental Study on Tactile Friction, revealed:

- The sliding direction is an important factor to consider when measuring dynamic friction between the skin and counter-surface with grooved channel texture. The skin friction is affected by different sliding directions. 
- The contact condition (partial or full contact) has an important role on the contact area between skin and counter-surface. The greater depth of texture was able to reduce the contact area under partial contact condition. Under the full contact condition, however, the contact area increased with deeper depth.

Chapter 4, Texture Design for Reducing Tactile Friction Independent of Sliding Orientation, revealed:

- Hilbert curve and grid textures had less influence of sliding direction, especially for the grid texture which had the least orientation effect.

- In the concern of friction reduction, all textured stainless steel sheets had the advantage over the reference sample $2 \mathrm{G}$, and the grid texture illustrated the best ability in decreasing the friction force under the partial contact condition compared with Hilbert curve and grooved channel textures.

- The grid pattern was proved to be the optimal textural design in the concern of friction reduction and orientation effect, it greatly reduce the dynamic friction between the skin and counter-surface without the influence of sliding directions.

Chapter 5, Texture Design for Light Touch Perception, revealed:

- From the touch perception experiments, the pre-defined deterministic textured stainless steel sheets were able to influence the participants' perceptual attributes including the perceived stickiness and perceived roughness.

- Less perceived stickiness was observed for all textured samples, however, the perceived roughness increased compared to the reference sample.

- The perceived roughness was consistent with 3D surface roughness $S a$ in a positive correlation, and a negative relationship was found with the perceived stickiness. 
Chapter 6, Finger Pad Friction and Tactile Perception of Laser Treated, Stamped and Cold Rolled Micro-structured Stainless Steel Sheet Surfaces, revealed:

- The perceived stickiness was illustrated as a perceptual stimulus which had a negative effect on the comfort level of touch perception. The comfort level increases with decrease of the perceived stickiness.

- The dynamic skin friction was proved to be an affective physical stimulus with a negative effect to the comfort perception. Higher comfort level of touch perception with lower friction generated between the skin and counter-surface.

\subsection{Recommendations}

This study was limited to the frictional interactions between the skin and counter-surface. The models were designed for deterministic textures and did not take wear into account. In other applications and contact situations, wear does play a decisive role and textures could be stochastic. As such it is recommended to:

- Develop a skin contact model with the concern of skin wear. This could be beneficial to a predictive model for skin injuries, for instance, the specific wear rate as a function of the operational conditions. In addition, the wear of skin can be a perceptual stimulus of unpleasant touch due to skin damage, sports injuries and desired wear control in Dermatology.

- Extend the current contact models to a non-uniform multi-asperity skin contact model to further understand of skin contact mechanics, especially for counter-surfaces with a non-deterministic surface texture.

The current study focused on the role of surface texture in the tactile perception of stainless steel and describes a method for assessing comfort in relation to objective stimuli. The same 
method could be beneficial for skin friction measurements and modelling under extreme conditions. Therefore it is recommended to

- Design experimental techniques for extreme conditions like contact at very high or low temperature, super sticky surfaces and an aqueous environment. The results could enhance comfort for people who work as the first response to emergency situations, e.g. as fireman or lifeguard. 


\section{List of Articles}

- S. Zhang, A. C. Rodriguez Urribarri, M. Morales Hurtado, X. Zeng and E. van der Heide, The Role of the Sliding Direction against a Grooved Channel Texture on Tool Steel: An Experimental Study on Tactile Friction, International Journal of Solids and Structures, 56-57, pp 53-61, 2015

- S. Zhang, X. Zeng, A. Rodriguez Urribarri, A. Igartua, E. Rodriguez-Vidal and E. van der Heide, Texture Design for Reducing Tactile Friction Independent of Sliding Orientation on Stainless Steel Sheet, submitted to International Journal of Solids and Structures, 03/2016

- S. Zhang, X. Zeng, D.T.A. Matthews, A. Igartua, E. Rodriguez-Vidal, J. Contreras Fortes and E. van der Heide, Texture design for light touch perception, Tribology International, Under Review, 03/2016

- $\quad$ S. Zhang, X. Zeng, D.T.A. Matthews, A. Igartua, E. Rodriguez-Vidal, J. Contreras Fortes and E. van der Heide, Finger Pad Friction and Tactile Perception of Laser treated, Stamped and Cold Rolled Micro-structured Stainless Steel Sheet Surfaces, Tribology International, Under Review, 03/2016

- S. Zhang, X. Zeng, D.T.A. Matthews, A. Igartua, E. Rodriguez-Vidal, J. Contreras Fortes, V. Saenz de Viteri, F. Pagano, B. Wadman, E. van der Heide, Selection of microfabrication techniques on stainless steel sheet for skin friction, Friction, Accepted for Publication, 2016

\section{Conference Paper \& Contributions}

- $\quad$ E. van der Heide, S. Zhang, A. Rodrigues Urribarri, M. Morales Hurtado, X. Zeng, Soft Tribology: research and applications, Annual meeting JSME, Sapporo, Japan, September $14-15,2015$

- $\quad$ E. van der Heide, S. Zhang, A. Rodrigues Urribarri, M. Morales Hurtado, X. Zeng, Soft Tribology: research and applications, Japan-the Netherlands symposium on SoftTribology, Kumamoto, Japan, September 10-13, 2015

- X. Zeng, S. Zhang, A. Rodrigues Urribarri, E. van der Heide, Tactile friction of laser textured surfaces, 1st International Conference on Applied Surface Science (ICASS), Shanghai, China, July 27-30, 2015

- S. Zhang, M. Masen and E. van der Heide, Non-uniform Contact Behaviour of Human Skin in Contact with Micro-Textured Pillar Surfaces, 5th World Tribology Congress, September 8-13, 2013, Torino, Italy.

- $\quad$ E. van der Heide, M. Masen, S. Zhang, J. van Kuilenburg and E. Gelinck, On the probability of skin damage due to frictional heating in real asperity contacts, 5 th World Tribology 


\section{Project Report}

- $\quad$ Van der Heide, E., Saenz de Viteri, V., Rodringuez-Vidal, E., Pagano, F., Wadman, B., Wiklund, D., Matthews, D.T.A., Contreras Fortes, J., Zhang, S., Steel sheet surfaces with enhanced tactile feel, European Commission Research Programme of the Research Fund for Coal and Steel, RFSR-CT-2011-00022, 2011-2014. 


\section{Acknowledgements}

Enormously grateful to Prof. Emile van der Heide (promoter) and Prof. Xiangqiong Zeng (promoter and daily supervisor). Sincerely appreciate them for the guidance and patience through the whole process of PHD researching. Their encouragement and generosity helped me to survive my study. I have to say I feel very lucky to have both of you to be my supervisors.

Special thanks to Erik and Walter for the technical support during my research. Also, I would like to thank the support of tribology group at the University of Twente. To all my colleagues with whom I had a great time in my four years study: Dik, Piet, Matthijn, Mark, David, Belinda, Debbie, Rob, Yuxin, Marina, Adriana, Michel, Dariush, Febin, Aydar, Yibo, Adeel, Dinesh, Mahdiar, Jincan, JianChang, GangQiang, Can, YingLei... Thanks to all of you.

I would like to express my gratitude to my committee members: Prof. Dr. G.P.M.R. Dweulf, Prof. dr. Y. Nakanishi, Dr. P.K. Sharma, Prof. dr. ir. A.H. van den Boogaard, Prof. dr. ir. H. van der Kooij, and Dr. D.T.A. Matthews, for their time.

I would like to thank all my friends living in Enschede: Huiyu family, XueLong family, Weitao family, YiJian family, Shaojie, Peter, Kui, Xiong, Hai...

At the end, I would like to thank my Mom for raising me and backing me up through all the important moments in my life. And, to my father whom is in the heaven watching me and supporting me spiritually. Deeply appreciate other family members and relatives: Bowen Zhang, Ning Chen, Johnny Xu, Huailiang Shi, Yu Zhang, Linsen Hu, Zheng Huang, Ziwei Zhang, etc., for their unconditional supports in the whole time.

To all of you, sincerely appreciate your supports.

Sheng Zhang

2016

Enschede, the Netherlands 
